\title{
GUIDELINES FOR DEVELOPMENT OF STRUCTURAL INTEGRITY PROGRAMS FOR DOE HIGH-LEVEL WASTE STORAGE TANKS
}

RECEIVED JuL 21 S

K. Bandyopadhyay, S. Bush, M. Kassir, B. Mather, P. Shewmon, M. Streicher, B. Thompson, OSTI D. van Rooyen, and J. Weeks
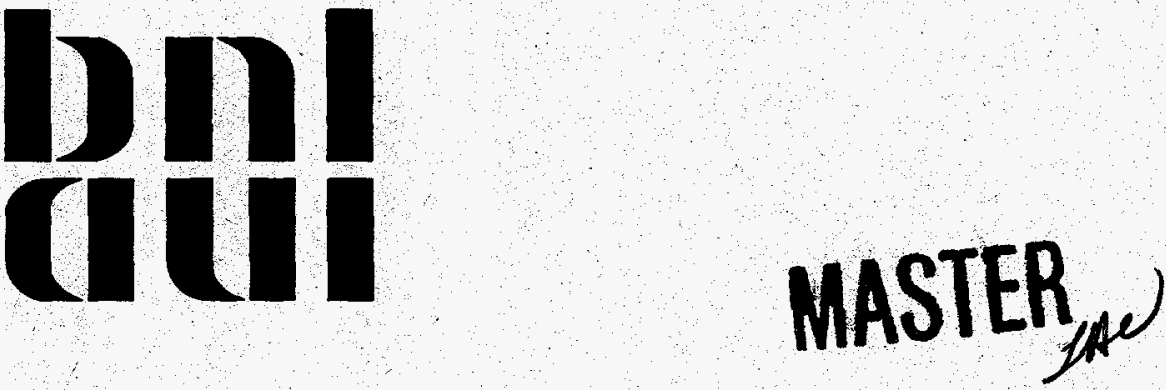

DeTruEUnoN OF THIS DOCUMEAT IS UNLAMTED

JANUARY 1997

ENGINEERING RESEARCH AND APPLICATIONS DIVISION DEPARTMENT OF ADVANCED TECHNOLOGY BROOKHAVEN NATIONAL LABORATORY, ASSOCIATED UNIVERSITIES, INC. UPTON, NEW YORK 11973-5000

Prepared for the

OFFICE OF ENVIRONMENTAL RESTORATION AND WASTE MANAGEMENT UNITED STATES DEPARTMENT OF ENERGY CONTRACT NO. DE-AC02-76-CH00016 


\section{DISCLAIMER}

This report was prepared as an account of work sponsored by an agency of the United States Government. Neither the United States Government nor any agency thereof, nor any of their employees, nor any of their contractors, subcontractors, or their employees, makes any warranty, express or implied, or assumes any legal liability or responsibility for the accuracy, completeness, or usefulness of any information, apparatus, product, or process disclosed, or represents that its use would not infringe privately owned rights. Reference herein to any specific commercial product, process, or service by trade name, trademark, manufacturer, or otherwise, does not necessarily constitute or imply its endorsement, recommendation, or favoring by the UnitedStatee Government or any agency, contractor or subcontractor thereof. The views and opinions of authors expressed herein do not necessarily state or reflect those of the United States Government or any agency, contractor or subcontractor thereof. 


\section{DISCLAIMER}

Portions of this document may be illegible in electronic image products. Images are produced from the best available original document. 


\title{
GUIDELINES FOR DEVELOPMENT OF STRUCTURAL INTEGRITY PROGRAMS FOR DOE HIGH-LEVEL WASTE STORAGE TANKS
}

\author{
K. Bandyopadhyay, S. Bush, M. Kassir, B. Mather, \\ P. Shewmon, M. Streicher, B. Thompson, \\ D. van Rooyen, and J. Weeks
}

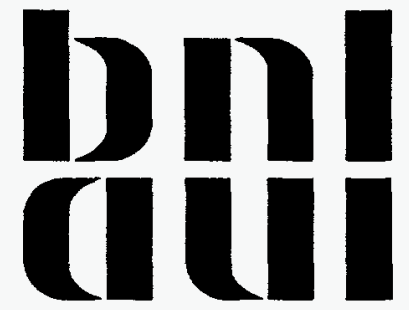

JANUARY 1997

ENGINEERING RESEARCH AND APPLICATIONS DIVISION DEPARTMENT OF ADVANCED TECHNOLOGY BROOKHAVEN NATIONAL LABORATORY, ASSOCIATED UNIVERSITIES, INC. UPTON, NEW YORK 11973-5000

Prepared for the OFFICE OF ENVIRONMENTAL RESTORATION AND WASTE MANAGEMENT UNITED STATES DEPARTMENT OF ENERGY CONTRACT NO. DE-AC02-76-CH00016 


\section{ABSTRACT}

Guidelines are provided for developing programs to promote the structural integrity of high-level waste storage tanks and transfer Iines at the facilities of the Department of Energy. Elements of the program plan include a leak-detection system, definition of appropriate loads, collection of data for possible material and geometric changes, assessment of the tank structure, and nondestructive examination. Possible aging degradation mechanisms are explored for both steel and concrete components of the tanks, and evaluated to screen out nonsignificant aging mechanisms and to indicate methods of controlling the significant aging mechanisms.

Specific guidelines for assessing structural adequacy will be provided in companion documents.

Site-specific structural integrity programs can be developed drawing on the relevant portions of the material in this document. 


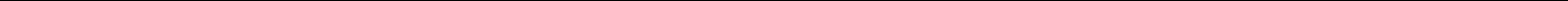


Abstract

Table of Contents List of Figures List of Tables Executive Summary Acknowledgements

iii

- V

ix

$x$

$x i$

xiii

Chapter 1 - Introduction

1.1 Purpose

1.2 Background

1.3 Tank Farms

1.4 Tank Designs

1.5 Function of Tanks

1.6 Aging Concerns

1.7 Scope

1.8 Glossary

1-1

1-1

$1-1$

$1-2$

$1-2$

$1-9$

$1-10$

$1-12$

Reference

Chapter 2 - structural Integrity Program

2.1

Introduction

$2-1$

2.2

Structural Integrity Verification

$2-1$

2.2.1

Data Collection

2.2.1.1

Loading

2.2 .1 .2

Geometry

2.2 .1 .3

Material Properties

2.2 .1 .4

Data Collection Summary

$2-1$

$2-2$

$2-2$

$2-3$

$2-3$

Data Evaluation......... . 2-3

2.2 .2

Structural Integrity Program Development

$2-4$

Identification of Aging Mechanisms

$2-5$

2.3 .1

Quantifying the Degree of Degradation

$2-7$

2.3 .3

Evaluation of the Effect of Degradation on Tank

Integrity

$2 \cdot 3 \cdot 3 \cdot 1$

Verifying Leak-Tightness

$2-7$

$2-8$

2.3 .3 .2

verifying structural stability

$2-8$

Management Options

$2 \cdot 3$.

Summary

$2-8$

$2-8$

References

2-9

Chapter 3 - Identification, Significance and Quantification of Aging Mechanisms

3.1 Introduction . . . . . . . . . . . . . . . . 3-1

3.2 Degradation Mechanisms for Steel Shell and Liner . 3-1

3.2.1 Potentially Significant Aging Mechanisms . . . . . 3-2

3.2.1.1 General Corrosion . . . . . . . . . . . . . . . . . 3-2

3.2.1.2 Pitting and/or Crevice Corrosion . . . . . . . . . 3-4

3.2.1.3 stress-Corrosion Cracking . . . . . . . . . . . . . 3-7

3.2.1.3.1 Carbon Steel . . . . . . . . . . . . . . . . . . 3-7

3.2.1.3.2 Stainless steel. . . . . . . . . . . . . . . 3-9 
$3 \cdot 2 \cdot 1 \cdot 4$

3.2 .1 .5

$3 \cdot 2 \cdot 1 \cdot 6$

3.2 .2

3.2 .2 .1

3.2 .2 .2

3.2 .2 .3

3.2 .2 .4

3.2 .2 .5

3.2 .2 .6

3.2 .2 .7

3.3

\section{3 .1}

$3 \cdot 3 \cdot 1.1$

3.3 .1 .2

$3 \cdot 3 \cdot 1 \cdot 3$

$3 \cdot 3 \cdot 1 \cdot 4$

$3 \cdot 3 \cdot 1 \cdot 5$

3.3 .2

$3 \cdot 3.2 .1$

3.3 .2 .2

$3 \cdot 3 \cdot 2 \cdot 3$

$3 \cdot 3 \cdot 2.4$

3.3 .3

$3 \cdot 3 \cdot 3 \cdot 1$

3.3 .3 .2

References
Microbiologically-Induced Corrosion

Concentration Cell Waterline Corrosion and

Galvanic Attack

Corrosion of External Tank Surfaces by In-leakage of Ground Water

Potentially Non-Significant Aging Mechanisms

for steel Shell and Liner.

Thermal Embrittlement .

Radiation Embrittlement

Creep and Stress Relaxation

Fatigue

Erosion and Erosion-Corrosion

Wear

Hydrogen Attack

Degradation Mechanisms for Concrete and

Reinforcing steel

Potentially Significant Aging Degradation

Mechanisms

Elevated Temperature

Freezing and Thawing

Leaching of Calcium Hydroxide

Aggressive Chemical Attack

Corrosion of Reinforcing steel

potentially Non-Significant Aging Mechanisms

for Concrete

Reaction of Aggregates with Alkalies

Creep and Shrinkage

Abrasion and Cavitation

Irradiation

Degradation of Refractory

Elevated Temperature

Effects of Chemicals

Chapter 4 - Monitoring for and Controlling Degradation

4. 1

4.2

4.2.1

4.2 .1 .1

4.2 .1 .2

4.2 .1 .3

$4 \cdot 2 \cdot 1.4$

4.2 .2

4.2 .3

4.3

$4 \cdot 3 \cdot 1$

4.3 .2

4.4
Introduction

Leak Detection

Types of Leak Detection Systems

Liquid Level Instrumentation

Visual Examinations

Radioactivity Monitoring

Moisture Detectors

Leak Detection Program Criteria for Tanks

Leak Detection in Transfer Piping Systems

Chemical Monitoring to Minimize Degradation of

steel Components of Tanks

Establishing Safe Operating Ranges

Monitoring Tank Chemistry

Corrosion Monitoring
$3-11$

$3-11$

$3-12$

$3-13$

$3-13$

$3-14$

$3-15$

$3-15$

$3-15$

3-16

3-16

3-17

$3-18$

$3-18$

3-22

3-23

3-24

3-25

3-26

3-27

3-27

3-28

$3-28$

$3-28$

3-29

3-29

3-29

4-1

4-1

4-1

4-1

4-2

4-2

4-3

4-3

4-4

4-4

4-4

4-4

4-5 
TABLE OF CONTENTS (Continued)

Page

4.5 Managing Degradation of Concrete Components of Waste Tanks . . . . . . . . . . . . . . . 4-5

References

$4-5$

Chapter 5 - Nondestructive Examination (NDE)

5.1

Introduction and scope

5.2

Exemptions . . . . .

$5-1$

5.3

Inspection Requirements and Procedures

$5-2$

$5 \cdot 3 \cdot 1$

General Requirements of Sampling and Inspection

$5-3$

5.3 .2

Inspection Coverage and Qualification of

$5 \cdot 3 \cdot 3$

Personnel and Equipment

$5-3$

$5 \cdot 3 \cdot 4$

Alternative Examination

$5-4$

Sample Size and Selection of Tanks for Inspection

$5-7$

5.3 .5

Tank Evaluation Criteria

$5-8$

5.3 .6

Concrete Inspection Requirements and Procedures

$5-9$

5.3 .6 .1

General Requirements for Inspection and Testing

$5-10$

5.3 .6 .2

of Concrete

$5-10$

Selection of Location for Concrete Inspection. . 5-11

$5.3 \cdot 6 \cdot 3$

Nondestructive Tests for Concrete

$5-11$

Program Initiation

$5-12$

5.5

Definitions, Abbreviations, and Acronyms

$5-13$

$5-13$

Chapter 6 - Evaluation of the Effects of Degradation

6.1

6.2

Introduction

Verification of Leak-Tightness

6.3

Verification of Structural Integrity

$6-1$

$6-1$

Analytical Models

6.4

6.4 .1

Steel Tanks

6.4 .2

Concrete Shells

6.5

Fracture Mechanics

6.5 .1

Evaluation of Crack Growth

6.5 .2

Critical Crack Size

$6-1$

$6-2$

$6-2$

$6-4$

$6-4$

$6-5$

$6-5$

$6-6$

Chapter

\section{- Transfer Piping}

7.1

7.2

7.2 .1

7.2 .1 .1

7.2 .1 .2

7.2 .1 .3

7.2 .1 .4

7.2 .1 .5

7.2 .1 .6

7.2 .2

7.3

7.3 .1

Introduction

Structural Integrity Verification

$7-1$

Data Collection

Loading

Geometry

Pressure Testing

Other Analysis of Transfer Line Condition

Material Properties

Data Collection Summary

$7-1$

7-1

$7-2$

$7-2$

$7-2$

$7-3$

$7-3$

$7-3$

Data Evaluation . . . . . . . . . . . . . . 7-3

Structural Integrity Program Development . . . . 7-4

Identify Aging Mechanisms

$7-4$ 
TABLE OF CONTENTS (Continued)

Page

7.3.1.1 Potentially Significant Degradation Mechanisms in Transfer Piping . . . . . . . . . . . . . . . . 7-4

7.3 .1 .2 Non-Significant Aging Mechanisms

$7-5$

7.3 .2

Quantify Degradation

$7-6$

$7 \cdot 3 \cdot 3$

7.3 .4

7.4

Evaluate Effect of Degradation on Pipe Integrity . 7-6

Management and Options

$7-10$

Summary . . . . . . . . . . . . . . . . . . 7-10

Chapter 8 - Management Options

8.1

8.2

8.2 .1

8.2 .1 .1

8.2 .1 .2

8.2 .2

8.2 .2 .1

8.2 .2 .2

8.2 .2 .3

8.2 .3

8.2 .4

Introduction

Management options, Including Preventive
Maintenance. . . . . . . . . . .

$8-1$

$8-1$

Corrosion Control

Chemistry Control Including Use of Inhibitors

in Alkaline Wastes

$8-1$

Electrochemical Techniques

$8-2$

Retrieval of Waste

Lowering the Waste Level

Complete Removal of the Liquid Phase

$8-2$

$8-3$

Total Removal of the Contents of the Tank . . . . . 8-3

Making Repairs

Additional Barriers and New Tanks

$8-4$

$8-4$

Appendix A - Philosophy and Interpretation of Bases Used in Nondestructive Examination (NDE) Guidelines

A. 1

A. 2

A. 3

A. 4

A. 5

A. 5.1

A. 5.2

A. 5.3

A. 5.4

A. 5.5
Introduction

Scope Purpose

Approach Taken

Bases Used for Evaluating Degradation

Bases for Flaw Sizes

Bases for Examination Percentages

Reasons for Selection of NDE Angles

Implication of Section XI Articles Cited

Exemption Mechanism with Examples
A-1

$A-1$

$A-1$

$A-2$

$A-3$

$A-3$

$A-3$

$A-3$

$A-4$

$\mathrm{A}-4$ 
Figure

Page

1.1 A Typical Single-Shell Tank . . . . . . . . . . . . . . 1-3

1.2 A Typical Double-Shell Tank . . . . . . . . . . . . . . 1-4

1.3 Tank with a Central Column . . . . . . . . . . . . . . . 1-5

1.4 Tank with Concentric Columns . . . . . . . . . . . . . . 1-6

1.5 Tank with Concentric Columns and other Superstructures . 1-7

1.6 Free-Standing Tank . . . . . . . . . . . . . . . . 1-8

2.1 Tank Structural Integrity Program . . . . . . . . . . 2-6

3.1 Minimum Nitrite Concentrations to Inhibit Pitting at Indicated Temperatures... . . . . . . . . . . . . . 3-6

3.2 Reduction of Compressive strength of Concrete at Elevated Temperatures . . . . . . . . . . . . . . . . 3-19

3.3 Reduction of the Modulus of Elasticity of Concrete at Elevated Temperatures ............... . 3-21

7.1 An Event Tree for Transfer Line Assessment . . . . . . . 7-8 
Table

3.1 Possible Degradation Mechanisms for Nuclear Waste Storage Tanks . . . . . . . . . . . . . . . . . . . . . 3-3

3.2 Results of Laboratory Experiments on the Effect of Environment on Crack Initiation Time and $\mathrm{K}_{\mathrm{ScC}}$ in

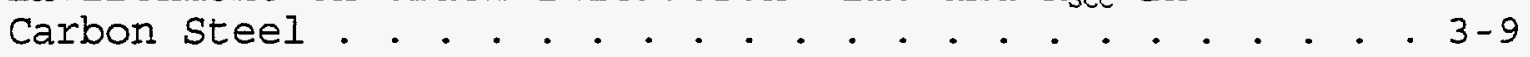

5.1 Examinations of Carbon or Low-Alloy and Austenitic Stainless Steel or High-Alloy Tank Containing HighLevel Waste . . . . . . . . . . . . . . 5-5

7.1 Further Discussion and Guidance on the Use of Figure 7.1 . . . . . . . . . . . . . . . . . 7-9 


\section{EXECUTIVE SUMMARY}

This document provides guidelines for developing a program that will promote the structural integrity of high-level waste storage tanks and transfer piping at the facilities of the Department of Energy. The structural integrity is demonstrated by prescribed leak-tightness as well as the load-carrying capability of the components.

The structural integrity program consists of: (1) definition of appropriate loads; (2) collection of data for possible material and geometric changes; and (3) assessment of the tank structure. The loads are defined according to the applicable national codes and standards. This document provides a "road map" of structural integrity assessment and focuses on potential material degradation over time, and subsequent assessment of the consequences. The specific guidelines for structural evaluation including loading, analytical techniques and acceptance criteria are discussed in companion documents some of which have been completed and others are in preparation.

Possible aging degradation mechanisms are explored and evaluated to screen out nonsignificant aging mechanisms. The conditions required for the remaining mechanisms to be potentially operative and damaging are identified and effects estimated. various types of corrosion are the dominant aging mechanisms for steel tanks. Thermal degradation of concrete is an aging mechanism for tanks that have stored hot waste sometime during their service lives.

The most important elements of the plan include a leak detection system and a reliable non-destructive examination (NDE) plan that is extracted from the applicable ASME Code Sections and commensurate with the physical conditions in the waste storage tanks. The desirability of controlling waste chemistry to minimize degradation of tank materials, and of monitoring for corrosioninduced degradation is also stressed. Based on data from these elements of the plan, analysis may be required to demonstrate structural integrity. Some management options are discussed for continued use of the aging tanks, including partial waste retrieval.

Some of the elements in this document may not be applicable to certain tank farms. Site-specific structural integrity programs will have to be developed for the tank farms or even individual tanks by judicious selection of the appropriate portions of the guidelines presented in this document.

These guidelines are intended to fulfill an immediate need to evaluate existing double-shell tanks and transfer piping. Some of the technical discussions included in this report are equally 
applicable to single-shell tanks. Detailed program elements addressing unique features of the single-shell tanks will be developed in a future revision of the report. 


\section{ACKNOWLEDGEMENTS}

The authors would like to express their thanks for the support and helpful suggestions provided by John Tseng, James Antizzo, Howard Eckert, Charles O'Dell, Dinesh Gupta, David Pepson, Owen Thompson, and Kenneth Lang of the DOE-EM staff, as well as helpful suggestions by members of the DOE-DP and DOE-EH organizations. In addition, the authors express their appreciation for the information provided by participants of the HLW tank structural integrity workshop meetings, especially the delegates from the four waste storage sites. 
CHAPTER 1

INTRODUCTION

\subsection{PURPOSE}

The purpose of this report is to provide general guidelines for demonstration of the structural integrity of high-level waste storage tanks and transfer lines at the facilities of the Department of Energy (DOE). These guidelines are expected to serve as the technical basis of a site-specific structural integrity program that needs to be developed for each site considering sitespecific tank designs, waste characteristics, and other issues.

\subsection{BACKGROUND}

Currently, there are about 250 underground high-level waste (HLW) storage tanks located in the DOE facilities at Hanford, Savannah River, INEL, and West Valley. Many of these tanks have served more than forty years and require an aging management program for assurance of their continued safe use. Many of them will be needed to store wastes for a period in excess of 20 years. At Hanford there are 177 tanks, at Savannah River there are 53 tanks, at INEL there are 11, and at West Valley there are four tanks. All tanks are made of carbon steel, except the Idaho tanks, and two West Valley tanks which are made of stainless steel. Detailed information on design and operation of these tanks is available in site-specific documents which are obtainable at the four sites. A brief discussion is included in the following sections.

\subsection{TANK FARMS}

The tanks at the four DOE sites were built for interim storage of the high-level waste until further processing and permanent disposal options become available. Some of these tanks are expected to be used for in-tank processing as well. A large portion of the waste is liquid of varying densities and viscosities; in addition, evaporation, crystallization, and settling of suspended solids have often resulted in the formation of "saltcake" and/or "sludge" underneath the supernatant liquid.

The tanks are built in groups and the area consisting of a group of tanks is commonly referred to as a "tank farm." They are underground, arranged side-by-side in two directions, each separated from the next one by 15 to 20 feet of earth. The soil over the tanks is up to 10 feet deep. 


\subsection{TANK DESIGNS}

Two basic tank designs exist, single-shell and double-shell, with variations in shape and size. Essentially, a single-shell tank consists of a cylindrical reinforced concrete vault, with a concrete floor and a flat or domed roof (Figure 1.1). The inside cylindrical and bottom surfaces of the concrete are lined with carbon steel. A double-shell tank consists of a vault containing a steel tank (Figure 1.2). The vault is a cylindrical reinforced concrete structure lined with carbon steel. Its roof could be domed or flat, and its reinforced concrete floor is overlain by insulating concrete on which the inner tank rests. There is about a 30-inch annular space between the steel tank and the lined concrete vault. Both single-shell and double-shell tanks are completely enclosed. In both cases, the concrete structure is the primary barrier to soil pressure, while in reality it also serves as additional confinement of the waste although usually no such credit has been taken in the tank design. Additional variations in design exist. For example, for flat roofs, concentric columns (or a column) of concrete act (s) as supports (a support) (Figures 1.3, 1.4 and 1.5). In one tank farm, the tanks are free-standing and enclosed by octagonal concrete vaults (Figure 1.6). All unique features of existing tanks are not necessarily illustrated in the figures. Also, the design of future tanks (all of which are required to be double-shell by regulation) may differ from that of existing ones. For instance, in a new tank farm the primary tanks may be located on a common footing enclosed by a large reinforced concrete vault, or could have a superstructure such as a weather enclosure. As shown in Figures $1.3,1.4$ and 1.6 cooling coils are located in some tanks.

The nominal tank storage capacities are one million gallons. Diameters range from 75 to 80 feet, with a waste level of 30 to 40 feet. Smaller tanks, with capacities of 750,000, 300,000 and 55, 000 gallons also exist.

Tanks are inter-connected by underground pipelines for the transfer of wastes. The transfer lines are three inches or less in diameter, and of various designs depending on vintage: e.g., pipe on soil, pipe in a concrete trench, pipe within a pipe, etc. ${ }^{1}$

\subsection{FUNCTION OF TANKS}

The primary purpose of the HLW storage tanks is to confine the liquid, salt cake, and sludge wastes so that they do not enter the environment. In this capacity, they serve the following functions:

Leak Tightness - The tank shells and liners provide barriers to the release of HLW.

\footnotetext{
${ }^{1}$ Transfer lines are discussed in detail in Chapter 7.
} 


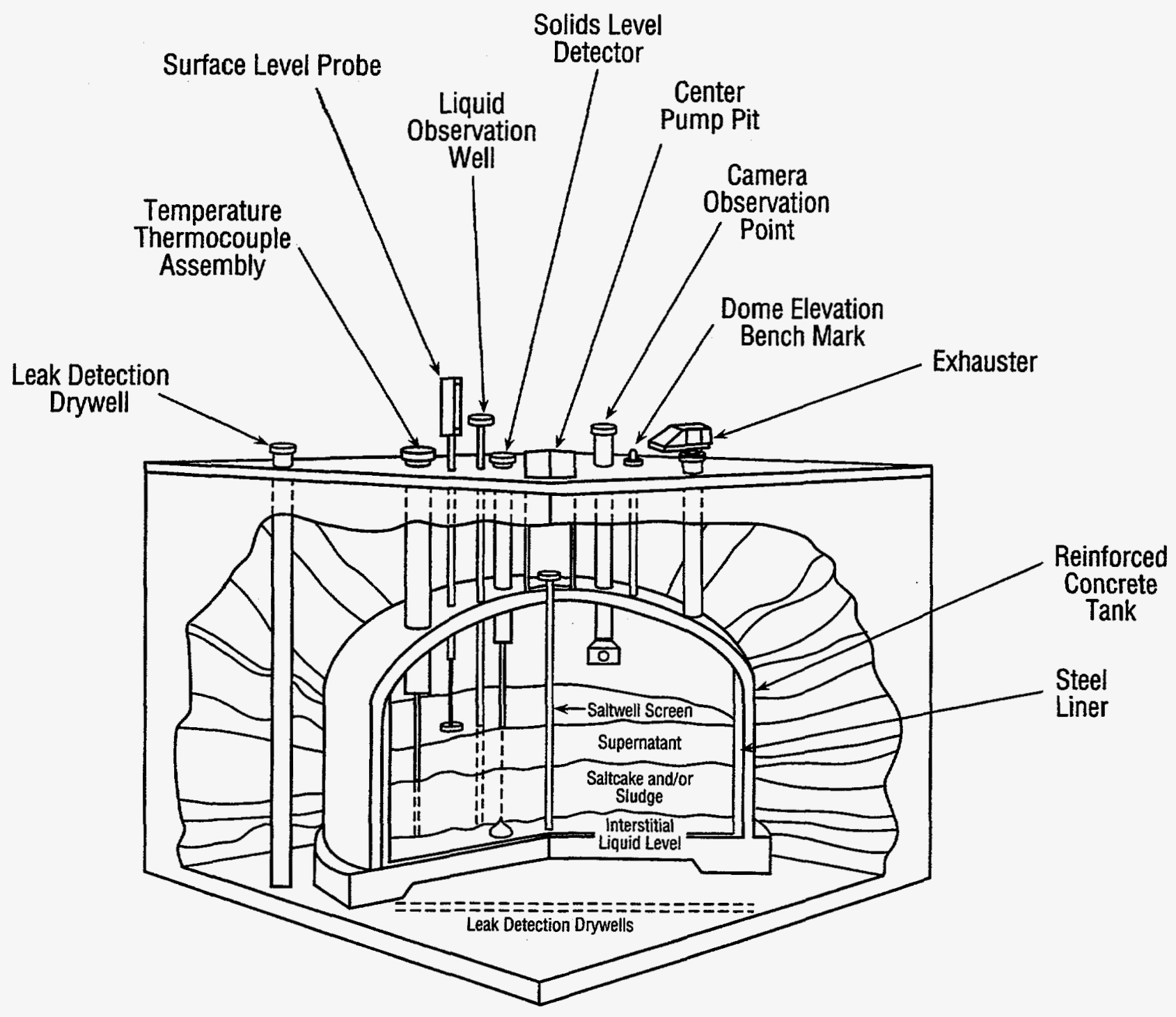

Figure 1.1 A Typical Single-Shel1 Tank 


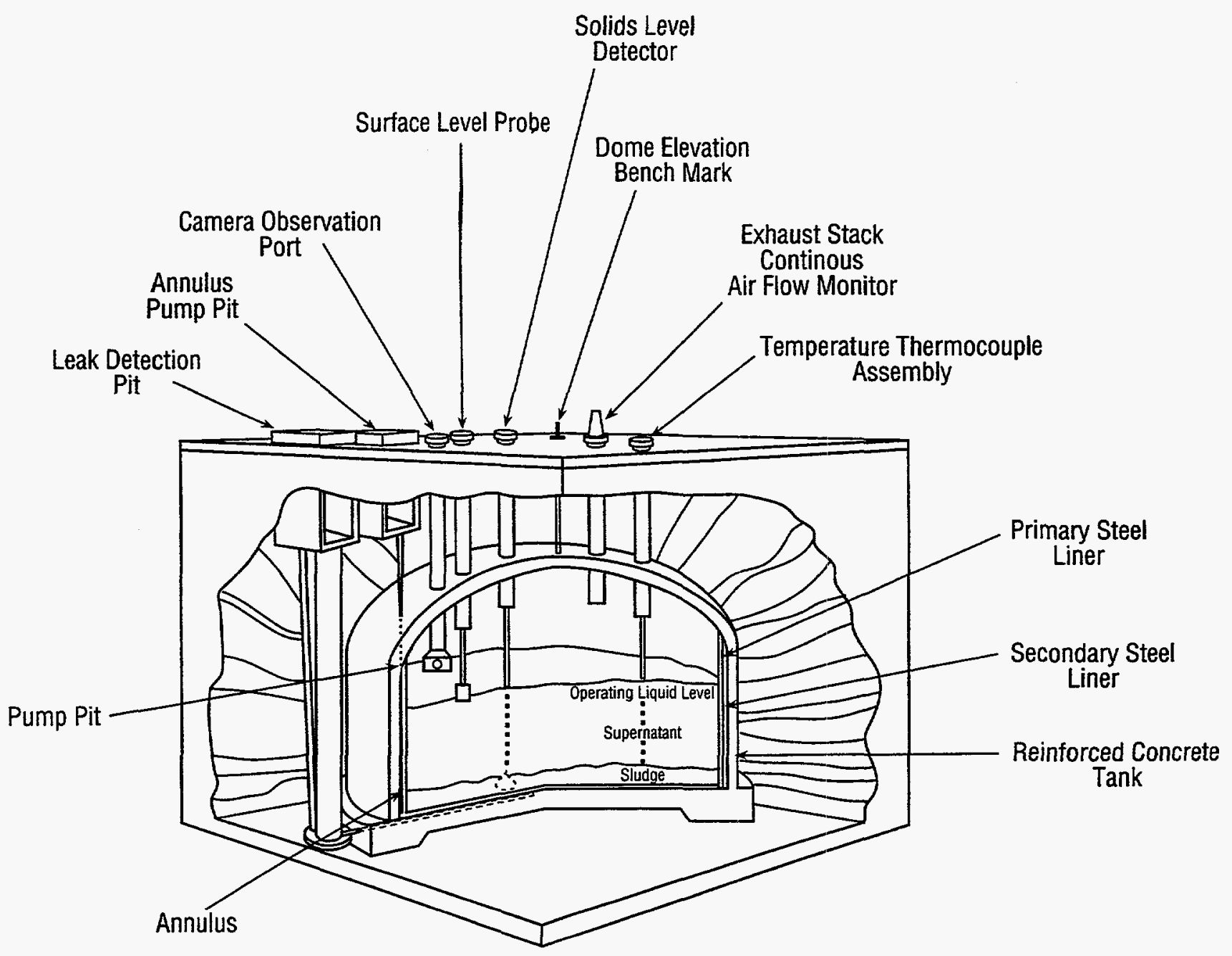

Figure 1.2 A Typical Double-Shell Tank 


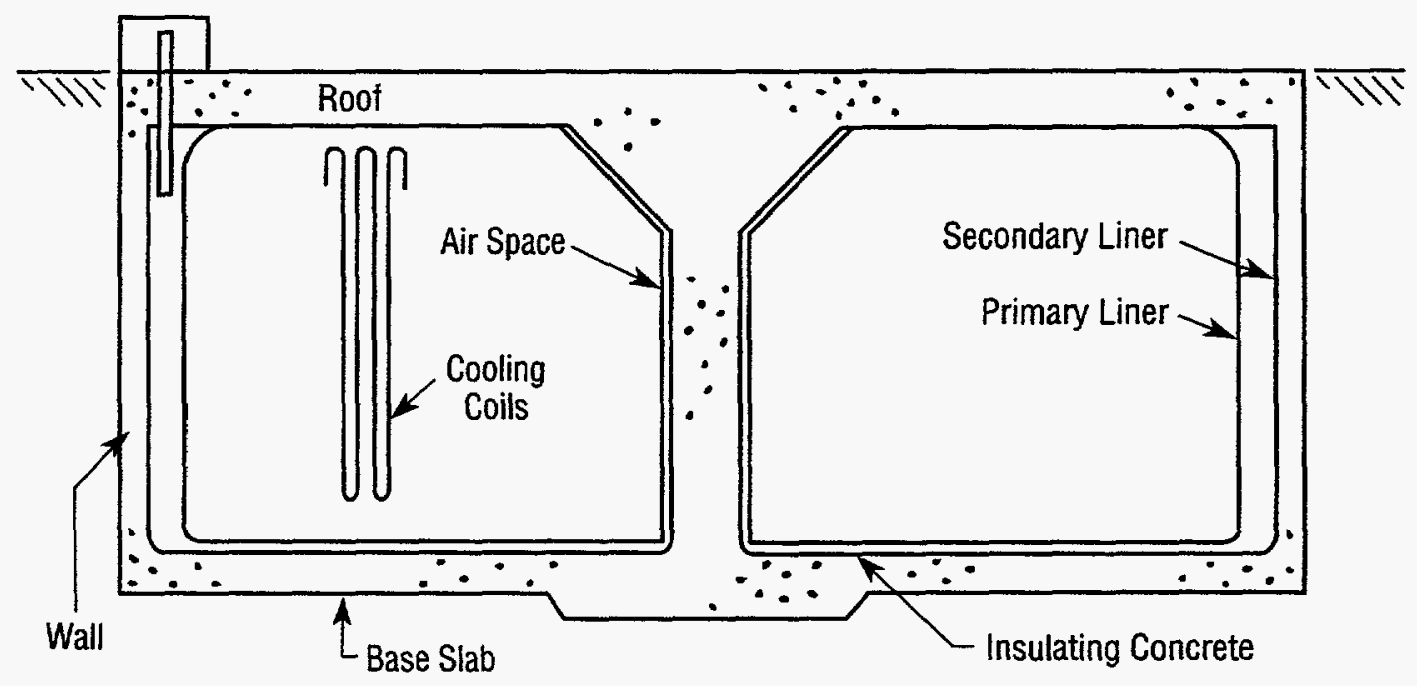

Figure 1.3 A Typical Tank with a Central Column $1-5$ 


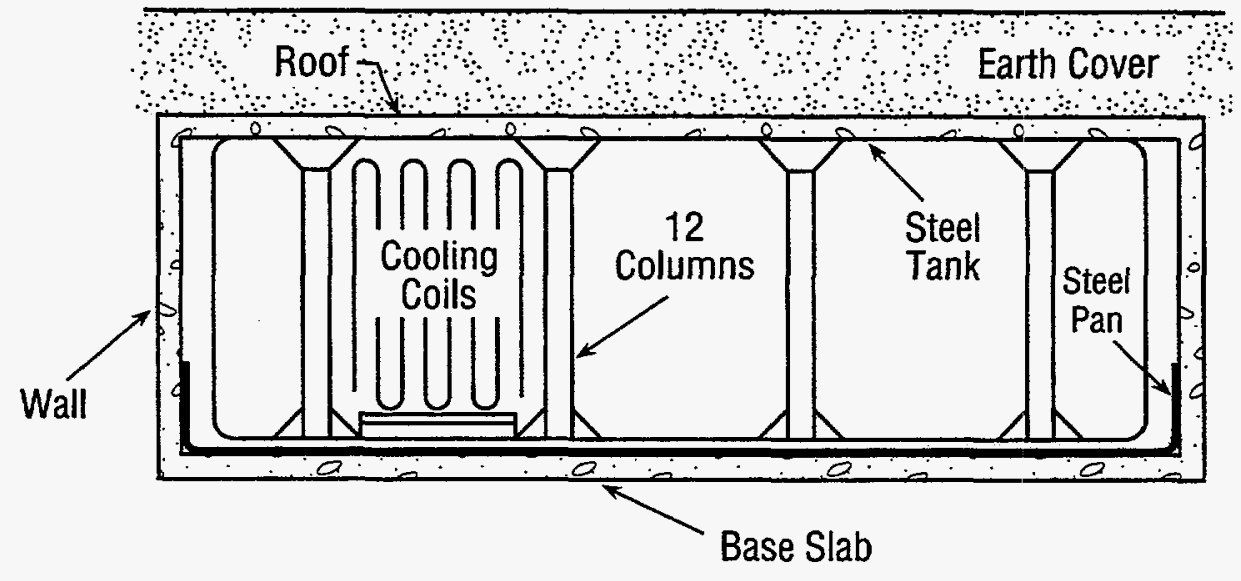

Figure 1.4 A Typical Tank with Concentric Columns $1-6$ 


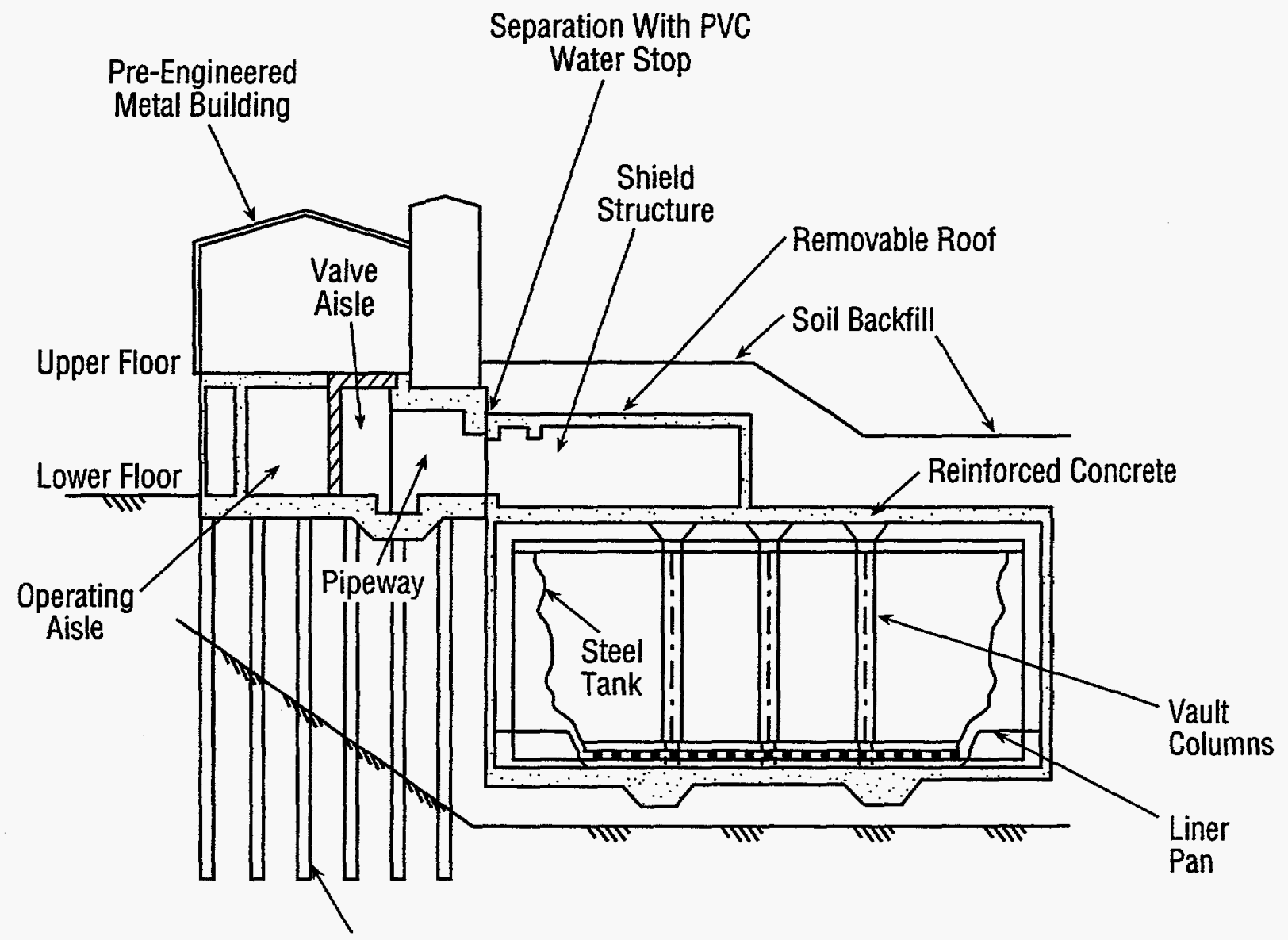

Pile Foundation

Figure 1.5 Tank with Concentric Columns and Other Superstructures 


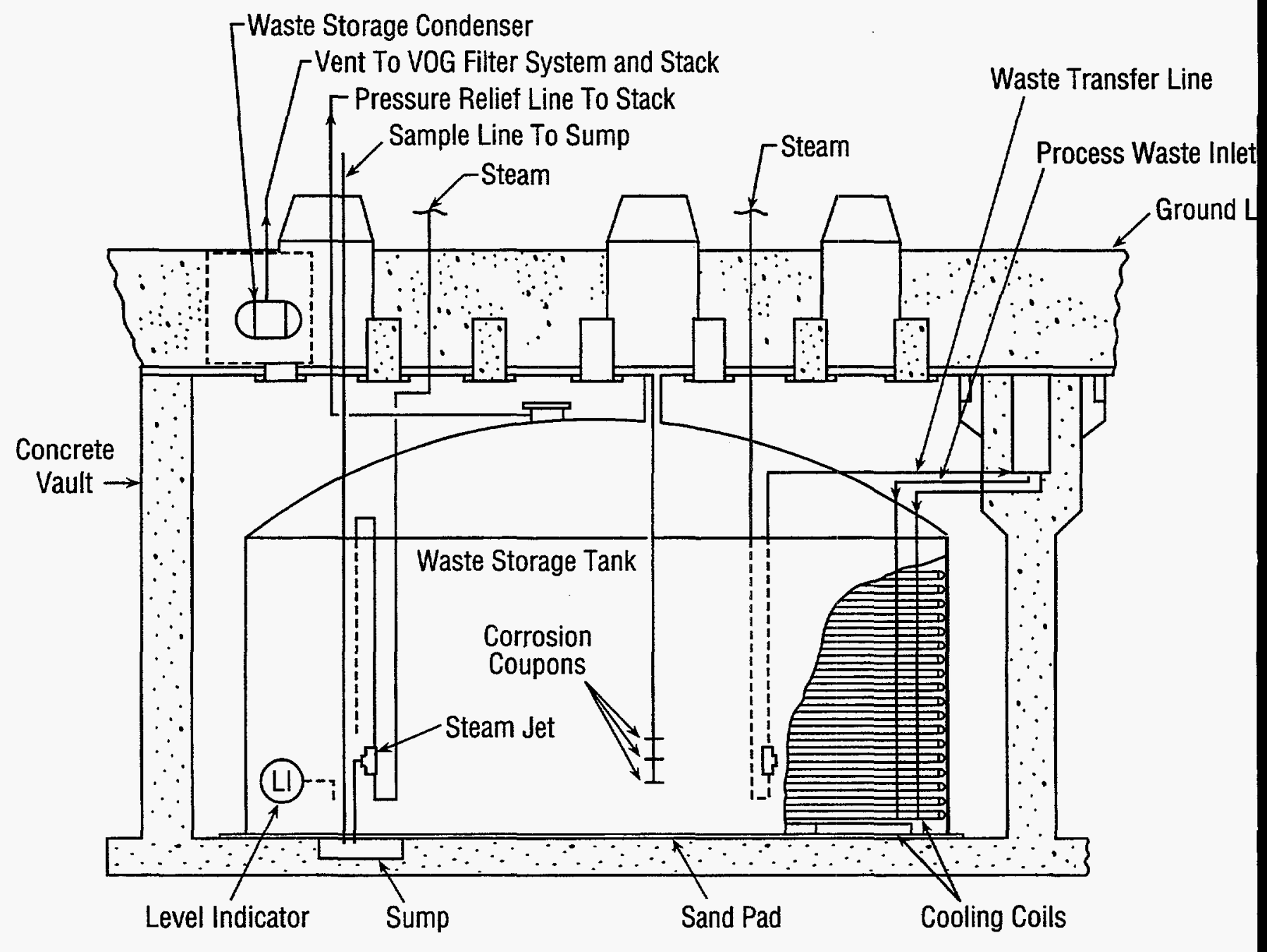

Figure 1.6 Free-Standing Tank 
Structural Adequacy - The concrete tanks or vaults, along with the steel shells and liners provide the necessary structural strength and stiffness against collapse or failure from postulated normal (e.g., soil) and abnormal (e.g., earthquake, explosion) loads.

Methods for assessing the structural adequacy of a high-level waste tank are the subject of a separate subsequent document.

\subsection{AGING CONCERNS}

Many of the HLW storage tanks have been in use since the 1940's, so that some are now approaching the end of their anticipated service lives, although most of them are expected to continue to store waste well beyond this anticipated life. Their performance depends on the degree to which aging degradation affects the concrete and steel components, regardless of compliance with design considerations that were appropriate at the time of construction. Leaks have occurred or have been suspected in over 70 tanks, mostly single-shell tanks at Hanford and a few singleshell and double-shell tanks at Savannah River, all of which were not stress-relieved after fabrication. No leaks have been identified in double-shell tanks that were stress-relieved after fabrication. At Savannah River, stress corrosion cracking in the vicinity of these welds was identified as the cause of the leakage; many cracks were found in these areas. At Hanford, no examinations have been made, but it is presumed stress corrosion cracking may have caused most of the leaks. It is difficult to project the propensity for the development of future leakage paths since the material conditions of many of the tanks are unknown and characteristics of the HLW itself often are not established to the degree required for estimating rates of potential degradation. Certain tanks are known or suspected to have initial imperfections and construction flaws.

older tanks appear to be at a greater risk, not only because of their age but also because some beneficial techniques were applied only to later tanks. Two examples are: heat treatment to relieve stresses resulting from the welding of steel plates to form shells, and corrosion control by addition of inhibitors, knowledge of which was gradually gained through tank farm management. As a consequence, the single-shell tanks and a few of the oldest doubleshell tanks were not stress-relieved, and the waste in many earlier tanks was not treated. Additionally, many tanks were subjected to thermal cycles due to addition of batches of hot wastes. Decay heating produced high temperatures over a long period in some tanks. Heat and thermal cycles could be detrimental to concrete strength. In two tanks, ground water intruded into the tank annular space through cracks in the concrete. 
As a result of these circumstances, namely, waste chemistries, thermal exposure, aging, and site conditions, waste has leaked from some tanks and contaminated the surrounding soll. Stress corrosion of heat-affected zones in the carbon steel shells was identified as the reason for leaks from several tanks. In other instances, the exact nature and cause of leakage are unknown, and sometimes it is uncertain whether observations that appear consistent with leaks are in fact due to leaks.

Currently, either initial material conditions (e.g., thickness, strength, and stiffness) or postulated parameters are used in structural analyses. Moreover, many of the tank structures are being reanalyzed due to redefined loads (e.g., earthquake and accidental loads). The relative gain in confidence regarding structural adequacy obtained from these analyses may be overshadowed by the uncertainties of the materials data. Therefore, in order to ensure leak-tightness and structural adequacy, i.e., to maintain the tanks within the safety envelopes defined in the respective Safety Analysis Reports (SAR's), it is essential that conditions of the tank materials and the trend or time behavior of any defect/damage be established to form the basis for determining the need for and selection of administrative controls.

Throughout the operational history of the tank farms, there have been efforts through experimental programs for estimating the effect of the waste on tank materials. Corrosion tests were performed to determine the material loss and search for effective inhibiting chemical agents. Concrete specimens were tested to determine the effect of temperature and waste chemistry. Data were also collected to establish possible trends of material degradation. Many of these efforts assisted in selection of corrosion inhibitors and similar other waste management processes. Visual inspections were performed for many tanks. Formal aging management programs are being initiated currently for many tank farms.

\subsection{SCOPE}

This document provides guidelines for the development of sitespecific structural integrity programs for both existing and new, single-shell and double-shell tanks. The primary steel tank, enclosure concrete vault, steel liner plate, and transfer piping are within the scope of this document. As such, this report is an extension of a general framework outlined by the DOE for material condition and aging management (Reference 1.1). The scope of the initial issue of this document is focussed primarily on existing double-shell tanks and transfer piping. However, some of the provisions are applicable to single-shell tanks and new tank designs. The present document addresses the potential age-related degradation mechanisms, recommends an acceptable inspection procedure, describes the structural integrity assessment steps, and 
offers preventive maintenance and management options. Additional procedures may be needed for site-specific programs in complying with local requirements, for example, state regulations. However, this document is expected to provide technical bases for inclusion or exclusion of major elements in the site-specific structural integrity program. References are provided throughout this document to inform the reader of the sources of the conclusions drawn, and to advise the reader where additional information can be found.

Most of the aging considerations for the double-shell tanks are equally applicable for the single-shell tanks. However, there are many unique features of the single-shell tanks, such as inaccessibility for inspection and determination of material conditions, particularly for the concrete vaults, which would require special considerations. Similarly, guidelines for singleshell tanks will also depend on the appropriate retrieval techniques that are currently being further developed. Many of these tanks are already out of active service for storing wastes, or will be removed from service in the near future. These issues will be further investigated and, subsequently, a revision of this document needs to be prepared addressing the structural integrity of the single-shell tanks.

This document proposes the institution of a structural integrity program that will allow verification of the current structural status of the tanks for making appropriate management decisions e.g., reduction of liquid level, elimination of pumpable liquid, prioritizing retrieval of waste, construction of new tanks, instituting emergency plans, dealing with regulatory agencies, investing in major repair programs, etc. Operation beyond the anticipated service life makes this particularly important in order to ensure compliance with the bounding parameters of the safety Analysis Report (SAR). The procedures outlined in these guidelines can be used to assess the structural integrity of new tank designs as well as for existing tanks.

The major elements of a structural integrity assessment program are identified in Chapter 2 with further elaboration in Chapters 3, 4 and 5. Assessment of tank integrity can be made either by subjective evaluations based on detrimental loading and service conditions, and the probabilities that these conditions could have occurred, or by deterministic evaluations based on actual measurements. Modes of assessment are described in Chapter 6. The transfer pipes are discussed in Chapter 7.

Regarding the verification of structural adequacy, this document provides general guidelines and serves like a "road map" to cite the companion documents that include specific structural provisions (e.g., loading, load combinations, seismic response, acceptance criteria, etc.). 


\subsection{GLOSSARY}

The following terminology is used throughout this document unless otherwise defined:

Primary Shell or Tank - A steel tank storing and in contact with the high-level waste.

Secondary Shell or Tank - A steel liner structure that provides confinement to the primary tank. A secondary tank may be a "pan" a few feet high, or may be as high as the primary tank. It may or may not be in direct contact with the concrete.

Concrete Vault or Tank - The reinforced concrete structure that encloses the primary and secondary tanks.

Single-Shell Tank - For the purpose of this document, a singleshell tank is defined as a primary tank in direct contact with the concrete vault where no access exists between the external surfaces of the tank and the concrete, and there are no secondary tanks.

Double-Shell Tank - A double-shell tank consists of the primary and secondary tanks, and the concrete vault. For the purpose of this document, a combination of the primary tank and concrete vault with an annular space between the two and without the secondary tank can also be considered a double-shell tank. Some tanks in a vault have Iimited access to both tank and vault.

Leak Tightness of a Tank - A tank is presumed to be "leak tight" if release of radionuclides to the environment is below the detection limit or the limit acceptable by regulatory agencies.

Non-Significant Degradation Mechanism - A degradation mechanism is classified as non-significant if it can be shown that the concrete enclosure is either not susceptible to it or affected by it to such a small degree that the intended function, namely providing a structural barrier to the primary and secondary shells, will be maintained during the remaining service life of the tank. (Section 3.3 and Table 3.1.)

Potentially Significant Degradation Mechanism - A degradation mechanism is classified as potentially significant when, if allowed to continue without mitigating measures, it cannot be shown that the concrete enclosure would continue to maintain its structural capability. (Section 3.3 and Table. 3.1.)

Potentially Non-Significant Degradation Measure - A degradation measure that is essentially the same as a non-significant degradation measure but which may become significant under certain specific circumstances. (Section 3.3 and Table 3.1.) 
Transfer Piping - Piping used to transfer wastes from the source to the tanks, from one tank to another, or from the tanks to waste processing facilities.

Structural Adequacy - A term denoting that a structure, system or component is capable to withstand appropriate loads without loss of function and has sufficient margin against failure.

Structural Integrity - An all-inclusive term denoting soundness, serviceability, and durability of a structure, system or component with respect to its primary functions of leak tightness and structural adequacy.

\section{REFERENCE}

1.1 DOE-STD-1073-93, Part $I$ and Part 2, "DOE-Standard Guide for Operational Configuration Management Program," November 1993. 
CHAPTER 2

STRUCTURAL INTEGRITY PROGRAM

\subsection{INTRODUCTION}

A structural integrity program shall be developed for each tank farm site according to its specific needs. These programs could be different from site to site according to the composition and nature of the wastes, and intended use of the tanks. However, there are several basic elements and considerations that shall be included in the programs to ensure a systematic assessment of the structural integrity. A broad framework for developing a structural integrity program is discussed and the major elements are identified in this chapter. These elements are further developed in subsequent chapters. To understand the need for developing an appropriate structural integrity program, the technical steps for verifying structural integrity are first discussed. The major goal should be to ensure that there is no release of radionuclides and hazardous chemicals to the environment.

This document provides a general framework for structural evaluation but does not include the technical details. Some technical requirements and acceptance criteria for structural evaluation have been developed in separate companion documents. For example, the seismic guidelines for tanks are included in BNL 52361 (Reference 2.1) and the effect of temperature on concrete vaults is discussed in BNL 52384 (Reference 2.2). Structural evaluation criteria for loadings other than seismic are under development and will be published in a separate document. This document cites the companion reports, national consensus standards, and site-specific considerations as applicable for structural evaluation.

\subsection{STRUCTURAL INTEGRITY VERIFICATION}

The basic steps for the verification of structural integrity are collection of structural and materials data, and subsequent assessment of these data. These two steps are elaborated in the following subsections.

\subsubsection{Data Collection}

The basic data that are required to verify integrity of a tank are related to the following parameters:

- Loading

- Geometry

- Material Properties 
The loadings considered in design of the tank system remain unchanged during its service life unless the mission changes, the knowledge about probable loadings (e.g., earthquake hazard) evolves, or a new loading is discovered. However, both the geometry (e.g., thickness) and material properties (e.g., strength) can change as the tank ages. Consequently, the magnitude and history of the loading, the geometry as it now exists as well as the original design, and the effects of past and present environments all need to be considered in evaluating the structural integrity of a tank.

Although information related to the above three parameters is required to verify structural adequacy of the tank, data related to geometric condition alone may be sufficient for assessment of leaktightness requirements. Each of these parameters is further discussed in the following subsections.

\section{2 .1 .1 Loading}

The loadings that were considered for design of the tanks include dead weight, liquid pressure, side soil pressure, soil overburden, earthquake loads, equipment weight, thermal load, and perhaps others. Additional loads, such as pressure build-up due to postulated chemical explosion may be defined in the Safety Analysis Report. As mentioned above, the loading requirement may change during the service life of a tank. Such changes will require revisions of the structural specification and/or Safety Analysis Report of the facility. In any event, it is assumed that there is an existing program at each tank farm facility that specifies and updates the loads that are required for verification of structural adequacy of tanks. Therefore, although loading is a major parameter in verification of structural adequacy of tanks, loading and load combinations will not be specified in this report. A separate guidance document on structural evaluation of tanks is being developed. However, if a facility did not specify the loads as part of the design process or development of the Safety Analysis Reports, loading and load combinations need to be defined for verification of structural adequacy of tanks. National standards and codes (e.g., ASME, ACI, AISC) as well as site-specific conditions should be consulted in defining the loads.

\subsubsection{Geometry}

The as-built geometric data should be used for structural evaluation. In addition, any change of dimension from mechanisms such as pitting, thinning, or cracking as a result of aging shall be considered. Since such information may not exist, these data need to be developed as part of the structural integrity program. Since degradation (i.e., thinning, pitting, cracking) is expected to continue with aging of the tanks, the condition at the end of their service lives should be estimated and used for structural integrity evaluation. 
The development of geometric data for structural integrity evaluation should be augmented by the use of techniques for the direct detection of leaks from the tanks. Soil or sump pit sample analyses and/or the use of moisture or radiation detectors should be introduced. Also, possible loss of contents should be monitored by tank liquid level indicators and checks for accumulation of any liquid that carries radionuclides into the annulus between the tank shells or beyond. These subjects are discussed further in Chapter 4 .

\subsubsection{Material Properties}

The initial material properties data are expected to be available from the design specifications and testing during construction. Although the actual material strength is expected to be greater than the specified values, no credit should be taken for this additional strength unless it can be demonstrated with confidence that all structural components possess a higher strength. On the other hand, the aging process can degrade material properties of some components of the tank structures and such data need to be developed as part of the structural integrity program.

\subsubsection{Data Collection Summary}

In summary, the loading data should be available from existing site-specific design and safety documents. However, the data related to changes in geometry (e.g., thinning, pitting, cracking) and possibly in material properties should be obtained as part of the structural integrity program. This subject will be further elaborated in this document as part of the aging degradation mechanisms and their effects. In addition, the leakage monitoring results for the tank should be compiled and validated to the extent possible.

\subsubsection{Data Evaluation}

The loading, geometry, and material properties data should be evaluated to determine whether tank integrity is maintained, i.e., the tank is able to perform its two intended functions: leaktightness and structural adequacy. Acceptable methods for evaluating leak-tightness should be developed as part of the structural integrity program. For the purposes of this report, a tank is presumed to be "leak tight" if release of radionuclides to the environment is below the detection limit or the limit acceptable by the regulatory agencies. In addition to the need for gathering geometric data, as described in section 2.2.1.2, direct leak-detection techniques should be developed and/or used to alert management to the need for action when any loss of tank contents is observed. The time required for detected pits and surface cracks to penetrate the thickness of the primary shell should be evaluated by fracture mechanics methodologies as described in chapter 6 
(Section 6.5). For brittle fracture, the structural stability against crack growth in the tank shells should be verified by use of fracture mechanics. On the other hand, local buckling, plastic collapse, and ductile tear should be evaluated assuming end-of-life wall thinning due to corrosion. Also, structural adequacy of the concrete tank should be assessed assuming degraded properties. The structural analysis will demonstrate the overall adequacy of the tank structure against the postulated loads. The structural analysis techniques and acceptance criteria are available in the design specifications and Safety Analysis Reports of the facility. It is planned to provide such information in a separate document.

\subsection{STRUCTURAL INTEGRITY PROGRAM DEVELOPMENT}

The structural integrity program should be developed in a way such that the steps required for verification of structural integrity as discussed above can be performed. This requires collection of adequate data and their evaluation. The worst combination of material properties data and loadings ${ }^{2}$ during the service life of the tank system should be considered in the structural analysis. An assessment of the current material properties in the tank allows a verification of its current structural adequacy. However, in order to demonstrate structural integrity at the end of the service life, projection of the component degradation may be required. Alternatively, if the maximum service life of a tank is to be estimated, a prediction model needs to be developed as part of the structural integrity program. In any event, a demonstration of structural integrity for future operation will require periodic inspection and commitment to maintenance programs, all of which should be included in an effective structural integrity program. Ultimately, if the structural integrity of a tank cannot be demonstrated, the program should provide adequate warning for management actions, such as retrieval of waste.

The elements of a structural integrity program should be defined and implemented in a logical sequence to achieve the above goals. The basic concern for structural integrity of the tanks is the degradation of materials. Therefore, the first step of a structural integrity program should be to identify any aging mechanisms that could cause material degradation. The next step is to quantify the degradation and determine its effect on performance of the two desired functions, namely, leak-tightness and structural adequacy. The program elements involving the leak detection system and non-destructive examination will verify the leak-tightness. A structural analysis program based on end-of-life material

${ }^{2}$ If loadings are expressed in probabilistic terms (e.g., seismic loads), such loadings commensurate with the safety significance of the systems, structures and components should be used. See BNL 52361 for further guidance on seismic loads. 
properties data will verify structural adequacy. If both analyses are successful, no further action is required. If not, additional steps should be considered, such as preventive maintenance, repairs, and management options (e.g., retrieval).

A flow chart identifying these program elements and their interactions in achieving a structurally sound tank is shown in Figure 2.1. Each element of this program is further discussed in the following sections.

\subsubsection{Identification of Aging Mechanisms}

As a tank ages, a variety of age-related (time-dependent) mechanisms may become operative. Age-related degradation of a tank system is the result of physical and chemical processes related to the environment including the consequences of waste storage. The aging mechanisms that may cause degradation of the materials should be identified considering tank-specific conditions, such as, thermal load, pH level, material types, chemical attack, and so forth. The most common mechanism affecting carbon steel tanks is corrosion. Both general and localized corrosion should be considered. Stress corrosion cracking can be a concern especially for non-stress-relieved tanks. Thermal history can have a detrimental effect on the condition of the concrete. In order to produce a realistic and cost-effective program, aging mechanisms expected to cause insignificant degradation should be eliminated from the study.

The potential failure modes include:

- Leakage of the primary shell due to formation of through thickness cracks (mainly stress corrosion cracks).

- Local ductile rupture and/or buckling of the primary shell due to thinning of the metal by corrosion.

- General failure of the primary shell due to large displacements and possible contact with the secondary liner or probes and intrusions in the annulus

- Structural integrity of the primary shells against unstable crack growth (assuming brittle conditions exist).

- Failure of the concrete vaults due to thermal degradation of mechanical properties (strengths and modulus of elasticity), corrosion of the reinforcing steel, loss of bond between concrete and reinforcing steel, large deflection of the dome due to thermal creep, and local buckling. 


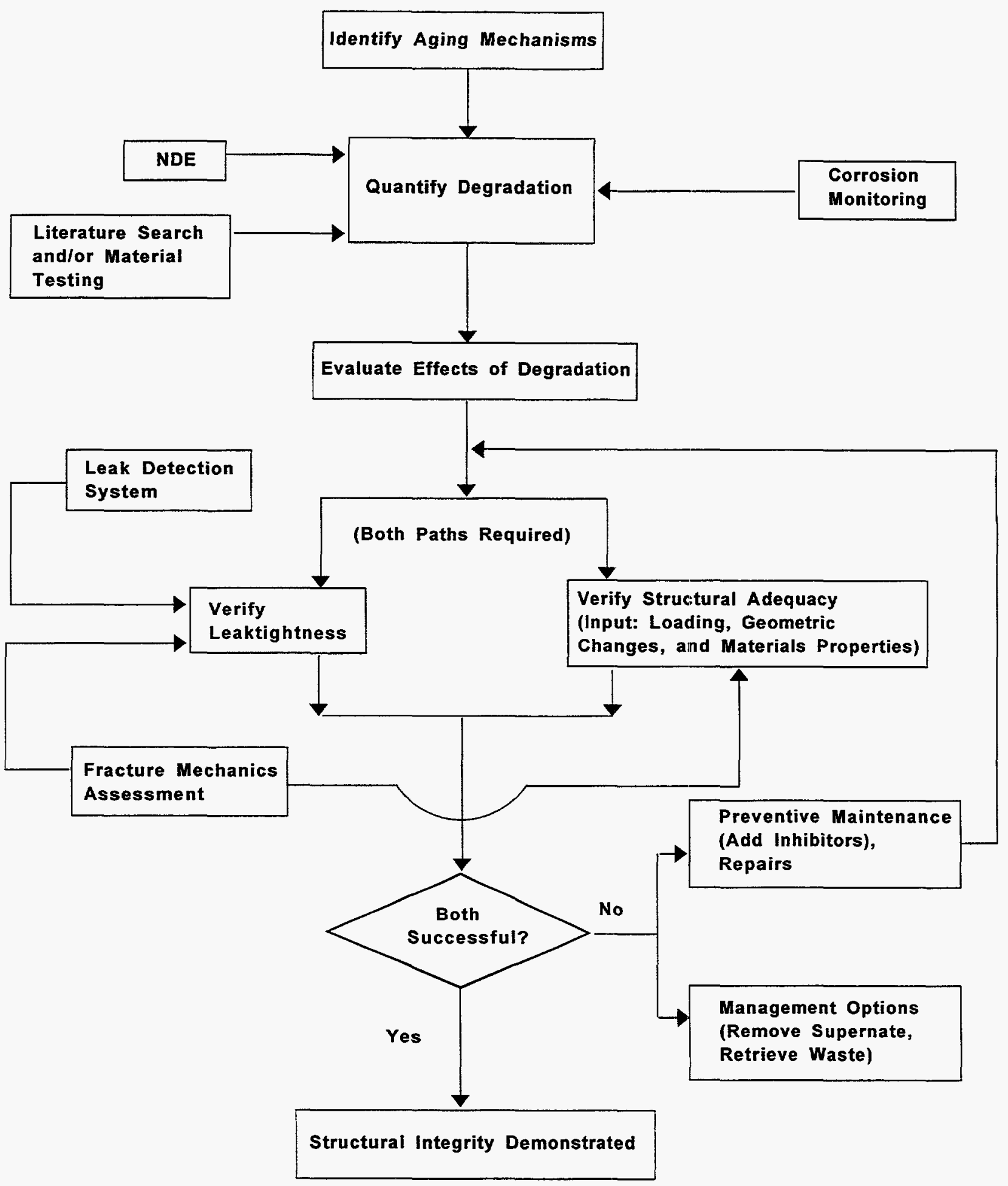

Figure 2.1 Tank Structural Integrity Program $2-6$ 
- Differential settlement of the soil beneath the tank.

Only the aging mechanisms which affect the likely failure modes should be included in the structural integrity evaluation.

\subsubsection{Ouantifying the Degree of Degradation}

For each aging mechanism identified as part of the above process, the possible structural and material properties degradation should be quantified. Typically, the degradation is manifested as changes in either geometry or material properties as discussed in section 2.2.1. Thinning, pitting, or cracking of steel plates due to corrosion, and buckling of the same due to thermal load are examples of geometric changes. A reduction of strength and stiffness (i.e., modulus of elasticity) of concrete due to thermal load, and a loss of ductility of steel due to thermal, corrosion, or hydrogen embrittlement are examples of possible changes in material properties. A nondestructive examination (NDE) is expected to provide data on geometric changes. A reliable leak detection system will provide data for extreme forms of geometric changes, such as, cracking and opening. A corrosion coupon monitoring program will provide information on the rate of material thinning. Testing is required to determine the changes in material properties. However, for many applications, testing may be avoided by performing a literature search since generic test data for most tank materials under various degrading environments may exist. Suggested documents providing generic test data for the various potential degradation processes are referenced in Chapters 3 and 4 . If after a literature search, it is decided that testing of tank-specific materials is required, such testing should properly simulate the aging environment. If material specimens are obtained by removing samples from the tanks, care should be taken to ensure that such specimens have been adequately aged, and that their properties have not been affected by the removal process.

Degradation data should be studied to determine whether there is any need for a preventive maintenance or repair program, or a change in operating procedures. For example, an inhibitor may need to be added to the waste for reduction of the corrosion rate or eliminate the propensity for stress corrosion cracking.

\subsubsection{Evaluation of the Effect of Degradation on Tank Integrity}

Once the degradation for each aging mechanism is quantified in terms of a change in either geometry or material properties, the next step is to determine its effect on the intended functions of the tanks, i.e., leak tightness and structural adequacy, as elaborated in the following sections. 


\subsubsection{Verifying Leak-Tightness}

The data (such as pitting or cracking) from an NDE program should be studied to estimate the potential for leakage. If a crack is detected, a fracture mechanics assessment may be required to determine its significance. Not all areas in a tank are accessible for an NDE. Moreover, NDE information can, at best, be taken at only a limited number of points in a tank. Therefore, for more reliable information, an appropriate leak detection system should be installed, such as moisture and radiation detection in a sump pit or an annular space.

\section{3 .3 .2 Verifying Structural Adequacy}

A reduction of material properties or significant geometric change can affect the ability of the tank structure to withstand the required loads. All loads including hydrostatic, soil pressure, thermal, earthquake, and other accidental loads, and their appropriate combinations, should be considered in the structural analysis. Typically, such loads are defined in the structural design specifications for the tank farms. ${ }^{3}$ The need for a fracture mechanics assessment should also be considered. A separate structural evaluation document is in preparation that describes this need more fully.

\section{3 .4 Management Options}

The structural integrity of a tank is demonstrated if it passes both the above analytical checks, i.e., leak tightness and structural adequacy. If it fails either check, management options should be considered. In addition to the preventive maintenance and repaix programs mentioned above, other options that may need to be considered are removal of supernate (in case of leakage) and retrieval of the entire waste (in case of leakage or structural inadequacy). However, a major undertaking such as interim stabilization or retrieval of waste should be judged in the context of the entire waste management process including a permanent disposal plan.

\subsection{SUMMARY}

The major considerations for a structural integrity program are presented in this chapter. In the remainder of this document, guidelines are provided for development of the above program elements. Possible age-related degradation mechanisms in an HLW tank environment are identified and their significance is discussed in Chapter 3. Incredible and nonsignificant degradation mechanisms are also identified so that they may be eliminated from

3 The earthquake loads for the underground tanks are defined by DOE in a separate guideline document (BNL Report No. 52361).

$$
\text { 2-8 }
$$


consideration in tank farm-specific structural integrity programs. Reasons for their elimination are provided.

The methods for monitoring and controlling degradation including leakage are described in Chapter 4. Nondestructive examination ( $\mathrm{NDE}$ ) methods that can be used to characterize material degradation are outlined in Chapter 5. An evaluation of the effects of degradation, with emphasis on the use of fracture mechanics, in the assessment of degradation data for determination of the effectiveness of the tank to provide a leak-tight confinement and structural adequacy (or integrity) is discussed in Chapter 6 . Guidance for managing degradation of transfer piping is provided in Chapter 7. Possible management options, in case structural integrity cannot be estimated reliably, are described in Chapter 8.

It is expected that a systematic consideration of all the steps delineated in this document will result in a successful structural integrity program. It is recognized that some of the above elements may not be applicable for certain tank farms. Therefore, the objective should be a judicious selection of the elements to define a structural integrity program for a tank farm or an individual tank. In developing the required structural integrity program for a specific tank farm, this document can be referenced for technical justifications, especially for inclusion or exclusion of certain aging mechanisms from consideration.

\section{REFERENCES}

2.I "Seismic Design and Evaluation Guidelines for the Department of Energy High-Level Waste Storage Tanks and Appurtenances," BNL 52361 (Rev. 10/95), October 1995.

2.2 "Thermal Degradation of Concrete in the Temperature Range from Ambient to $315^{\circ} \mathrm{C}\left(600^{\circ} \mathrm{F}\right), "$ BNL 52384 (Rev. 10/96), October 1996. 


\subsection{INTRODUCTION}

As a tank ages, a variety of aging mechanisms may become operative that impact either or both of the functions of the tanks as described in paragraph 1.5; leak tightness and structural adequacy. The physical and chemical characteristics of the waste as well as the environment surrounding the tank structure can accelerate the aging process. Based on experience gained from operation of the tank farms, a number of possible aging mechanisms have been identified. However, not all of them are expected to be operative in a specific tank structure or tank farm. The technical causes for occurrence of these mechanisms are discussed in this chapter, and engineering justifications are provided for possible inclusion or exclusion of certain aging mechanisms. For example, several of the aging mechanisms that have been observed for other applications, such as nuclear power plants, do not apply to the waste storage tanks because conditions are too different. Therefore, they need not be included in developing tank farmspecific structural integrity programs. Similarly, aging mechanisms having insignificant effects on tank performance, along with justification for their unlikelihood and nonsignificance are discussed in a generic manner, and are then excluded from subsequent consideration. The aging assessment presented in this document is based on the current use of the HLW storage tanks. However, if their use changes significantly in the future, additional considerations may be needed. Examples of possible changes in operation are: storage of low $\mathrm{pH}$ waste in carbon steel tanks; in-tank processing requiring high temperature or pressure; installation of large mixing pumps; etc. Table 3-1 summarizes the possible types of degradation of both steel and concrete components of the tanks, and their significance with respect to establishing tank structural integrity.

For those aging mechanisms deemed significant for both the steel and concrete components of the tank, existing information on the rates of these degradation processes is reviewed, in order to quantify the extent of degradation. The anticipated rates of change in material properties or in geometry of the components of the tanks are estimated; this information is provided to guide the user in planning and managing the site-specific structural integrity plan.

\subsection{DEGRADATION MECHANISMS FOR STEEL SHELL AND LINER}

A variety of degradation mechanisms potentially may affect both the steel shell and liner. Those of concern are listed in 
Table 3.1. The following provides a description of each, along with an estimate of its significance to tank aging and anticipated rates:

\section{Corrosion-Based}

General Corrosion (Bulk, Uniform)

Pitting/Crevice Corrosion

Stress-Corrosion

Microbiologically-Induced Corrosion (MIC)

Concentration Cell/Waterline Corrosion

Other

Fatigue

Erosion and Erosion-Corrosion

Wear

Hydrogen Embrittlement

\subsubsection{Potentially Significant Aging Mechanisms}

The potentially significant aging degradation mechanisms are corrosion-based and described in this section. It is expected that the site-specific programs should consider these aging mechanisms. other aging degradation mechanisms for steels, including nonsignificant aging mechanisms, are discussed in section 3.2.2.

\subsubsection{General Corrosion}

General or uniform corrosion of carbon steel is a potentially significant aging mechanism. In alkaline wastes of pH 11-14, carbon steel forms a protective oxide, and corrosion rates are expected to decrease with time to a low, fairly uniform rate of less than $1 \mathrm{mil} /$ year [3.1]. Consequently, general corrosion processes should penetrate less than half the steel thickness in 100 years, in this range of $\mathrm{pH}$. Increasing the $\mathrm{pH}$ above 14 causes the $\mathrm{FeO}_{2}$-ion to become stable, resulting in partial dissolution of the protective oxide and increasing corrosion rates. Literature data suggest this increase is not large, of the order of 2 to 5 mils per year at temperatures below the boiling point of water. While there are tanks in service that have contained wastes at $\mathrm{pH}$ 14.5 for many years without reported leaks, the extent of wall thickness loss is not known. For this reason, a $\mathrm{pH}$ of 14.0 is considered the top of the safe operating range for extended storage of wastes in carbon steel tanks.

The rate of general corrosion may increase significantly if the $\mathrm{pH}$ of the waste solution falls below 9 because of the increased solubility and dissolution of protective oxides. General corrosion rates can also increase significantly if the protective oxides are mechanically removed, as by rubbing of solid wastes (salt cake) against the tank surface. 
TABLE 3.1

POSSIBLE DEGRADATION MECHANISMS FOR NUCLEAR WASTE STORAGE TANKS

\begin{tabular}{|c|c|c|}
\hline COMPONENT & MECHANISM & SIGNIFICANCE ${ }^{a}$ \\
\hline $\begin{array}{l}\text { Steel Shell and } \\
\text { Liner }\end{array}$ & $\begin{array}{l}\text { 1. General Corrosion (Bulk, } \\
\text { Uniform) } \\
\text { 2. Pitting/Crevice } \\
\text { Corrosion } \\
\text { 3. Stress-Corrosion } \\
\text { Cracking (SCC) } \\
\text { 4. Microbiologically- } \\
\text { Induced Corrosion (MIC) } \\
\text { 5. Concentration } \\
\text { 6. Corrosion of External } \\
\text { Tank Surfaces by In- } \\
\text { Leakage } \\
\text { 7. Thermal Embrittlement } \\
\text { 8. Radiation Embrittlement } \\
\text { 9. Creep and Stress } \\
\text { 10. Fatigue } \\
\text { 11. Erosion and Erosion- } \\
\text { Corrosion } \\
\text { 12. Wear } \\
\text { 13. Hydrogen Embrittlement } \\
\text { and Attack }\end{array}$ & $\begin{array}{l}\text { A } \\
\text { A } \\
A^{b} \\
\text { A } \\
\text { A } \\
\text { A } \\
\text { C } \\
\text { C } \\
\text { C } \\
\text { B } \\
\text { B } \\
\text { B } \\
\text { B }\end{array}$ \\
\hline Concrete & $\begin{array}{l}\text { 1. Elevated Temperature } \\
\text { 2. Freezing and Thawing } \\
\text { 3. Leaching of Calcium } \\
\text { Hydroxide or Other } \\
\text { Soluble Constituents } \\
\text { 4. Aggressive Chemical/ } \\
\text { 5ulfate Attack } \\
\text { 5. Corrosion of Embedded } \\
\text { 6. Alkali-Aggregate } \\
\text { 7. Reactions } \\
\text { 8. Abrasion and Cavitation } \\
\text { 9. Irradiation }\end{array}$ & $\begin{array}{l}\mathrm{A} \\
\mathrm{A} \\
\mathrm{C} \\
\mathrm{C} \\
\mathrm{C} \\
\mathrm{C}\end{array}$ \\
\hline $\begin{array}{l}\text { Refractory } \\
\text { Concrete }\end{array}$ & $\begin{array}{l}\text { 1. Elevated Temperature } \\
\text { 2. Effects of Chemicals }\end{array}$ & $\begin{array}{l}A \\
A\end{array}$ \\
\hline
\end{tabular}

${ }^{a}$ Significance (Section 3.3):

A - Potentially significant

B - Potentially non-significant, but may become significant under certain specific circumstances

C - Non-significant

${ }^{b} S S C$ is the only identified cause of leakage 
Since the HLW may vary widely in composition from tank to tank, and in different parts of a given tank, there is no assurance that the general corrosion rate will be uniform in all tanks or portions of a given tank. In practice, no HLW tank is known to have leaked by general corrosion, while at the same time, no measurements of tank wall thickness have yet been made. In-situ coupons have generally shown corrosion rates in both the liquid and vapor phases to average $0.5 \mathrm{mil} / \mathrm{yr}$ over times ranging from 0.5 to 6 years. The corrosion rate was measured to be as high as 5 mil/year in wastes containing zeolites.

The rates of general corrosion of austenitic stainless steel tanks should be low, of the order of $0.02 \mathrm{mil} / \mathrm{yr}$ or less, over a wide range of waste compositions and $\mathrm{pH}$, due to the great stability of the protective oxides on stainless steels. In-situ coupons of austenitic stainless steels in tanks containing acid fluorides, nitrates, and sodium wastes showed general corrosion rates to be below $10^{-2} \mathrm{mil} / \mathrm{yr}$ in all cases.

General corrosion of both carbon and stainless steel tanks becomes a potentially significant aging mechanism if waste chemistries are changed (or vary locally) to bring the pH out of the recommended range, or if mechanical damage can occur to the protective oxides.

\subsubsection{Pitting and/or Crevice Corrosion}

Pitting corrosion is one of the more common types of localized corrosion [3.2], and can occur on either carbon or stainless steels. Basically, an electrochemical cell is formed, consisting of a small anodic (corroding) area surrounded by a larger cathodic (non-corroding) surface region that stimulates the localized dissolution at the anode. Once started, pits may continue to grow autocatalytically. Crevice corrosion is associated with geometries where a localized area is occluded, setting up anode/cathode relationships closely related to conditions just described for pitting corrosion.

While austenitic stainless steels may have very low uniform corrosion rates, they often pit severely, particularly in the presence of chlorides. Pitting has been observed in some carbon steel HLW tanks in the past $[3.1,3.3,3.4,3.6]$, but it has not been reported to date in stainless steel tanks storing nitrate solutions. Since the growth rates of pits can be very high, it is important to minimize their initiation.

The chloride ion and other halogen ions can cause localized breakdown of passivity on the surface of carbon steels and stainless steels at relatively low $\mathrm{pH}$. Nitrate and sulfate are also adverse for carbon steel. This results in the formation of a small anode surrounded by a relatively large cathode, leading to pitting. As pitting proceeds, $\mathrm{pH}$ and the concentration of oxygen 
inside the pit decrease and the chloride content increases, all of which cause an increase in the rate of attack. The addition of other ions, such as $\mathrm{OH}^{-}$(and $\mathrm{NO}_{3}^{-}$in the case of stainless steel) mitigates pitting. Local corrosion starting in an occluded region acts in the same way as pitting, and the resulting crevice corrosion propagates by the same mechanism.

In the case of caustic HLW, pitting and crevice corrosion are possible in the carbon steel, but should be dependent on the specific waste composition, and would be prevented by the high $\mathrm{NO}_{2}^{-}$ and $\mathrm{OH}^{-}$contents of the waste. Laboratory work indicates that the $\mathrm{pH}$ must be less than 10 to cause pitting in carbon steel. A statistical analysis of laboratory measurements carried out to assess the susceptibility of ASTM A 537 Class I steel when subjected to aggressive environment yielded the following equation for the minimum nitrite concentration required to inhibit pitting corrosion at a given temperature [3.7]:

$$
\left[\mathrm{NO}^{-}\right]=0.038\left[\mathrm{NO}_{3}^{-}\right]^{0.98}(10)^{0.061 \mathrm{~T}},\left[\mathrm{NO}_{3}^{-}\right]<1 \mathrm{M}
$$

where $\left[\mathrm{NO}_{2}^{-}\right]$and $\left[\mathrm{NO}_{3}^{-}\right]$are the molar concentrations of the nitrite and nitrate ions, respectively, and $T$ is the temperature in ${ }^{\circ} \mathrm{C}$. Solutions to equation (1) using temperatures of $23,30,40,50$, and $60{ }^{\circ} \mathrm{C}$ are plotted in Figure 3.1 , along with the experimental data. This report [3.7] also shows the relationships between concentrations of sulfate, chloride, and fluoride anions and the minimum effective nitrite concentrations required to prevent corrosion pitting of ASTM A 537 Class I carbon steel. Other carbon steels should behave similarly.

Determining the rates of pitting/crevice corrosion is difficult or impossible because of a lengthy and poorly defined initiation period. However, once initiated, pits may grow at rates up to $50 \mathrm{mils} / \mathrm{yr}$ or higher, and can penetrate the tank wall in a few years, if mitigating measures (i.e., changes in chemistry) are not instituted. The difficulties of quantification apply to both ferritic and austenitic steels.

The operating history of the tanks reveals a few confirmed cases of pitting corrosion in carbon steel. A 1/2 in. (13 mm) wall section of ASTM A 285 Grade B steel, extracted from a tank, revealed broad, shallow pits up to 0.02 in. $(0.51 \mathrm{~mm})$ deep [3.7]. In addition, pitting corrosion was confirmed to have caused leaks in cooling coils of a number of tanks [3.7]. The pitting was attributed to dilute waste that is low in caustic and nitrite inhibitors and relatively high in sulfate dissolved from the sludge. The coils are 2 -in. (5.08 mm) ID, schedule 40 pipes fabricated from ASTM A 53 and A 106 carbon steels. The vapors in 


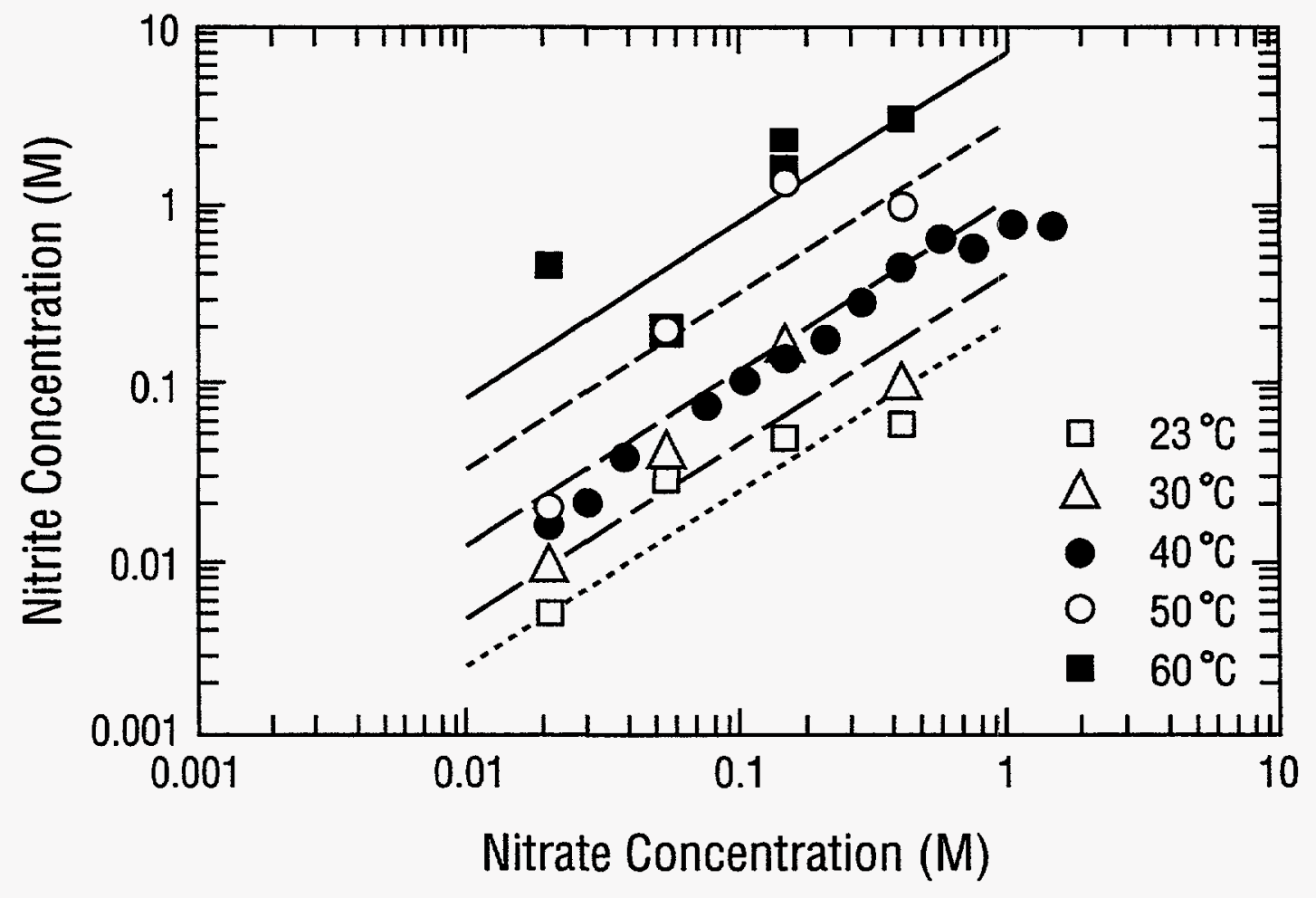

Figure 3.1 Minimum Nitrate Concentrations to Inhibit Pitting at Indicated Temperatures 
another tank severely attacked the mild steel liner resulting in pitting corrosion [3.1]. Pitting corrosion rates as high as 24 to $37 \mathrm{mils} / \mathrm{yr}(0.61 \mathrm{~mm}$ to $0.94 \mathrm{~mm}$ per year) have been found in original $\mathrm{BiPO}_{4}$ wastes in the vapor, liquid, or interphase regions $[3.8]$. The pH was 6 to 8 .

In stainless steel tanks containing acid HLW, the presence of $\mathrm{NO}_{3}^{-}$should be beneficial in spite of the low $\mathrm{OH}^{-}$level. To date, no pits or crevice corrosion have been identified in these tanks. However, in a recent test program, pitting was observed in 7 out of 25 specimens of 304L stainless steel tested for two months in a solution with pH 5, high chloride/fluoride, high nitrate, and low nitrite [3.9]. The pitting was observed in immersed specimens, specimens in the vapor phase and at the waterline, and exceeded the test plan criterion of $0.4 \mathrm{mil} / \mathrm{yr}(0.01 \mathrm{~mm} / \mathrm{yr})$ based on the deepest pit. The pitted specimens included U-bend and crevice-corrosion specimens. The maximum temperature and chloride content of the operating stainless steel tanks are controlled to minimize this problem.

\section{2 .1 .3 Stress-Corrosion Cracking}

Stress-corrosion cracking (SCC) requires a susceptible material as well as the simultaneous presence of a sustained tensile stress and an aggressive environment. Both carbon and stainless steels are susceptible to SCC in certain environments and temperatures. Welding causes residual tensile stress (which is sustained unless a stress-relieving treatment is performed); welding also causes changes in the material adjacent to the weld, making it susceptible to some forms of SCC. Tensile stresses from occasional short-duration loads are not of concern. Intergranular and transgranular cracking (IGSCC and TGSCC) are possible in both materials. The only identified cause of leakage was SCC in tanks at Savannah River that were not stress-relieved after welding. SCC is presumed to have occurred in some of the SSTs at Hanford as well.

\subsection{Carbon Steel}

Two environmental causes of SCC that could apply to carbonsteel HLW tanks are hot nitrate and hot caustic solutions. The ratio of hydroxide and nitrate ions determines whether or not SCC is likely to occur. Nitrite has been found to act as an inhibitor of nitrate SCC. In service there has been extensive SCC in nonstress-relieved carbon steel tanks with nitrates providing the aggressive environment at Savannah River $[3.1,3.4,3.10,3.11]$. Hundreds of cracks were found, all in the vicinity of welds that were not stress-relieved after welding. There has been no reported leakage in stress-relieved tanks at either Hanford or Savannah River. When the tanks have had sufficient caustic and a nitrite inhibitor added, no further leakage developed in non-stressrelieved tanks at Savannah River. However, there is no assurance 
that SCC will never occur, particularly when tanks contain no inhibitor and may have localized regions of cold work or stresses due to local buckling.

Extensive studies have shown that SCC of carbon steel tanks can be reduced or eliminated by implementing the following [3.1]:

Controlling the $\mathrm{pH}$ and caustic/nitrate ratio and adding nitrite to the high level wastes;

Heat treating the inner tank at $590^{\circ} \mathrm{C}\left(1100^{\circ} \mathrm{F}\right)$ followed by controlled slow cooling to relieve stresses in and adjacent to the welded joints;

Reducing stress concentrations during construction;

Using an improved steel grade such as ASTM A 516 or A 570 Grade I for liners.

The first option is available to both existing and new tanks; whereas, the last three items can be implemented only during new tank construction.

The rates of SCC propagation have been studied in laboratory measurements, using pre-cracked wedge opening load (WOL) specimens immersed in $5 \mathrm{M} \mathrm{NaNO}$ solutions with various additions of nitrite and hydroxide ions at $95^{\circ} \mathrm{C}\left(203^{\circ} \mathrm{F}\right)$. The experimental conditions used in the laboratory, e.g., stresses and strain rates, are more severe than those likely to exist in the waste tanks presently in service. The measured crack initiation time and the threshold stress corrosion cracking stress intensity factor, $\mathrm{k}_{\mathrm{scc}}$, are given in Table 3.2 [3.7]. In solutions that caused crack growth, the rate of the crack growth and the factor, $\mathrm{K}_{\mathrm{scc}}$, were independent of the chemistry of the bulk solution. Crack growth occurred at a constant rate of approximately $1300 \mathrm{mils} / \mathrm{yr}(33.02 \mathrm{~mm} / \mathrm{yr})$ which implies crack growth through wall in a typical waste storage tank in less than a year if the stresses are uniform through the wall and the waste chemistry favors crack growth. However, the initiation time was related to the composition of the solution as indicated in Table 3.2. The initiation of crack growth (since the specimen was originally cracked) can be inhibited by increasing the concentration of either the nitrite or hydroxide (or preferably both) as indicated by the data in Table 3.2. The essential message is that chemical controls that prevent SCC initiation and propagation should be in effect in tanks that have not been stress-relieved after welding.

It is difficult to apply these data to estimate DST life, since controls on chemistry and stress-relieving after welding has prevented the formation of new cracks in the double shell tanks (DSTS). In some of the old DSTs, which were not stress relieved, the inhibitor program had stopped the growth of old cracks, as 
evidenced by the absence of new tank leaks. Nitrite inhibitor is consumed during the inhibiting process and must be monitored and replenished periodically because a certain minimum concentration is needed for inhibition. Also, the inhibitor must be mixed into the waste uniformly so that it is not depleted at local regions. When the inhibitor cannot be replenished at the metal surface because of barriers formed by salt deposits, the inhibition may become ineffective. However, some nitrite is produced in the tanks by radiolytic reduction of nitrate ions.

TABLE 3.2

RESULTS OF LABORATORY EXPERIMENTS ON THE EFFECT OF ENVIRONMENT ON CRACK INITIATION TIME AND $\mathrm{K}_{\text {SCC }}$ IN CARBON STEEL [3.7] *

\begin{tabular}{|c|c|c|c|}
\hline$\left[\mathrm{NO}_{2}^{-}\right], \mathrm{M}$ & {$\left[\mathrm{OH}^{-}\right], \mathrm{M}$} & $\begin{array}{l}\text { INITIATION TIME } \\
\text { (HOUR) }\end{array}$ & $\begin{array}{l}\left.\text { THRESHOLD } \mathrm{K}_{\mathrm{Scc}_{1 / 2}}\right) \\
\mathrm{MPa} \cdot \mathrm{m}^{1 / 2}\left(\mathrm{ksi} \cdot \mathrm{In}^{1 / 2}\right)\end{array}$ \\
\hline- & - & $75-200$ & $31(28.2)$ \\
\hline 0.5 & - & 200 & $31(28.2)$ \\
\hline 0.75 & - & 400 & $31(28.2)$ \\
\hline 1.5 & - & 600 & $36 \quad(32.7)$ \\
\hline 3.0 & - & No Crack Growth & - \\
\hline- & 0.3 & 75 & $27(24.5)$ \\
\hline- & 0.5 & 400 & $33(30.0)$ \\
\hline- & 1.0 & 350 & $30(27.3)$ \\
\hline- & 1.2 & No Crack Growth & - \\
\hline 0.2 & 0.5 & 615 & $30 \quad(27.3)$ \\
\hline 0.2 & 0.2 & 525 & $33(30.0)$ \\
\hline 0.3 & 0.3 & 1100 & $35 \quad(31.8)$ \\
\hline 0.5 & 0.1 & 150 & $29(26.4)$ \\
\hline
\end{tabular}

* The experimental conditions including stresses and strain rates may not be representative of those in existing tanks that are still operating.

\section{2 .1 .3 .2 Stainless steel}

Stainless steel tanks could be susceptible to either form (intergranular or transgranular) of SCC. For stainless steels with carbon levels greater than 0.015\%, IGSCC is possible under a sustained tensile stress in hot water containing only a few parts per million of oxygen. Impurities such as chloride or more oxygen make the attack worse. Temperatures of about $200^{\circ} \mathrm{C}\left(392^{\circ} \mathrm{F}\right)$ cause the most severe cracking, but cracks can occur at $90^{\circ} \mathrm{C}\left(194^{\circ} \mathrm{F}\right)$ and lower on prolonged exposure. A non-stress-relieved welded region can contain residual tensile stresses near the yield point as well 
as chromium depletion (sensitization); other thermal treatments can also lead to sensitization [3.2].

TGSCC is associated with a tensile stress and exposure to a hot, oxidizing, chloride-containing solution. TGSCC becomes more severe as temperature and chloride content increase. TGSCC is not confined to a particular $\mathrm{pH}$, but appears to be more severe under acid conditions. Even low chloride levels can lead to cracking in crevices or at points of evaporation where concentrations can build up.

SCC in stainless steels can be reduced or eliminated by the following :

\section{IGSCC:}

- Elimination of the aggressive environment, such as maintaining very low oxygen and very low impurities (this is not practical in waste storage).

Avoiding tensile stress by one of several methods, such as, heat-sink welding, special heat treatment of welded areas, or stress-relief; although the latter is an unattractive option because of possible sensitization in steels other than extralow carbon grades. Also, stress-relief does not remove tensile stress completely.

Reducing sensitization at grain boundaries through heat treatment to reduce chromium depletion. This is not, however, beneficial in chloride-containing wastes.

Using materials with added stabilizers (e.g., niobium or titanium) or with extra-low carbon, e.g., less than about $0.015 \%$. With nitric acid wastes titanium-rich areas may be selectively attacked, and niobium stabilization is more effective [3.12].

These preventive measures are practical only in the case of new tank construction.

\section{TGSCC:}

In new construction, using more resistant alloys, including higher nickel alloys (above about 35\%) and alloys containing high nickel and molybdenum concentrations.

Also, in new construction, removing tensile stress, although thermal stress relief may have an adverse secondary effect, i.e., sensitization, and may not eliminate the stress totally.

Eliminating chloride, or regions where chlorides could concentrate. 
- Maintaining temperatures below the TGSCC threshold for the environment in the tanks; this may not be possible in chloride-containing wastes.

The only stainless steel tanks in current use were fabricated of type 304-I stainless steel, which minimizes the chance of IGSCC, and strict controls on both chloride and temperature were placed to minimize the chance of TGSCC. These tanks were not stress-relieved after welding.

\subsubsection{Microbiologically-Induced Corrosion}

MIC is more liable to occur in buried piping. It is also possible in tanks in the presence of stagnant water that might occur, for example, in the interface between the outer tank and the concrete containment or in the annulus between primary and secondary tanks if ground water leaks in. Both MIC and subsequent localized concentration cell corrosion are unpredictable until they occur. Once detected, they can be monitored or corrective action can be taken. If aerobic bacteria exist in stagnant water, they can multiply rapidly and attack can be anywhere on the wetted surface. The usual corrective action is to check soil and water conditions and to apply anodic/cathodic protection. In the waste tank systems, the operating history reveals a few documented cases of MIC. MIC was observed in several stainless steel piping systems of one tank farm due to improper testing procedures and lay-out practices. It was also observed in the annulus region between the primary shell and the secondary liner during construction of tanks due to water accumulation in that region [3.4].

\subsubsection{Concentration Cell Waterline Corrosion and Galvanic Attack}

Localized attack on carbon (and, in some cases, stainless) steels can occur where concentration gradients can develop in the environment in contact with the steel. Crevice corrosion, discussed above in Paragraph 3.2.1.2, is a specific example. Within the waste, the presence of solids against the tank surface can lead to local oxygen concentration cells, and possibly to local attack or pitting. Chelating or complexing species could also affect the anodic reaction of metals by lowering the local concentration of corrosion products.

A condition that has received considerable attention is waterline corrosion, resulting from local differences in $\mathrm{pH}$ at the surface of the waste; in principle, water is continuously evaporating from the surface of the waste and condensing on the inner surfaces above the liquid level. This condensate is inherently lower in $\mathrm{pH}$ than the waste, both because $\mathrm{NaOH}$ does not evaporate and because the condensate may be acidified by absorption of $\mathrm{CO}_{2}$ from the air above the waste surface. Pitting by condensate has caused penetration of cooling coils suspended in the vapor 
region by localized pitting. It has been hypothesized to be a potential mechanism for attack on the tank walls at the interface; in laboratory experiments, pitting has occurred on specimens at this location. No tank leaks are known to have occurred from this mechanism, nor has waterline attack been identified by visual inspections: local - almost daily - changes in interface levels plus diffusion and convection processes from the bulk waste solutions may have prevented sufficient gradients from developing for long enough periods of time to initiate this potential degradation mechanism. The ultrasonic inspection program described in Chapter 5 includes examination of stable interface areas, in an attempt to identify if waterline attack has developed in actual tanks.

Galvanic attack could develop where foreign objects (i.e., tools) are inadvertently dropped into the tank during loading, or other operating procedures. This is akin to crevice corrosion, and electrochemical potentials for bi-metal contact can give rise to localized attack. This attack should be evaluated based on individual tank operating records, where available.

\subsubsection{Corrosion of External Tank Surfaces by In-leakage of Ground Water}

In tank farms where the water table is high, or excessive soil moisture is occasionally present following heavy rains, ground water leakage into the annulus between the inner and outer carbon steel tanks is possible. This water contains some dissolved ionic impurities, concentration of which, by evaporation, can cause local corrosion cells to develop on the external surfaces of tanks. Also, excess humidity in the annulus can cause external corrosion of the steel surface. The presence of aerobic bacteria in this water can accelerate attack on the external surface, especially at or near the bottoms of the tanks, as described above in 3.2.1.4. In some areas, the pH of the ground water may be slightly acidic and increase the corrosion rate. However, seepage through the concrete can raise the $\mathrm{pH}$ of the in-leaking water.

No known leakage of waste materials has developed to date by this mechanism; deposits of corrosion products can, however, prevent reliable UT inspections, unless they can be mechanically removed from the areas to be examined.

Remedial measures include the following:

- Early detection of water inleakage

- Prompt removal of the liquid

- Maintaining low humidity in the annulus by dry air circulation

Introducing an inert gas such a nitrogen into the annulus to exclude oxygen and reduce the corrosion rate 


\subsubsection{Potentially Non-Significant Aging Mechanisms for Steel Shell and Liner}

Aging mechanisms considered to be potentially non-significant for carbon or stainless steel shells and liners during their design and extended life cycles include the following:

- Thermal Embrittlement

- Radiation Embrittlement (neutron and gamma)

- Creep and Stress Relaxation

The reasons that these aging mechanisms need not be considered any further in the site-specific programs are discussed in the following sections:

Aging mechanisms normally considered to be non-significant, but which may occur under special circumstances include the following:

- Fatigue

- Erosion and Erosion-Corrosion

- Wear

- Hydrogen Embrittlement

These mechanisms along with conditions required for their significance, are discussed in the following sections. Generally, fatigue, erosion-corrosion, hydrogen embrittlement, and wear mechanisms for DSTs; however, their probability of occurrence cannot be eliminated completely as potential degradation should be very low. Each will be sensitive to the geometry of the tanks, changes such as soil settling, and to specific operating conditions.

Since it is possible that a given tank may have a unique set of conditions that could promote one of these degradation mechanisms, it may be necessary to consider them on a case-by-case basis.

\subsubsection{Thermal Embrittlement}

Stress-relieved carbon steel is not prone to embrittlement even during long periods of holding in the temperature range of interest for waste storage tanks $\left(300-600^{\circ} \mathrm{F}, i . e ., 149-316^{\circ} \mathrm{C}\right)$. The toughness of many carbon steels is reduced when they are cooled to temperatures below room temperature, usually below $40^{\circ} \mathrm{F}$. However, it is difficult to conceive of any scenario in which these underground tanks filled with heat-generating waste would be cooled to such a low temperature, even though the waste cooled underground temperatures would not drop this low. The other way in which such steels can lose ductility and toughness requires cold working and then aging in the range of $200^{\circ} \mathrm{F}$ to $300^{\circ} \mathrm{F}\left(93^{\circ} \mathrm{C}\right.$ to $\left.149^{\circ} \mathrm{C}\right)$ and is called strain aging. The degree of embrittlement only becomes 
severe in regions that undergo strains of approximately $10 \%$ or greater, and/or quenching from elevated temperatures (> $1000^{\circ} \mathrm{F}$, > $538^{\circ} \mathrm{C}$ ) [3.13]. Such conditions do not occur when welds are stressrelieved. Even if the stress relief were incomplete in some region of the tank, the expected strains would be so low that the aging effect would be to raise strength and reduce ductility only mildly. It would not produce any change that could properly be called embrittlement. It has also been shown that repair welds (done after the stress relief) also demonstrate acceptable structural integrity [3.14].

For those tanks made of stainless steel, embrittlement is not expected, and a transition from ductile to brittle at around room temperature is absent.

\subsubsection{Radiation Embrittlement}

Radiation embrittlement of ferritic steels arises from displacement of atoms in the steel by high energy $(>0.1 \mathrm{MeV})$ neutron bombardment. Gamma irradiations normally have little effect since these primarily affect the electronic (or ionic) structure of solids, and free electrons are already present in metals including steels; however, very high energy gamma radiation can produce some atomic displacements.

In an attempt to estimate the combined effects of the delayed neutrons and high energy gamma irradiation, Caskey [3.15] has calculated the possible displacements per atom (dpa) under a number of potential situations. Radiation embrittlement of carbon steels results in a reduction in ductility and/or a measurable increase in the ductile-brittle transition temperature (DBTT) of the steel. In neutron irradiations, these changes are not observed in power reactors at neutron fluences $<10^{17} \mathrm{n} / \mathrm{cm}^{2}(\mathrm{E}>0.1 \mathrm{MeV})$ or about $10^{-4}$ dpa. The lowest threshold observed to date, in the low-temperature High Flux Isotope Reactor at Oak Ridge, was $10^{16} \mathrm{n} / \mathrm{cm}^{2}\left(10^{-5}\right.$ dpa). The maximum fast neutron flux (from delayed neutrons) anticipated in the waste tanks is far too low $\left(\sim 10^{3} \mathrm{n} / \mathrm{cm}^{2} / \mathrm{sec}\right)$ to cause threshold fluences to develop in the normal or extended life times of these tanks.

Even considering the unlikely case of a tank being continuously exposed to the high energy gamma flux in "fresh canyon waste," Caskey estimated the maximum dpa to be $4 \times 10^{-7}$ in 50 years, i.e., a dose more than 20-fold lower than the most conservative threshold values. Therefore, radiation embrittlement of the carbon steel tanks is concluded to be a non-significant aging mechanism.

Stainless steel tanks are expected to be at least as resistant as carbon steel to radiation embrittlement. 
The only mechanism by which high dpa could develop in these waste tanks would be if criticality were to occur and continue for extended periods; under such accidental conditions, embrittlement of the tanks would be a very minor problem compared with the thermal effects of the accident.

\subsubsection{Creep and Stress Relaxation}

Creep is the time-dependent inelastic deformation of a material subjected to a stress that is typically below the elastic limit. It is not a concern for steels below a temperature of $800^{\circ} \mathrm{F}$ $\left(427^{\circ} \mathrm{C}\right)$. Neither is stress relaxation likely to occur below $800^{\circ} \mathrm{F}$. Therefore, these phenomena should not occur even in non-stressrelieved waste storage tanks during operation. Indeed, the apparent instances of stress-corrosion cracking developing in heataffected zones of welds in such tanks many years after fabrication suggests that residual stresses are not relieved under tank operating conditions.

Stainless steel is equally resistant to creep and stress relaxation.

\section{2 .2 .4 Fatique}

Fatigue is an incrementally damaging process that occurs when metals are subject to cyclic stresses. The number and intensity of alternating stress cycles due to loading/unloading of wastes in the tanks are both sufficiently small so that mechanical fatigue can be classified as a non-significant aging mechanism.

Fatigue stresses due to thermal cycling, however, could be a potential aging concern. These need to be treated on a case-bycase basis. They may be a function of how cooling water is added to the tank.

\subsubsection{Erosion and Erosion-Corrosion}

Erosion and erosion-corrosion are potential age-related degradation mechanisms for carbon steel where flowing waste slurries impinge on the steel surface. In the former, the steel is mechanically eroded away, while in the latter, erosion removes the protective oxide film on the steel surface in a local area, resulting in rapid reoxidization, renewed film removal, etc. This process can lead to local thinning and/or penetration of the steel tank wall. In most waste storage tanks, the fluid or slurry is essentially stagnant for much or all of the time, so this phenomenon is not likely to be a significant degradation process. Where the contents of tanks are stirred or agitated, however, a potential for this degradation process to occur can develop; it should therefore be considered if agitators are used in a tank. 
In general, the low temperature, high $\mathrm{pH}$, and high oxygen content of the waste solutions are all beneficial factors in minimizing the risk of degradation by erosion/corrosion processes.

For stainless steel tanks, erosion/corrosion should not be of concern because of the inherent resistance of the material to this form of degradation. Erosion and erosion-corrosion may especially affect transfer piping, as discussed in Chapter 7.

\section{2 .2 .6 Wear}

Wear is an age-related degradation mechanism resulting from relative motion of two solids against each other. In these massive tanks, with their largely static loads, there is little reason for wear to develop. During loading and unloading of the inner tank of a DST, the bottom of the steel inner tank may rub against the ceramic support blocks, and the inner and outer tanks may rub where they are in contact (but not welded) in the lower part of the dome (in the Hanford DSTs). During addition of hot waste (or cold water) thermal expansion or contraction of the inner tank may also cause some relative motion. The number of such cycles, however, is small, and no leaks are known to have developed by this mechanism. Wear should, therefore, not be considered a significant aging degradation mechanism for most tanks, but it should be considered in the assessment of those tanks that have had many loading or thermal cycles. In such tanks, areas susceptible to wear should be selected and examined in the NDE program.

\subsubsection{Hydrogen Attack}

Two types of hydrogen attack need to be considered in assessing aging-related materials degradation:

In the first, high temperature hydrogen attack, hydrogen diffuses into the steel from the solution (where it is produced by radiolysis) and reacts with carbon in the steel to form methane gas, resulting in loss of strength and ductility of the steel. This tends to be a high-temperature, high-pressure phenomenon, and should not occur at tank operating temperatures and pressures. The American Petroleum Institute has published curves [3.16] delineating safe zones of operation to avoid this phenomenon. They show that, for a carbon steel such as those used in the tanks, at temperatures below $500^{\circ} \mathrm{F}$, pressures of several hundred psi lie in the safe range for an indefinite period of operation. Therefore, this type of hydrogen embrittlement should be a non-significant age-related degradation process.

The second, hydrogen embrittlement, results from the presence of interstitial hydrogen in the steel lattice. The embrittlement is exhibited only at low temperatures, i.e., below $200^{\circ} \mathrm{F}\left(93^{\circ} \mathrm{C}\right)$, and the effect is most pronounced at or below room temperature and in high strength steels. It is usually attributed to electrochemical 
feeding of hydrogen into the steel by an active corrosion process. The absorption of hydrogen by the steel can be drastically increased by the presence of "poisons," such as cyanide and arsenic, which are present in some single-shell tanks. For the double-shell tanks, at the temperatures experienced with hot waste, above $200^{\circ} \mathrm{F}\left(93^{\circ} \mathrm{C}\right)$, the hydrogen produced by the limited corrosion occurring in these tanks readily diffuses out of the steel and the concentration required for embrittlement on cooling cannot accumulate. It is hard to imagine how such embrittlement (reduced ductility) could cause any problems in the steel waste storage tanks because:

a) the hydrogen will diffuse out before the tank cools to a temperature where embrittlement can occur, and

b) the stress-relieved carbon steel tank is sufficiently soft that even if a high concentration of hydrogen did accumulate the steel would undergo substantial strains (> 10\%) before it would fracture.

Experience to date has shown that steel samples removed from an existing tank after exposure to waste solutions retained normal ductility in bend tests [3.10]. This suggests hydrogen embrittlement should be considered a non-significant degradation mechanism.

For the case of austenitic stainless steel tanks there is no problem expected from hydrogen embrittlement, regardless of temperature changes or waste composition.

\subsection{DEGRADATION MECHANISMS FOR CONCRETE AND REINFORCING STEEL}

The age-related degradation mechanisms which may affect concrete and the reinforcing steel in the tank structures are identified from a review and evaluation of their operating history, relevant laboratory test data, analytical assessment, and related experience of similar structures in other industries. The potential age-related degradation mechanisms are listed in Table 3.1 .

These degradation mechanisms are described below and generically evaluated with respect to their potential significance to the continued performance of the intended function of the concrete in the vaults. The degradation mechanisms are classified into non-significant and potentially significant. A degradation mechanism is classified as non-significant (significance " $C$ " in Table 3.1) if it can be shown that the concrete enclosure is either not susceptible to it or affected by it to such a small degree that the intended function, namely providing a structural barrier to the primary and secondary shells, will be maintained during the remaining service life of the tank. An age-related degradation mechanism is defined as potentially significant (significance " $A$ " 
in Table 3.1) when, if allowed to continue without mitigating measures, it cannot be shown that the concrete enclosure would continue to maintain its structural capability. Such degradations require mitigating measures to manage the degradation.

\subsubsection{Potentially Significant Aging Degradation Mechanisms}

This section contains a discussion of the potentially significant degradation mechanisms of the concrete and reinforcing steel. The non-significant mechanisms are discussed in section 3.3.2. To the extent that available information permits, this section also contains quantitative interpretations of these significant aging degradations.

\subsubsection{Elevated Temperature}

When conventional (non-refractory) concrete is exposed to sufficiently elevated temperatures, it begins to experience reactions involving loss of adsorbed and combined moisture present in the cement paste, possible thermal incompatibilities between paste and aggregate, and eventual deterioration of some possible constituents of the aggregate due to phase changes if the temperature becomes high enough and suitable aggregates were not used. Typically, such degradation is accompanied by a decrease in the compressive strength and in the stiffness (modulus of elasticity) of the concrete. Generally speaking, the threshold of degradation in the concrete is at a temperature range of $66^{\circ} \mathrm{C}$ to $95^{\circ} \mathrm{C}\left(150^{\circ} \mathrm{F}\right.$ to $\left.200^{\circ} \mathrm{F}\right)$. Because the high-level wastes in many storage tanks are reported to have reached a temperature range of $150^{\circ} \mathrm{C}-180^{\circ} \mathrm{C}\left(302^{\circ} \mathrm{F}-356^{\circ} \mathrm{F}\right)$, and in few tanks the temperature of the waste is suspected of having attained a higher range, e.g., $200^{\circ} \mathrm{C}-$ $315^{\circ} \mathrm{C}\left(392^{\circ} \mathrm{F}-600^{\circ} \mathrm{F}\right)$, the exposure to elevated temperature could be a significant age-related degradation mechanism for the concrete enclosure of the storage tanks. It is possible that creep of concrete at an elevated temperature, under a sustained load, could have an adverse effect on the concrete structure over a period of time. A detailed review of this significant aging degradation is provided in a BNL report [3.17].

The compressive strength of concrete is expected to be reduced when the concrete is exposed to a high temperature. A compilation of experimental data obtained from a literature search is shown in Figure 3.2 [3.17]. The residual strength is expressed as percentage $(\%)$ of the 28 -day strength. The upper and lower bound strength curves represent the full spread of the data base. The variations of the mean and $84 \%$ compressive stengths (based on standard log-normal distribution of the data) with rise in temperature are also shown. It is clear that the upper bound of the test data indicates almost no reduction in the concrete strength for elevated temperatures through almost $315^{\circ} \mathrm{C}\left(600^{\circ} \mathrm{F}\right)$. The lower bound data, however, indicate a reduced strength for temperatures above $38^{\circ} \mathrm{C}\left(100^{\circ} \mathrm{F}\right)$. For example, for specimens tested 


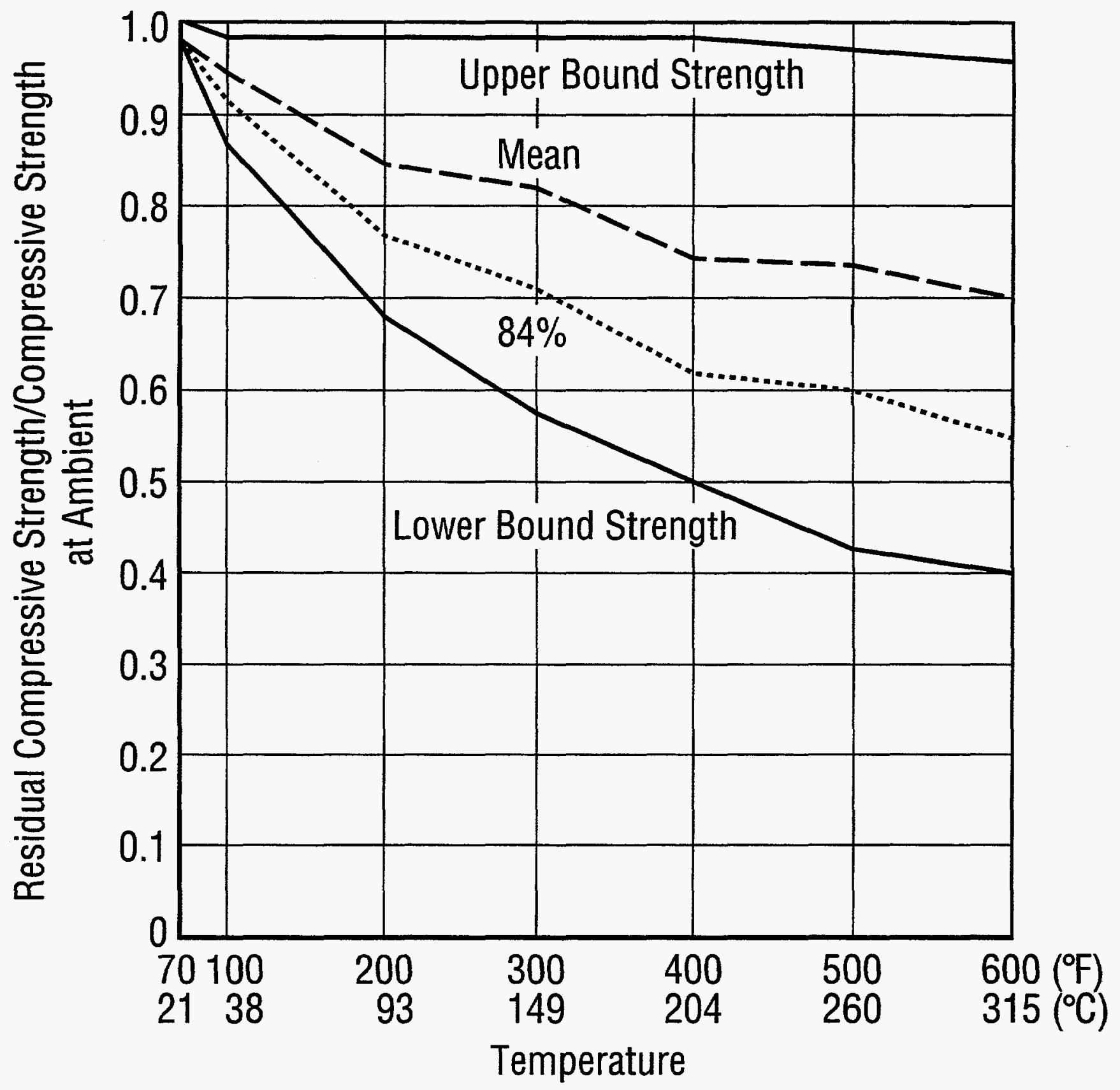

Figure 3.2 Reduction of Compressive strength of Concrete at Elevated Temperatures 
at $149^{\circ} \mathrm{C}\left(300^{\circ} \mathrm{F}\right)$, the lower bound reduced strength is $60 \%$ of the initial compressive strength at room temperature while the mean reduced strength is about $85 \%$ of its original value.

The modulus of elasticity, or stiffness, of concrete is a measure of its ability to withstand deformation. Figure 3.3 shows experimental data available in the literature indicating reduction in the modulus of elasticity (expressed as $\%$ of the initial room temperature value, $\left.E_{c}\right)$ with increase in temperature [3.17]. At $100^{\circ} \mathrm{F}\left(38^{\circ} \mathrm{C}\right)$, the upper-bound envelope indicates no reduction in the modulus while the lower-bound curve reveals a reduction of about $20 \%$. At $300^{\circ} \mathrm{F}\left(149^{\circ} \mathrm{C}\right)$, the upper-bound curve indicates a modulus of $0.9 E_{c}$ while the lower-bound curve shows a modulus of $0.45 \mathrm{E}_{c}$. This indicates that in the temperature range of concern for the waste storage tanks, the reduction in the stiffness of concrete is more pronounced than that of the compressive strength. As shown in Figure 3.3, the reduction in modulus of elasticity at temperatures higher than $300^{\circ} \mathrm{F}\left(149^{\circ} \mathrm{C}\right)$ is significantly greater.

The above information on reduction of the compressive strength and modulus of elasticity is generic since it was extracted from a study of a vast data base that includes experimental results of concrete specimens from a wide variety of sources. There are some tests performed on aged concrete for tank farms. For example, in 1981, 3-in. diameter concrete core specimens were drilled from the haunch and wall of an empty single-shell tank (SST) [3.18]. The tank was built in 1953 and was known to have leaked in 1965. It is also known that it held about 700,000 gallons of waste for about 8 years at temperatures which reached the range of $260^{\circ}$ to $280^{\circ} \mathrm{F}\left(127^{\circ}\right.$ to $138^{\circ} \mathrm{C}$ ). The specimens, which included samples extracted from different elevations of the wall excluding the lower portion near the foundation, were tested in the laboratory to determine the influence of elevated temperatures and aging on the strength properties of the concrete. The compressive strengths of all the specimens were found to exceed the 3000-psi design strength [3.18]. However, since the real initial strength data were not known, the results could not be used to determine whether there was any strength reduction.

If the bulk operating temperature of the concrete vaults external to the steel tanks is maintained below the degradation level of, say, $150^{\circ} \mathrm{F}\left(66^{\circ} \mathrm{C}\right)$, exposure of the concrete to elevated temperature is not a significant age-related degradation mechanism. The design codes allow a temperature rise up to $150^{\circ} \mathrm{F}\left(66^{\circ} \mathrm{C}\right)$ without any punitive effect on concrete [3.19]. For those tanks suspected of achieving higher temperatures any time during the service life, the aging degradation due to elevated temperature could be a significant issue and requires further evaluation. The degradation in strength and modulus of elasticity are not recoverable when the temperature returns to lower operating temperatures. Additional information may be found in the referenced BNL report [3.17]. 
Residual Elasticity/Elasticity at Ambient

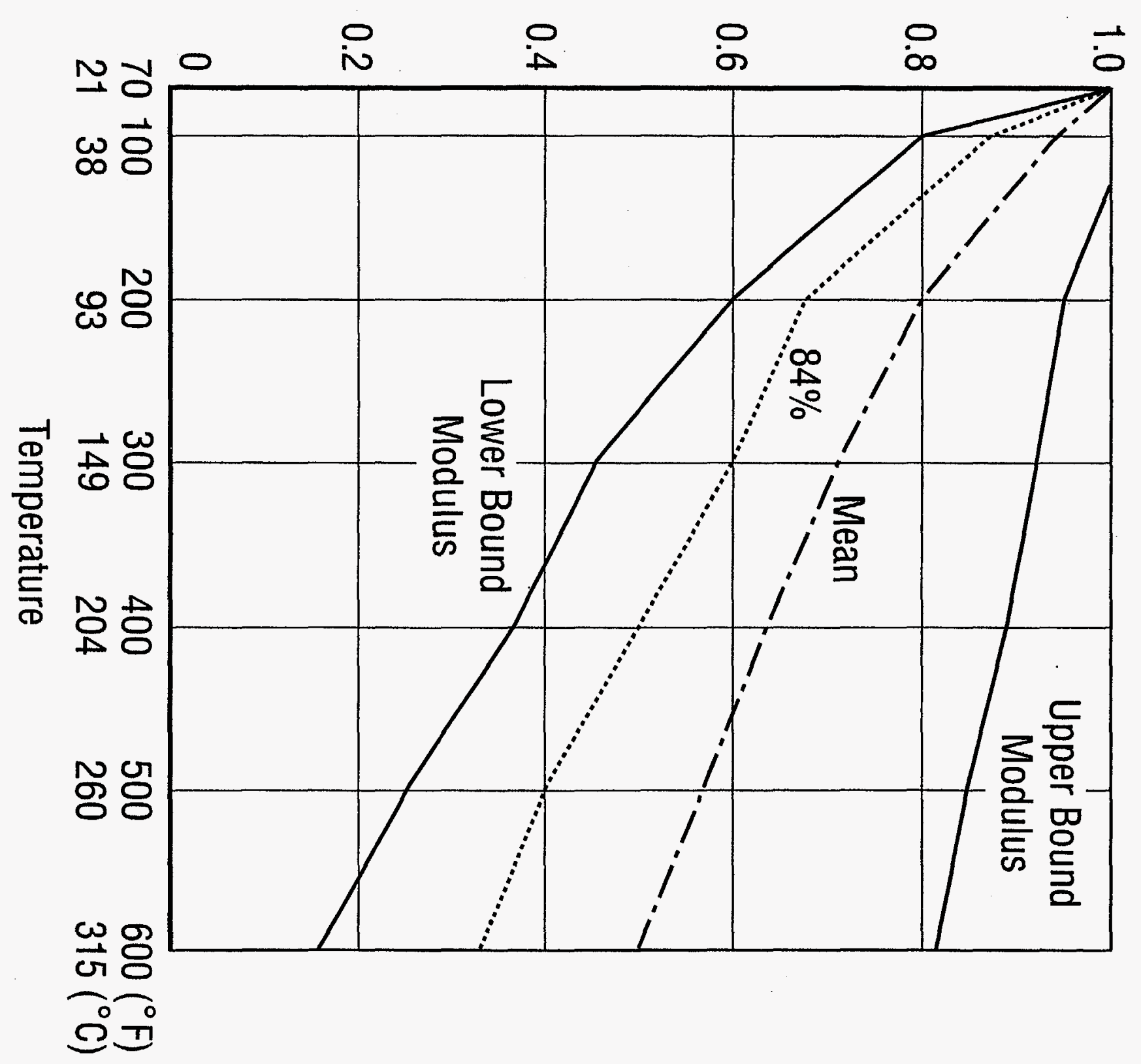


In underground concrete vaults, a thermal gradient is expected to exist between internal and external faces of the wall or basemat so that the entire wall may not be subjected to the same amount of thermal damage. Such site-specific conditions may need to be considered for realistic estimates of concrete degradation.

A temperature rise in the concrete also influences the strength properties of the embedded reinforcing steel. Up to a temperature rise of about $371^{\circ} \mathrm{C}\left(700^{\circ} \mathrm{F}\right)$, experiments have shown that hot-rolled reinforcing steels exhibit a linear decrease in yield strength of about $15 \%$. More pronounced reductions are observed at higher temperatures. In addition, as concrete and reinforcing steel have different coefficients of thermal expansions, the local bond strength may be influenced by a rise in temperature. Limited data under laboratory-controlled conditions have indicated that the loss in bond strength between the concrete and reinforcing steels in the temperature range of interest is in the range of $0-15 \%$ [3.17].

\subsubsection{Freezing and Thawing}

Waste tanks exposed to extreme cold and situated in sites with high water table (above the depth of frost penetration) are potentially vulnerable to damage due to freezing and thawing, which could lead to eventual degradation of the concrete. This is because water freezing within the capillary pores of concrete creates hydraulic pressure which either increases the size of the cavities due to ice formation or forces some of the water into small voids in the surrounding areas created by entrained air bubbles. The physical manifestations of such damage include cracking, scaling, and spalling. In extreme cases, the degradation could expose the reinforcing steel to accelerated corrosion, and the resulting expansion from the corrosion products deteriorates the concrete further and could reduce its strength and loosen the bond between concrete and the embedded steel. The primary parameters which affect the occurrence of such degradation in the concrete vaults of the tanks include the air content of the concrete and the number, size and distribution of the pores within the aggregate of the concrete [3.20]. The air content of the mixture needed to prevent such damage should meet the minimum requirement of Building Code ACI 318 [3.21].

The following factors increase the resistance of concrete to degradation due to freezing and thawing:

(a) Adequate entrained air-void system in the cement paste (4\% to $7 \%$ ).

(b) Frost-resistant aggregate.

(c) Low water/cement ratio and adequate placing and curing.

Degradation due to freezing and thawing may be a significant issue for storage tanks under certain adverse conditions. For 
tanks where the concrete will not freeze repeatedly, the risk is not significant. This potential is almost nonexistent for underground tanks once earth backfill is put in place.

The environment is measured in terms of "Weathering Index" which is defined as the product of the average number of freezing cycles times the average annual winter rainfall. ASTM C 33, "Standard Specification for Concrete Aggregates," [3.22], groups the U.S. into "severe," "moderate" and "negligible" weathering regions. Freezing and thawing damage potential is "severe" when the index exceeds 500 day-inches (1270 day-centimeter), it is "moderate" between 100 and 500 day-inches $(254$ and 1270 daycentimeter), and it is "negligible" when it is less than 100 dayinches (254 day-centimeter). If the concrete mixture of the vault of the waste tank meets the air content and water-cement ratio requirements of ACI 318 [3.19] then freeze-thaw damage is not a significant degradation mechanism for the "negligible" and "moderate" regions. For exposed concrete surfaces of waste tanks situated in "severe" weather regions, the degradation of affected surfaces of concrete could be significant and requires inspection and evaluation. However, such conditions may not exist for any of the high-level waste tank farms since they are underground structures.

\subsubsection{Leaching of Calcium Hydroxide}

Water flowing through cracks or inadequately prepared construction joints in the concrete vaults of the tanks can dissolve some calcium-containing products in concrete. The most readily soluble material is calcium hydroxide (hydrated lime). When calcium hydroxide has been leached away, other cementitious constituents become exposed to chemical decomposition, which eventually could leave behind silica and alumina gels with little or no strength [3.23]. Leaching over long periods increases the porosity and permeability of concrete, making it more susceptible to other forms of aggressive attacks and eventually reducing its strength and stiffness. Generally speaking, leaching also lowers the $\mathrm{pH}$ of concrete and can permit corrosion of the reinforcing steel.

Concrete vaults that are exposed to ground water may be susceptible to leaching of calcium hydroxide. In order to cause leaching, the water must be flowing, not just filling a crack or a void. For tanks situated in such an environment, this aging degradation mechanism is plausible and needs to be considered; otherwise it does not apply to the tank structures. Moreover, dense and well-cured concrete usually develops low permeability, minimizing the possibility of degradation caused by leaching of the calcium hydroxide.

Manifestation of damage by calcium hydroxide leaching is the appearance of white deposits (leachates) on the surface of the 
concrete. Leaching of this material from the concrete increases the permeability of the concrete and could lower its $\mathrm{pH}$, and thereby makes it more susceptible to attack by other damaging mechanisms, for example, freezing and thawing and corrosion of the reinforcing steel. Quantifying the degradation is difficult. Inspection of the suspected surfaces should reveal the degree and extent of any degradation. In a recent laboratory work, which was set-up to simulate a breached hazardous waste line embedded in concrete, nitric acid with 4-molar concentration was allowed to leak and react with the concrete in regions containing reinforcing steel and construction joint [3.24]. The leaching rates of calcium from the concrete were measured, initially at 1.1 to $1.6 \mathrm{~g} /$ day, and decaying to 0.15 to $0.5 \mathrm{~g} /$ day after 110 days. These rates are equivalent to 0.4 to $0.7 \%$ in volume of the test cylinder after 110 days of continuous contact with $4 \mathrm{M} \quad \mathrm{HNO}_{3}$. The concrete used to fabricate the test cylinders had a siliceous-calcareous aggregate, water/cement ratio of 0.5 , air content of $1.5 \%$ and density of 2.2 $\mathrm{g} / \mathrm{cm}^{3}$ (137 pound mass $/ \mathrm{ft}^{3}$ ).

\subsubsection{Aggressive Chemical Attack}

Because of the high alkalinity of concrete ( $\mathrm{pH}>12.5$ ), it is degraded by strong acids whenever the concrete is exposed to such solutions $[3.23,3.24,3.25]$. Sulfates in the soil and ground water are potential sources of chemical attack on concrete. Chemical attack usually increases the porosity and permeability of concrete, reduces the alkaline nature of concrete and subjects it to further deterioration which can result in reduced compressive strength and stiffness. Sulfates typically attack concrete by reaction with the aluminate phase in the cement to produce internal expansion and cause degradation if the concrete was not made using sulfate-resisting cement. Sulfate attack is usually accompanied by expansive stress within the concrete which can lead to spalling, cracking, and strength loss. Chlorides lower the $\mathrm{pH}$ of concrete and can cause corrosion of the reinforcing steel (see section $3.3 .1 .5)$.

For the concrete vaults of the tanks, chemical attack is possible if the concrete comes into contact with the waste and with vapor of aggressive compositions, e.g., in the under-surface of the exposed domes of the single-shell tanks. Thus, for the dome regions in all single-shell tanks and also in the vaults of the single-shell tanks, which are known to have leaked, this mechanism could be significant.

The result of this degradation mechanism is an erosion of the cement in the concrete which results in a reduction in its compressive strength and an increase in its porosity. Its only outward manifestation is the appearance of a "pock marked" surface, which may ultimately lead to spalling. Quantifying the degradation is difficult; however, inspection should reveal the extent of the degradation. 
For concrete below grade, the critical zone occurs along the exterior surface where the ground water table fluctuates. The environment in contact with the concrete surface must have a $\mathrm{pH}$ level of less than 5.5 for this attack to occur. The minimum chloride concentration for potential corrosion of the reinforcing steel is approximately $500 \mathrm{ppm}$. A concentration of 1500 ppm sulfate (water-soluble $\mathrm{SO}_{4}$ ) is the minimum degradation threshold limit when Type II cement is used while a concentration of over 150 ppm may cause degradation when Type I cement is used in the concrete.

\subsubsection{Corrosion of Reinforcing Steel}

Concrete is a highly alkaline material ( $\mathrm{pH}>12.5$ ) which provides an ideal environment to protect the embedded reinforcing steel rods from corrosion. However, when the $\mathrm{pH}$ of the environment in contact with the steel is reduced below the threshold level of 11.5, then corrosion of the embedded steel can occur [3.26]. In the high-level waste storage tanks, concrete surfaces which are continuously exposed to aggressive environments are susceptible to embedded steel corrosion. This is because the corrosive agents could have access to the steel through cracks in the concrete. A reduction in the $\mathrm{pH}$ requires an ongoing intrusion of aggressive ions (most notably, chlorides in the presence of oxygen) and could be caused by entry of acidic materials from the waste (i.e., in single-shell tanks with breached liners) or from aggressive environments surrounding tanks situated in a zone of fluctuating ground water. The chloride ions cause a breakdown of the normal passive condition of the steel in the pore solution of portland cement and cause the corrosion. Calcium chloride accelerates the corrosion more than sodium chloride. Leaching of the alkaline products in the concrete through cracks or carbonation can also result in lower $\mathrm{pH}$ in concrete. In addition to the corrosive agents, the severity of corrosion is influenced by the quality of concrete (cement type, properties of aggregates, and moisture content), depth of concrete cover over steel, and the permeability of concrete. Generally speaking, concrete with low permeability contains less water and hence is more likely to have low electrical conductivity and better resistance to corrosion. Such concrete also provides a barrier to oxygen which is an essential element of the corrosion process.

Solid corrosion products of steel have a volume greater than that of the original metal. When corrosion occurs, this factor will subject the concrete to stress, eventually causing hairline cracking, followed by rust staining, spalling, and more severe cracking. Such development may expose more of the reinforcing steel to the corrosive environment and the concrete to further degradation. The degradation in concrete is usually manifested by a reduction in its strength, stiffness, and other physical properties, and a loss of bond between concrete and embedded steel. $A$ reduction in the cross sectional area of the steel can occur 
which ultimately could impair the structural integrity of the concrete enclosure of the tanks. For single-shell tanks and all tanks situated below the ground water table, corrosion of embedded steel could be a significant age-related degradation mechanism. For other tanks such age-related degradation is not significant.

Corrosion of the reinforcing steel in concrete is an electrochemical reaction between the reinforcing steel and its surrounding environment. It occurs whenever the oxide film, formed during cement hydration and maintained by the alkalinity of the concrete, is broken by the intrusion of aggressive ions (mainly chlorides) from the environment. Laboratory simulation indicates that the threshold for $\mathrm{Cl}^{-} / \mathrm{OH}^{-}$in the concrete pores necessary to cause corrosion is approximately 0.3 [3.7]. This is equivalent to a pore water chloride level of about 9,000 ppm. In bridge deck concrete structures, corrosion is thought to occur when the chloride ion concentration reaches 0.35 to $1.0 \%$ by mass based on cement content of the concrete. Results of subjecting reinforced concrete test cylinders to direct contact with nitric acid of 4molar concentration have been reported [3.19]. Acid penetration rates of 0 and $9.84 \times 10^{-4} \mathrm{~mm} /$ day $(0.025 \mathrm{in}$./day) were determined. The combined dissolution of the reinforcing steel and concrete created a cavity in the test cylinder which increased at a rate between 0 and $0.2 \mathrm{~cm}^{3} /$ day $(0$ and $0.0127 \mathrm{in.} /$ day). This amounts to approximately 0.29 of the length of the reinforcing steel degraded after 110 days of direct contact with the acid.

The quality of concrete and its permeability play a major role in its resistance to intrusion of chloride ions and the resulting corrosion. If the concrete has a water-to-cement ratio of 0.35 to 0.45 and 3 to $6 \%$ air content, it will have low permeability and provide good resistance to corrosion of the reinforcing steel. During the sampling operation of the in-situ concrete core mentioned in section 3.3.1.1, a 10-in. slice of vertical reinforcing steel (\#4) was removed from the wall of the tank. The bar showed no sign of degradation.

\subsubsection{Potentially Non-Significant Aging Mechanisms for Concrete}

This section contains a discussion of the aging mechanisms the effects of which are non-significant for the concrete of the underground $H L W$ storage tanks subject to the stated design conditions. A poor design or construction process, on the other hand, may lead to manifestation of any of these mechanisms during the service life. Such design and construction-related deficiencies are not addressed in the following assessment, and if existent, are expected to be identified and treated accordingly in the site-specific structural integrity programs. 


\subsubsection{Reaction of Aggregates with Alkalies}

Certain concrete aggregates can react chemically with alkalies introduced in the cement or from the environment [3.27]. Two types of reactions have been identified. They are alkali-silica reaction, and alkali-carbonate reaction. Moisture must be available for the chemical reactions to occur. Thus, concrete that is either consistently wet or that experiences wet and dry periods is susceptible to such deterioration in the presence of potentially reactive aggregates. The chemical reactions can cause expansion and cracking of the concrete. The cracking is irregular map cracking. Most reactive aggregates have been identified and, when they are used, appropriate precautions can be taken: low-alkali cement is required and additional protection can be obtained from the use of ground slag or pozzolan, such as fly ash or silica fume.

Since the storage tanks are buried in the ground, the cracking due to reaction with aggregates should not be a significant agerelated degradation mechanism unless the operating history indicates otherwise.

\subsubsection{Creep and Shrinkage}

Creep is defined as an increase in inelastic strain with time under a sustained stress. The stress results from dead load; live load, and the effects of elevated temperature on the concrete enclosure of the waste storage tanks. The influence of elevated temperature on creep is discussed in [3.17]. Creep strain which varies exponentially with time can cause cracking at the aggregate cement-paste interface. Except for the creep strain induced by elevated temperatures as mentioned in section 3.3.1.1, creepinduced concrete cracks are usually small and do not result in concrete deterioration, nor do they reduce the compressive strength by significant amounts. Guidance for predicting creep in structures is available in ACI 209 [3.28].

Shrinkage of concrete occurs as a result of water leaving the concrete. As water leaves the concrete, tensile stresses remain in the concrete. When the strains produced by these stresses exceed the tensile strain capacity of concrete, a shrinkage crack is formed. Excessive shrinkage may cause cracking of concrete surfaces. Most of the shrinkage (98\%) typically occurs during the first few (e.g., five) years of service. The significance of a shrinkage crack as a potential contributor to degradation depends primarily on its size and environmental exposure conditions. A crack can provide aggressive agents access to the reinforcing steel, promoting the possibility of corrosion.

If the concrete is designed and constructed according to standard codes, the shrinkage degradation should not be significant. 


\subsubsection{Abrasion and Cavitation}

Abrasion and cavitation are age-related degradation mechanisms for concrete exterior surfaces of the waste storage tanks that are continuously exposed to flowing water moving at high velocity or carrying suspended solids. As the water moves over concrete surfaces, it has the ability to transport materials which can abrade the concrete, or it can create negative pressure at the water/air-to-concrete interface that can result in removal of concrete materials as the vacuum collapses (cavitation). Cavitation can occur at velocities as low as $25 \mathrm{ft} / \mathrm{sec}$ at abrupt changes in slope or curvature [3.29]. If significant amounts of concrete are removed by this mechanism, the degradation is readily detected in accessible locations by visual examination as pitting or aggregate exposure due to loss of cement paste. This is very unlikely to be significant to these tanks.

\section{3 .2 .4 Irradiation}

The degradation of concrete exposed to neutron and/or gamma radiation is manifested in many ways. Fast and slow neutrons usually cause aggregate growth, decomposition of water, and warming of concrete. Gamma radiation affects the cement paste portion of the concrete, producing heat and causing water migration. The degradation due to nuclear heating and water loss is more serious than degradation associated with direct radiation damage [3.30]. This is because nuclear heating causes the free water within the concrete to evaporate, and both the neutron shielding and structural characteristics of the concrete become impaired. As a consequence, the concrete could experience a decrease in its strength (compressive, tensile, and bonding strengths), and in its stiffness (modulus of elasticity), due to the development of drying shrinkage cracking if the thermal gradient is excessive.

According to the American National Standard ANSI/ANS-6.4-1985 [3.31], nuclear heating can be neglected if the incident energy fluxes are less than $10^{10} \mathrm{MeV} / \mathrm{cm}^{2}-\mathrm{sec}$. Existing information [3.30] indicates that the strength properties of concrete (compressive strength and modules of elasticity) are degraded if the concrete is exposed to greater than $10^{19} \mathrm{n} / \mathrm{cm}^{2}$ or to an integrated dose of gamma radiation exceeding $10^{10}$ rads. In the high-level waste storage tanks the energy flux is negligible and irradiation is a nonsignificant aging degradation mechanism.

\subsubsection{Degradation of Refractory Concrete}

Refractory concrete consists of graded, refractory aggregates bound by a suitable cementing medium. It is suitable for use at 
elevated temperatures up to about $1800^{\circ} \mathrm{C}\left(3272^{\circ} \mathrm{F}\right)$ when calciumaluminate cement is used with fused-alumina aggregate [3.32]. The cementing agent commonly used is high-alumina cement which is a hydraulic cement unlike portland cement [3.33]. However, when portland cement is used as the binder, refractory concrete loses some of its strength and performs poorly when thermally cycled to temperatures above $430^{\circ} \mathrm{C}\left(806^{\circ} \mathrm{F}\right)$ especially in the presence of moisture. In the double-shell tanks, refractory concrete is used as a basemat to the primary shell. The basemat, typically $30 \mathrm{~cm}$ to $45 \mathrm{~cm}$ (12 in. to $18 \mathrm{in.)}$ thick, is placed directly beneath the primary shell and its bottom is in contact with the secondary shell. The secondary shell is supported by the foundation of the tank which is constructed of conventional reinforced concrete. The purpose of refractory concrete is to provide appropriate resistance to the effects of elevated temperatures produced during stress relief of the tanks.

The properties of refractory concrete depend on both time and temperature. The possible age-related degradation mechanisms are discussed in the following sections:

\subsubsection{Elevated Temperature}

Initial heating of refractory concrete causes physical and chemical changes mainly due to removal of water. The compressive strength is reduced after exposure to about $540^{\circ} \mathrm{C}$ (I004 $4^{\circ} \mathrm{F}$ ) but further increase in the temperature does not influence the strength [3.27]. The effect of elevated temperature on the modulus of elasticity is relatively insignificant. Exposure to hot moist environment greatly reduces the compressive strength unless a rich dense mixture has been used [3.34].

\section{3 .3 .2 Effects of Chemicals}

Refractory concrete can be corroded by acid condensates on the cold face of the steel liner if the cold face temperature is below the dew point [3.35]. Concrete made using high-alumina cement can suffer major losses in strength when exposed to moisture at relatively low temperatures due to conversion of the unstable lowdensity to the stable high-density calcium-aluminate hydrate. Formation of high density alkali-alumina silicates can cause disintegration of the refractory concrete [3.33].

\section{REFERENCES}

3.1 Mahidhara, R.K., et al., "Corrosion and Failure Processes in Low Carbon steels," North Carolina State University report for LANL, November 20, 1992.

3.2 ASM Metals Handbook, Volume 13, "CORROSION," 9th Edition. 
3.3 Mahidhara, R.K., et al., "Corrosion and Failure Processes in High-Level Waste Tanks," North Carolina state University Report for LANL, November 20, 1992.

3.4 Dacres, C.M., "Corrosion Evaluation and Protection Programs of External Surfaces for High-Level Waste (HLW) Underground Storage Tanks and Piping at the Hanford and Savannah River Sites," DACCO SCI InC. Report for DOE $3 / 93$.

3.5 Lini, D.C., "Compilation of Hanford Corrosion Studies," ARCO Report ARH-ST-111, July 1975.

3.6 Oblath, S.B., "Recommended Method to Control Pitting Corrosion for Washed Precipitate Storage Tanks," DPST-86-741, 1986.

3.7 Hsu, T.C., et al., "Savannah River Site Waste Tank Corrosion Program (U)," WSRC-TR-93-373, Draft, September 1993.

3.8 Leach, C.E., and Stahl, S.M., "Hanford Site Tank Farm Facilities Interim Safety Basis," WHC-SD-WM-ISB-I, Sec. 5.7, "Proposed Corrosion Assessment at Hanford Site Waste storage Tanks in Support of ISB Report," Table 1, p. 5.7-16, (1993).

3.9 Carlos, W.C., "Multi-Function Waste Tank Facility Corrosion Test Report," WHC-SD-W236A-TRP-001, Westinghouse Hanford Company, Richland, Washington, December 1993.

3.10 Girdler, R.M., "Leaks in Radioactive Waste Tanks," DP-990, December 1965 .

3.11 Ondrejcin, R.S., et al., "Control of Stress-Corrosion Cracking in Storage Tanks Containing Radioactive Waste," Nuclear Technology, 44, July 1979.

3.12 Streicher, M.A., "Effect of Heat Treatment, Composition and Microstructure on Corrosion of $18 \mathrm{Cr}-8 \mathrm{Ni}-\mathrm{Ti}$ Stainless steels in Acids," Corrosion 20, 57t, 1964.

3.13 Baird, J.D., Metal. Rev. 16:1, 1971.

3.14 EPRI-NP-3614, "Repair Welding of Heavy-Section steel Components in LWR's," The Babcock and Wilcox Company, 1984.

3.15 Caskey, Jr., G.R., "Potential Radiation Damage of storage Tanks for Liquid Radioactive Waste (U)," WSRC-TR-92-350 $8 / 21 / 92$.

3.16 American Petroleum Institute Report "Steels for Hydrogen Service at Elevated Temperatures and Pressures, "API-941, 2nd Edition, 1977. 
3.17 Kassir, M.K., K.K. Bandyopadhyay, and M. Reich, "Thermal Degradation of Concrete in the Temperature Range from Ambient to $315^{\circ} \mathrm{C}\left(600^{\circ} \mathrm{F}\right), "$ BNL Report, No. 52384, Revised October 1996.

3.18 Defigh-Price, D., "Strength and Elastic Properties of Concrete Exposed to Long-Term Moderate Temperatures and High Radiation Field," American Concrete Institute Fall Convention, 1984. Rockwell International Report \#RHO-RE-SA-55R.

3.19 "Building Code Requirements for Reinforced Concrete," ACI Standard 318, ACI Committee 318, American Concrete Institute, Detroit, Michigan, 1963 and later editions.

3.20 Mather, B., "How to Make Concrete That will be Immune to the Effects of Freezing and Thawing," in Paul Klieger symposium on Performance of Concrete, David Whiting, Editor, American Concrete Institute, SP-122, pp. 1-18, Detroit, Michigan, 1990.

3.21 "Building Code Requirements for Reinforced Concrete, "American Concrete Institute, ACI 318, (Revised 1992), ACI Manual of Concrete Practices, Part III, Detroit, Michigan, 1994.

3.22 "Standard Specification for Concrete Aggregates," American Society for Testing and Materials, ASTM C 33, Philadelphia, $P A$, Annual.

3.23 Troxell, G.E., H.E. Davis, and J.W. Kelly, Composition and Properties of Concrete, second Edition, McGraw-Hill, 1968.

3.24 Mehta, P.K., Concrete-Structure, Properties and Materials, Prentice-Hall, Inc., Englewood Clifts, New Jersey, 1986.

3.24 Brewer, K.N., "Effects of Rebar and Concrete construction Joints on the Migration of $4 \mathrm{M} \mathrm{HNO}_{3}$ in concrete Test Cylinders," Idaho National Engineering Laboratory, WINCO-1125, June 1993.

3.25 Mindess S. and Young, J.F., CONCRETE, Prentice Hall, Inc. Englewood, New Jersey, 1981.

3.26 "Corrosion of Metals in Concrete," American Concrete Institute, ACI 222R-89. American Concrete Institute Manual of Concrete Practice, Part 1, Detroit, Michigan, 1993.

3.27 "Guide to Durable Concrete," American Concrete Institute Committee 201, Chapter 5, Report 201.2R-92, American Concrete Institute Manual of Concrete Practice, Part 1, Detroit, Michigan, 1993.

3.28 "Prediction of Creep, Shrinkage, and Temperature Effects in Concrete Structures," American Concrete Institute, ACI 209 R- 
92, American Concrete Institute Manual of Concrete Practice, Part 1, Detroit, Michigan, 1993.

3.29 "Erosion of Concrete in Hydraulic Structures," American Concrete Institute, ACI 210R-87, American Concrete Institute Manual of Concrete Practice, Part 1, Detroit, Michigan, 1993.

3.29 Uhlig, Herbert H., "Corrosion and Corrosion Control," 2nd Edition, John Wiley \& Sons, Inc., 1971.

3.30 Hilsdorf, H.K., Kroop, J., and Koch, H.J., "The Effects of Nuclear Radiation on the Mechanical Properties of Concrete," Douglas McHenry International symposium on Concrete and Concrete Structures, American Concrete Publication SP 55-10, pp 223-251, 1978 .

3.31 American Nuclear Society, "Guidelines on the Nuclear Analysis and Design of Concrete Radiation Shielding for Nuclear Power Plants," American National Standards, ANSI/ANS-6.4-1985, LaGrange Park, Illinois, 1985.

3.32 Refractory Concrete, ACI Committee 547, ACI Report 547 R-79, American Concrete Institute, Detroit, Michigan, May 1979.

3.33 Robson, T.D., High-Alumina Cements and Concrete, John Wiley and Sons, New York, 1962.

3.34 Naus, D.J., "A Review of the Effects of Elevated Temperature on Concrete Materials and Components with Particular Reference to the Modular High Temperature Gas-Cooled Reactor (MHTGR)," ORNL/NRC/LTR-88/2, LTR Report CTP-8801, Concrete Technology Program. Oak Ridge National Laboratory, Oak Ridge, Tennessee, March 1988.

3.35 Gitzen, W.H., et al., "Carbon Monoxide Disintegration of Calcium Aluminate Cements in Refractory Castables, "Amer. Cer. Soc. Bull. $43(7), 1964$. 


\section{1 INTRODUCTION}

Methods for monitoring for and controlling the degradation mechanisms identified in Chapter 3 are reviewed in this chapter. These include leak detection systems, chemical controls for minimizing the impact of the potentially-significant corrosion processes, corrosion monitoring technology, and sampling and testing concrete components for aging-related changes in properties. Inservice inspection techniques for determining the current status of the structural components of the tanks are reviewed in Chapter 5 .

\subsection{LEAK DETECTION}

The age-related degradation processes outlined above may lead, in time, to leakage of the waste solutions through the steel components of the tanks and then through the concrete into the environment. Since inspections cannot possibly cover all areas of the tanks, the first warning of age-related degradation may, in many instances, be the development of a leak. A reliable, safe, and accurate leak detection system must, therefore, be an integral part of any structural integrity program. As noted in Chapters 3 and 6 , the inherent toughness of the steels used in these tanks ensures that structurally unstable flaws need to be large, of the order of several feet or more in length; therefore, a reliable leak detection system will provide an ample, early warning that degradation processes are occurring and minimize the probability of structural failure.

The term "leak tightness" as used in this document means that leakage rates are lower than the detection limit (or the acceptable limit specified by the regulators). It is, therefore, imperative that the leak detection systems be as sensitive as possible.

\subsubsection{Types of Leak Detection Systems}

The types of leak detection systems that are applicable inherently differ for single-shell tanks, double-shell tanks, and waste transfer lines. In all cases, however, they include elements of the following general types of measurements: Iiquid level (or waste level) measurements in the tanks, and visual examinations, radioactivity monitoring, and moisture detection external to the primary tank or in the environment external to the concrete vault.

\subsubsection{Liquid Level Instrumentation}

In waste tanks, the simplest liquid level monitors are probes lowered through risers in the tank roof that indicate the Iiquid 
level by the completion of an open electrical circuit by the presence of the (electrically-conducting) waste solutions. Due to the large diameters of the waste tanks and the long distance the probe must be lowered from the surface of the ground, these are inherently not accurate. For example, if the measurement is reliable to approximately \pm 1 inch, the potential error corresponds to \pm 2750 gallons of liquid wastes in a 75 -foot diameter tank. Further, the waste surface is often not level, due to the presence of solid salts at or near the liquid-vapor interface. Also, these probes could collect salt crystal buildup on their tips over a period of time and provide erroneous readings.

In some waste tanks, the presence of solid crusts at the waste-vapor interface prevents the reliable use of resistance probes. Also, these probes are ineffective in estimating the loss of drainable interstitial liquid in the sludge-pack areas. For these purposes, and for increased reliability where supernatant liquid is present, other devices, such as resonance-frequency (RP) probes and differential bubbler tubes are available and have been tested. The RF probe, which detects the presence of liquids with high electrical conductivity, is particularly sensitive to the presence of interstitial solutions. The differential bubbler approach reduces the problems cited above with the resistivity probe. All these devices are most effective when used in combination to reduce ambiguities in interpreting the signals.

Since the liquid level in a tank can drop from causes other than leaks, such as temperature drop, evaporation, or de-gassing, liquid level instrumentation by itself cannot identify small leaks of waste reliably, and is best used in conjunction with the external monitoring techniques described below.

\subsubsection{Visual Examinations}

In double-shell tanks, leaks into the annular space between the primary and secondary shells can be detected and sometimes located by periodic remote visual inspections. In many cases, leaks can be identified by the buildup of salt crystals on the outer surface of the primary tank at the location of the leak, or by the presence of liquids and/or salt crystals on the bottom of the annulus. This technique, while beneficial in identifying the sites of leaks and the presence of small leaks, does not necessarily provide early warning of leakage, since the inspections are only made periodically, e.g., annually, and do not cover 100\% of the outer surface of the primary tank. Portions of the tank vertical wall and the bottoms of the primary tank are frequently inaccessible for visual inspection.

\subsubsection{Radioactivity Monitoring}

In double-shell tanks, monitoring the air in the annular space between the tanks for airborne radioactivity offers the potential for early detection of small leaks. Such monitors can be operated continuously. In most such tanks, the air in the annular space is 
continuously circulated (to control humidity) and radioactivity monitors are placed in the effluent piping for maximum sensitivity. In single-shell tank farms, radioactivity monitors in an array of wells or channels in the ground external to the concrete vault and extending under it can offer an early warning of leakage of wastes into the environment.

\subsubsection{Moisture Detectors}

In double-shell tanks, continuous monitoring of the annular space for moisture can be achieved using conductivity monitors similar in principle to those used for liquid level monitoring. Many DST's have channels through the concrete support under the bottom of the primary tank which drain leaked liquids into the annulus, so that moisture detectors, along with radiation monitoring, offer the only early warning of leakage through the tank bottoms. There are possible sources of moisture to these annuli other than leakage of wastes from the primary tanks, such as condensation and groundwater in-leakage. Thus, the moisture detectors should be designed or used in conjunction with other monitors to distinguish waste solutions (i.e., by their electrical conductivity, radiation level, and/or $\mathrm{pH}$ ) from moisture from these other sources.

In single-shell tank farms, moisture detectors in an array of wells around and extending under the concrete vaults can offer, provided the wells are above the water table, an indication that leakage to the environment is occurring. Again, these detectors should be designed to distinguish leaking waste solutions from other sources of water.

\subsubsection{Leak Detection Program Criteria for Tanks}

In most tank farms, use of all of these leak detection techniques should be in effect, to provide redundancy and complement each other, since each approach, used alone, has its weaknesses or insensitivities. Tank farm sites should have in place a leak detection program containing these elements, or others that may be developed, in sufficient redundancy to ensure continuous monitoring. This program should also clearly specify actions to ensure continued operability of these systems, and actions to be taken should one or more sensors become inoperable, including limits on duration for any sensors being out of service. Finally, actions to be taken should the sensors indicate that a leak has developed, including response time must be part of the program.

Soil or sump pit sample analyses in the vicinity of and below the tanks should be made where possible to supplement the leak monitoring systems. In specific cases, use of all of the techniques discussed above may not be feasible. For instance, when the tanks rest on bedrock, soil and sump pit sampling would be ruled out, and it also may be difficult to locate radiation detectors below the tanks. The detailed leak detection plan for 
the site or tank farm should, therefore, justify the specific monitoring program chosen.

\subsubsection{Leak Detection in Transfer Piping Systems}

Transfer piping systems, which are discussed in Chapter 7 of these guidelines, likewise require a leak detection system to be operable at all time when these transfer systems contain wastes. The leak detection methods to be used, the surveillance to determine this operability, and actions to be taken following detection of leaks or malfunction of the monitoring system need to be specified in the safety documentation for the transfer facility. Typically, both moisture detectors and radiation monitors should be included, as well as pressure tests (coupled with leak detectors) which should be performed to ensure the integrity of a specific transfer line prior to its use.

\subsection{CHEMICAL MONITORING TO MINIMIZE DEGRADATION OF STEEL COMPONENTS OF TANKS}

In Chapter 3, ranges of concentration of hydroxide ions nitrite ions, and pH were given that have been shown in the laboratory to minimize the incidence of general corrosion, pitting, and stress corrosion cracking of both carbon and stainless steel tanks. In the time since these concentration limits were originally established, laboratory tests have shown, for some waste compositions, pitting or SCC could develop within the original limits. Further, capabilities for homogeneous mixing of wastes in a given tank do not exist at all facilities.

\subsubsection{Establishing Safe Operating Ranges}

A site-specific program needs to be implemented to establish the safe operating ranges of chemical parameters for the waste types and tank designs existing at each site, or group of tanks within a site. These safe operating ranges need to be based on the tank material (i.e., carbon or stainless steel), specific waste types at the site, or tank farm within a site, and the possibilities for stratification and concentration gradients existing or developing within a tank. They may be based on laboratory experiments, the results of corrosion monitors (see section 4.4 below) or on analogy with experience at other waste tank farms.

\subsubsection{Monitoring Tank Chemistry}

A site-specific program needs to be implemented to ensure that changes in those chemistry parameters that potentially affect tank integrity, such as hydroxide, pH, nitrite, nitrate, and chloride, are monitored, and corrective actions made to ensure that tank integrity is maintained. Emphasis solely on controlling additions to the tank does not provide information on changes in waste chemistries that can occur during storage. A formal sampling program needs to be developed for each site, with sampling 
intervals not to exceed three years for any given tank, unless examination of the results of three consecutive analyses shows no detrimental trends in these parameters; sampling intervals in this case could be increased to five years. As part of this program, potential remedial actions need to be specified in anticipation of possible trends.

\subsection{CORROSION MONITORING}

Because of uncertainties in the establishment of chemistry controls to minimize corrosion processes in a given tank, and of difficulties in obtaining representative samples of the waste solutions, a site-specific corrosion monitoring program should be established to provide assurance that integrity of the steel tanks will be maintained. Several types of monitoring programs have been proposed and discussed [4.1]; each has advantages and disadvantages over the others. The principal types include insertion of corrosion coupons, electrical resistance probes, Iinear polarization resistance probes, zero resistance ammetry, electrochemical impedance measurements, and electrochemical noise (both in potential and current). Determination of the specific forms of corrosion monitors to be used is the responsibility of the sites, based on their specific waste-material combinations and site needs.

\subsection{MANAGING DEGRADATION OF CONCRETE COMPONENTS OF WASTE TANKS}

If the history of exposure of concrete in a given tank suggests that one or more of the age-related degradation mechanisms could be operative, then a site-specific plan should be developed to verify whether significant degradation has occurred, and, if so, to formulate plans to avoid further degradation and possibly repair the degraded concrete.

\section{REFERENCE}

4.1 Hsu, T.C., et al., "Savannah River Site Waste Tank Corrosion Program (U)," WSRC-TR-93-373, Draft, September 1993. 
CHAPTER 5

NONDESTRUCTIVE EXAMINATION (NDE)

\subsection{INTRODUCTION AND SCOPE}

A non-destructive examination (NDE) plan is described in this Chapter. This NDE plan is directed to the detection of degradation of double-shell high level waste storage tanks. The interpretation of philosophy and bases used in this chapter are included in Appendix A. Definitions, abbreviations, and acronyms that are specifically used in the NDE plan are provided at the end of this chapter. Single-shell tanks, inaccessible from the outside, are exempt from the requirements of this chapter; requirements for such tanks will be covered under a separate set of criteria to be included in a future revision of this document, recognizing the substantial differences in accessibility for examination. Also outside the scope of this plan are piping, pumps, valves, and nozzles above the liquid level, as well as small (10-20,000 gallon) staging tanks, provided that they can be emptied quite rapidly in the event of a leak. In accordance with standard ASME practice, requirements in this chapter are denoted by shall and permissive items or "good practice" by should. Alternative approaches to the NDE Guidelines provided in this chapter may be proposed by one or more sites, for review and concurrence by DOE.

The NDE is intended primarily to detect degradation due to generic mechanisms that cause damage such as pitting, wall thinning, or cracking of steel materials. A secondary element is the detection of degradation in the concrete shells due to such mechanisms as elevated temperature damage, creep, acid attack, leaching, and so forth as discussed in chapters 3 and 4 . Greater details of materials and mechanisms are provided in chapters 2 through 4. Either nondestructive or destructive examination may be necessary to detect such damage. No claim is made that the program will detect random cases of failure where failure is defined as the development of a crack or a leak. The use of leak detectors is the most reliable technique for detection of such random leaks. The role of NDE, on the other hand, is to detect conditions such as potentially unstable cracks in the steel shells, or generic evidence of degradation (pitting, thinning, cracking) that might lead to leakage in the future. Leak detection is discussed in Chapter 4 and not repeated here.

The NDE plan described in this chapter selectively chooses segments of ASME Boiler \& Pressure Vessel Code Section XI, "Rules for Inservice Inspection of Nuclear Power Plant Components," [5.1] to formalize the NDE procedure. Section XI is the only definitive document in the United States covering nuclear inservice inspection (ISI); however, there is no intent to invoke section XI per se. Rather, the intent is to use applicable Articles relevant to high-

$$
5-1
$$


level waste storage tanks. For ultrasonic thickness measurements, Appendix I, Article 23 of the ASME Code, Section V, can be used in addition to section XI [5.1]. Emphasis is on the detection of incipient failure when the flaw sizes are much smaller than the large, potentially unstable flaws that might lead to a substantial release of high-level waste from the inner tank. For inservice inspection of the concrete, applicable segments of ACI 201.1R [5.2] and Subsection IWL of section XI are relied upon to develop the necessary procedures and tests.

The nondestructive examination programs for both old and new tanks, assuming any of the latter are fabricated, represent protection against relatively low probability events. New tanks should be optimized for access for NDE to essentially all of the primary tank wall, and weldments should be ground to improve UT detection and sizing. The emphasis with old double-shelled tanks with respect to postulated flaws should be in the following ranked order:

- Pitting in vapor, liquid and/or sludge regions. Leakage is the concern; pitting has occurred on Savannah River cooling coils in HLW tanks;

- Stress corrosion cracking (SCC), particularly in tanks that have not been stress relieved; inhibitors prevent SCC, providing the solution concentrations are controlled within permissible limits. SCC is considered less probable than pitting in stress-relieved tanks.

- Uniform corrosion is expected to be relatively limited, on the order of 0.5 mils per year; however, ultrasonics should be used to detect loss of wall thickness due to bulk or uniform corrosion. Extensive testing in simulated HLW has repeatedly confirmed the low rate of uniform corrosion.

\subsection{EXEMPTIONS}

Since the criteria incorporated into this chapter cover generic requirements, no specific exemptions based on accessibility, operating conditions, and the like are cited. It is recognized that several tanks or tank designs have limited accessibility because of limited head penetrations, lack of access due to cooling coils, or to other geometric considerations. In such instances the site should prepare the program and incorporate specific requests for exemption, or alternative approaches to achieve compliance. These requests for exemption should be resolved by appropriate DOE organizations at the local or headquarters levels. 


\subsection{INSPECTION REQUIREMENTS AND PROCEDURES}

The sub-sections that follow describe details of the ASME Code sections to be used in NDE. This includes the procedures to be used, the coverage and sampling of tanks and areas for inspection, as well as the qualification of personnel and equipment. Definitions of acronyms are included in section 5.5 .

\subsubsection{General Requirements of Sampling and Inspection}

A sampling will be conducted in accessible regions believed to have the potential for leakage; regions of concern are the liquidvapor interface with the probable failure mechanism being pitting, the knuckle region, and weldments where stress levels may be conducive to stress corrosion cracking, the bottom plate, or the vapor region where lower $\mathrm{pH}$ may lead to cracking or pitting. The NDE of the base plate should not be a requirement where access is very limited; however, if tanks are emptied, $\mathrm{NDE}$ visual examination (VT)plus ultrasonic examination (UT) from the inside is considered prudent because any attack observed may be pertinent to tanks with similar operating histories.

The secondary tank should have limited NDE, presumably at the lower knuckle welds, where liquid may have collected, to ensure that welds and base metal have not been attacked.

If new tanks are to be installed at any site, they should be optimized for accessibility on the external surface of the primary tank, including the bottom, and the internal surface of the secondary tank. Welds should be prepared for optimum UT examination, including weld preparation using section XI, Appendix D, "Conditioning of Class 1 and 2 piping welds which require examination", as a model. Any examination during construction should use UT rather than radiographic examination (RT), provided that ASME section III has approved this option; this UT construction examination should be acceptable as the preservice baseline. Another option is requesting an ASME code case to permit and provide acceptance standards for baseline UT examinations.

Selected provisions of section XI are recommended as a model; Section XI should not be applied as an overall requirement. Specific sections believed to be applicable are discussed in a following section. It is expected that the reader will have sufficient knowledge of section XI. The terminology used in this document is consistent with section XI unless otherwise defined.

With regard to sample size to be examined, and in recognition of the relatively limited regions of the tank believed susceptible to attack, a value of five percent for each class of examinations shall be used for each interval, where the interval corresponds to the requirements of IWA-2432, which specifies 10 years. In recognition of the unique conditions of high-level waste storage 
tanks, this interval should be divided into two roughly equal periods.

An NDE program modeled after section XI for applications to thin-walled tanks is summarized in Table 5.1. It is modeled after the tables in IWC-2500.

Pertinent Articles of Section XI, Appendix III should be used as a basis for NDE examinations. See "Inspection Coverage and Qualification of Personnel and Equipment" below.

Applicable portions of section XI Appendix VIII should be limited to 2100 (a), (b), (c), (d); and supplements 2 and 3 . The intent is not to obtain statistical validation; rather, it is to determine the reliability of the UT procedure on applicable flaws such as hemispherical pits (35-50\%t), loss of wall ( $\geq 20 \% t)$, and stress corrosion cracks $(20-50 \% t$ where $20 \%$ cracks are about one foot long). Sufficient samples should be available so that the capability to detect and size flaws is established with minimal false calls. Wall thickness is denoted by $t$.

Internal defects that do not break either surface are not of major concern. The purpose of the examination in this NDE plan is to detect operationally-induced defects.

For concrete, the approach should be employed on a case-bycase basis, depending on accessibility, anticipated degradation mechanisms, and prior evidence of degradation. These factors should determine whether nondestructive examination is applicable, or whether core samples will need to be taken, preferably near the base slab, to determine the degree of degradation. Any nondestructive examinations should define the regions to be examined, methods of examination, and acceptance criteria.

Invoking selected Articles of section XI does not imply that the Authorized Nuclear Inservice Inspector (ANII) is required; third-party inspection requirements are the responsibility of DOE.

\section{3 .2 Inspection Coverage and Qualification of Personnel and Equipment}

The following items apply to coverage and qualification:

- The latest edition of appropriate ASME Codes and their addenda such as section XI shall be used.

- Pertinent sections of Section XI Appendix III shall be used with the exception that III 4410 shall include $45^{\circ}, 60^{\circ}$ and $70^{\circ}$ plus $0^{\circ}$. The capability of detection and sizing of flaws shall use Appendix VIII of section XI; as limited below. 
TABLE 5.1

EXAMINATIONS OF CARBON OR LOW-ALLOY AND AUSTENITIC STAINLESS STEEL OR HIGH-ALLOY TANK CONTAINING HIGH-LEVEL WASTE

\begin{tabular}{|c|c|c|c|c|c|}
\hline $\begin{array}{l}\text { REGION } \\
\text { EXAMINED }\end{array}$ & $\begin{array}{l}\text { EXAMINATION } \\
\text { REQUIREMENTS }\end{array}$ & $\begin{array}{l}\text { EXAMINATION } \\
\text { METHODS }\end{array}$ & $\begin{array}{l}\text { ACCEPTANCE } \\
\text { LEVELS }\end{array}$ & $\begin{array}{l}\text { EXTENT OF } \\
\text { EXAMINATION }\end{array}$ & $\begin{array}{l}\text { FREQUENCY } \\
\text { OF } \\
\text { EXAMINATION }\end{array}$ \\
\hline $\begin{array}{l}\text { LIQUID-VAPOR } \\
\text { INTERFACE }\end{array}$ & $\begin{array}{l} \pm \text { ONE FOOT OF } \\
\text { INTERFACE }\end{array}$ & $\begin{array}{l}\text { VOLUMETRIC } \\
\left(0^{\circ} \mathrm{UT}\right)\end{array}$ & PITS, $(<50 \% \mathrm{t})$ & $\begin{array}{l}\text { 5\% OF INTERFACE } \\
\text { LENGTH OF EACH } \\
\text { TANK TO BE } \\
\text { EXAMINED* } \\
\end{array}$ & $\begin{array}{l}\text { EACH INSPECTION } \\
\text { INTERVAL } \\
\text { (DIVIDED INTO } \\
\text { TWO PERIODS) } \\
\end{array}$ \\
\hline $\begin{array}{l}\text { LIQUID-SLUDGE } \\
\text { INTERFACE, IF } \\
\text { SUCH EXISTS }\end{array}$ & $\begin{array}{l} \pm \text { ONE FOOT OF } \\
\text { INTERFACE }\end{array}$ & $\begin{array}{l}\text { VOLUMETRIC (UT) } \\
\text { FROM OUTER } \\
\text { SURFACE }\end{array}$ & $\begin{array}{l}\text { PITS }(<50 \%) \text {, } \\
\text { CRACKS }(<50 \% t)^{* * *} \\
(<20 \% \mathrm{t}) * * \\
\text { GROSS } \\
\text { CORROSION }(<20 \% \mathrm{t})\end{array}$ & $\begin{array}{l}\text { 5\% OF INTERFACE } \\
\text { LENGTH OF EACH } \\
\text { TANK TO BE } \\
\text { EXAMINED }\end{array}$ & $\begin{array}{l}\text { EACH INSPECTION } \\
\text { INTERVAL }\end{array}$ \\
\hline $\begin{array}{l}\text { LOWER KNUCKLE } \\
\text { OF PRIMARY TANK }\end{array}$ & UPPER WELD & VOLUMETRIC & $\begin{array}{l}\text { CRACKS }(<20 \% t)^{* *} \\
(<50 \% t)^{* * *}\end{array}$ & $\begin{array}{l}5 \% \text { OF LENGTH } \\
\text { DIVIDED INTO TWO } \\
\text { OR MORE SEGMENTS } \\
\text { IF ACCESSIBLE } \\
\end{array}$ & $\begin{array}{l}\text { EACH INSPECTION } \\
\text { INTERVAL }\end{array}$ \\
\hline $\begin{array}{l}\text { LOWER KNUCKLE } \\
\text { OF PRIMARY TANK }\end{array}$ & $\begin{array}{l}\text { PREDICTED MAXIMUM } \\
\text { STRESS REGION OF } \\
\text { BASE METAL PLUS LOWER } \\
\text { WELD IF ACCESSIBLE }\end{array}$ & VOLUMETRIC & $\begin{array}{l}\text { CRACKS }(<20 \% t)^{* * *} \\
(<50 \% t)^{* * * *}\end{array}$ & $\begin{array}{l}5 \% \text { DIVIDED BETWEEN } \\
\text { KNUCKLE BASE } \\
\text { METAL AND LOWER } \\
\text { WELD IF ACCESSIBLE } \\
\text { OTHERWISE 5\% OF } \\
\text { KNUCKLE DIVIDED } \\
\text { INTO TWO OR MORE } \\
\text { SEGMENTS } \\
\end{array}$ & $\begin{array}{l}\text { EACH INSPECTION } \\
\text { INTERVAL }\end{array}$ \\
\hline $\begin{array}{l}\text { EXTERNAL SURFACE } \\
\text { OF PRIMARY TANK IF } \\
\text { ACCESSIBLE, AND } \\
\text { INTERNAL SURFACE OF } \\
\text { SECONDARY TANK IF } \\
\text { SUCH EXISTS }\end{array}$ & $\begin{array}{l}\text { OVERALL SCAN OF } \\
\text { ACCESSIBLE REGIONS }\end{array}$ & REMOTE VISUAL & $\begin{array}{l}\text { ANY SIGNS OF } \\
\text { DEGRADATION } \\
\text { MUST BE } \\
\text { EVALUATED }\end{array}$ & $\begin{array}{l}\text { ALL ACCESSIBLE } \\
\text { REGIONS }\end{array}$ & $\begin{array}{l}\text { AT LEAST ONCE } \\
\text { EACH INSPECTION } \\
\text { INTERVAL }\end{array}$ \\
\hline
\end{tabular}


TABLE 5.1 (Continued)

EXAMINATIONS OF CARBON OR LOW-ALLOY AND AUSTENITIC STAINLESS STEEL OR HIGH-ALLOY TANK CONTAINING HIGH-LEVEL WASTE

\begin{tabular}{|c|c|c|c|c|c|}
\hline $\begin{array}{l}\text { REGION } \\
\text { EXAMINED }\end{array}$ & $\begin{array}{l}\text { EXAMINATION } \\
\text { REQUIREMENTS }\end{array}$ & $\begin{array}{l}\text { EXAMINATION } \\
\text { METHODS }\end{array}$ & $\begin{array}{l}\text { ACCEPTANCE } \\
\text { LEVELS+ }\end{array}$ & $\begin{array}{l}\text { EXTENT OF } \\
\text { EXAMINATION }\end{array}$ & $\begin{array}{l}\text { FREQUENCY } \\
\text { OF } \\
\text { EXAMINATION }\end{array}$ \\
\hline $\begin{array}{l}\text { EXTERNAL SURFACE } \\
\text { OF PRIMARY TANK IF } \\
\text { ACCESSIBLE }\end{array}$ & $\begin{array}{l}\text { BELOW NOMINAL VAPOR- } \\
\text { LIQUID INTERFACE }\end{array}$ & VOLUMETRIC $\left(0^{\circ}\right)$ UT & $\begin{array}{l}\text { WALL. THINNING } \\
(<20 \% \mathrm{t})\end{array}$ & $\begin{array}{l}\text { EACH INSPECTION } \\
\text { INTERVAL }\end{array}$ & $\begin{array}{l}\text { EACH INSPECTION } \\
\text { INTERVAL }\end{array}$ \\
\hline $\begin{array}{l}\text { VAPOR REGION AT TOP } \\
\text { OF PRIMARY TANK }\end{array}$ & $\begin{array}{l}\text { CONFIRM VT WITH PT OR UT } \\
\text { IF ATTACK IS FOUND }\end{array}$ & REMOTE VISUAL & $\begin{array}{l}\text { EVIDENCE OF } \\
\text { ATTACK SHOULD BE } \\
\text { EVALUATED }\end{array}$ & $\begin{array}{l}\text { REMOTE SCAN OF } \\
\text { VAPOR REGION }\end{array}$ & $\begin{array}{l}\text { EACH INSPECTION } \\
\text { INTERVAL }\end{array}$ \\
\hline $\begin{array}{l}\text { PLATE MAKING UP } \\
\text { BOTTOM OF TANK IF } \\
\text { ACCESSIBLE }\end{array}$ & $\begin{array}{l}\text { "BEST EFFORT" NDE } \\
\text { EXAMINATION }\end{array}$ & VOLUMETRIC & $\begin{array}{l}\text { CRACKING } \\
(<20 \% \mathrm{t})^{* *} \\
(<50 \% \mathrm{t})^{* * *} \\
\text { THINNING }(<20 \% \mathrm{t}) \text {, } \\
\text { PITTING }(<50 \% \mathrm{t})\end{array}$ & $\begin{array}{l}\text { PRIMARILY FOR NEW } \\
\text { TANKS DESIGNED FOR } \\
\text { ACCESSIBILITY: } \\
\text { HOWEVER, LIMITED } \\
\text { SCANS SHOULD BE } \\
\text { CONDUCTED IF } \\
\text { FEASIBLE }\end{array}$ & $\begin{array}{l}\text { EACH INSPECTION } \\
\text { INTERVAL }\end{array}$ \\
\hline $\begin{array}{l}\text { OVERALL SCAN OF } \\
\text { INTERNAL SURFACE }\end{array}$ & $\begin{array}{l}\text { WHEN A TANK IS } \\
\text { ESSENTIALLY EMPTY }\end{array}$ & REMOTE VISUAL & $\begin{array}{l}\text { EVIDENCE OF } \\
\text { DEGRADATION } \\
\text { SHOULD BE } \\
\text { EVALUATED }\end{array}$ & $\begin{array}{l}\text { GENERAL SCAN OF } \\
\text { INSIDE OF PRIMARY } \\
\text { TANK }\end{array}$ & $\begin{array}{l}\text { WHEN A TANK IS } \\
\text { EMPTY }\end{array}$ \\
\hline
\end{tabular}

* TANK POPULATION TO BE EXAMINED IS 10\% OF TANKS, BUT NOT LESS THAN ONE; ALTERNATIVELY, THE POPULATION EXAMINED MAY BE GREATER THAN 10\% WITH A COMPARABLE REDUCTION IN THE AMOUNT EXAMINED IN EACH TANK, PROVIDED THE TOTALS ARE THE SAME AS FOR THE 10\% POPULATION. ** $<20 \% t$ FOR CRACKING APPLIES WITH FLAW LENGTHS $\geq$ ONE FOOT.

*** $<50 \%$ t FOR CRACKING APPLIES WITH FLAW LENGTHS < ONE FOOT WITH LOWER BOUND LENGTHS ABOUT 0.5-INCH.

THE INSPECTION INTERVAL IS 10 YEARS; THE INSPECTION PERIOD IS APPROXIMATELY 5 YEARS.

SPECIAL EMPHASIS MUST BE PLACED ON WELDMENTS, WHERE LEAKS ARE MOST LIKELY TO DEVELOP.

+ VALUES GREATER THAN ACCEPTANCE LEVELS REQUIRE ADDITIONAL EXAMINATIONS. VALUES GREATER THAN ONE-HALF ACCEPTANCE LEVELS REQUIRE SUCCESSIVE EXAMINATIONS. 
- Limit application of Appendix VIII to establishing the capability of the UT equipment to detect $50 \%$ pits, $20 \% t$ thinning, $20 \% t$ and one-foot in length or $50 \%$ for shorter lengths for SCC. This will require sizing with an uncertainty of no more than $\pm 20 \%$ of the above. Applicable sections of Appendix VIII are 2100 (a), (b), (c), (d); and Supplements 2 and 3 .

- Use IWA-2430 with a 10-year interval per IWA-2432.

- Conduct Successive Examinations as defined in IWC-2420.

- If flaws are detected, conduct Additional Examinations as defined in IWC-2430.

- Personnel qualification should be based on ANSI/ASNT CP-189, "ASNT Standard for Qualification and certification of Nondestructive Testing Personnel."

\subsubsection{Alternative Examination Procedures for Tanks}

Alternative examination procedures are permissible per section XI IWA-2240. Some that might be considered include eddy current, electromagnetic acoustic transducers, and creeping waves.

- Eddy Current (EC) may be used to supplement UT or as an alternative to UT, provided that adequate reliability can be established. There are, however, severe limitations to the use of EC for the examination of ferritic steels. The ferromagnetic nature of the material is often accompanied by a high background noise level associated with local fluctuations in magnetic permeability. This noise can be suppressed by magnetizing the tank wall with an obvious increase in the complexity of the instrumentation. Moreover, in order to obtain inner wall information with an outer wall probe, two steps will be required to ensure that the electromagnetic fields penetrate the wall. It will be necessary to use both a large coil, with dimensions on the order of the wall thickness, and an unusually low frequency, perhaps on the order of a $\mathrm{kHz}$. One consequence would be a reduced spatial resolution. An alternative option would be to inspect from the inner surface. In any case, the EC procedure would require a fully qualified calibration.

- In another alternative, electromagnetic-acoustic transducers (EMATs) could be used to excite and detect the ultrasonic waves in place of the piezoelectric transducers normally used. The ultrasonic waves propagate through the material and interact with flaws in the same way when excited by either type of transducer. However, EMATs have the advantages of requiring no couplant, of being able to easily excite shear waves propagating normal to surfaces, and of being less 
influenced by the presence of surface scale and roughness. The engineering trade-off is a considerably lower efficiency than that of piezoelectric transducers, necessitating the use of specially designed electronics. Again, adequate reliability must be established.

\subsubsection{Sample Size and Selection of Tanks for Inspection}

A description of sample size and tank selection is as follows:

- At least $10 \%$ of tanks, or if there are less than ten tanks, at least one will be subjected to NDE.

- Select the tanks to be examined on the basis of age, severity of operating conditions, and transients, so that tanks with the highest potential for attack are examined. If the population is not homogeneous and clear arguments cannot be made regarding the most severe effect, selection of more than 10\% may be required to include representation of all worstcase tanks.

- Each site has the option of increasing the percentage of tanks examined. If this option is exercised, the percent examined in a given tank can be reduced accordingly; e.g., if $20 \%$ of the tanks are examined the minimum amount examined per tank can be one half of the sample size values.

- Examine 5\% of the length of the liquid-vapor interface region, if such exists, \pm one foot of the interface for pitting using $0^{\circ}$ UT optimized for detection of $50 \% t$ pits.

- Examine 5\% of the length of the liquid-sludge region, if such exists, \pm one foot of the interface for pits, cracks, or wall thinning using UT optimized for detection of these defects.

Examine the lower knuckle region including $5 \%$ of the length of the upper weld, at least $2.5 \%$ of the area of the predicted maximum stress region of the knuckle base metal and $2.5 \%$ of the lower weld if accessible. Emphasis should be on weld/HAZ cracking such as SCC. If the lower weld is not accessible, one-square-foot sections whose length adds up to $5 \%$ of the circumference of the knuckle base metal shall be examined. In recognition of the limited accessibility of the knuckle region, a pressure/leak test can be substituted for the NDE, if such is feasible and it can be determined that such a pressure/leak test is not detrimental.

- The bottom plate should be examined volumetrically if there is sufficient access. In recognition of the very limited access in this region, no specific area is established for such examinations. They should be on a "best effort" basis. For new tanks a definite effort should be made to provide 
sufficient accessibility to permit UT of 5\% of the bottom plate.

- In accessible regions, if there is VT evidence of external surface attack, conduct UT of those regions for wall thinning; if there is no evidence of thinning, select no more than 10 areas of $1 \mathrm{ft}^{2}$ area for thickness measurement. These areas should be documented so that future measurements can serve to establish rates of thinning.

- On the secondary tank, VT should be used to detect any degradation; also, select 5 areas of $1 \mathrm{ft}^{2}$ for thickness measurements and 5\% of the knuckle region welds or of the weld-wall intersection for evidence of cracking using $45^{\circ}$ and $60^{\circ}$ shear-wave ( $T$-wave) probes provided that accessibility exists. For new tanks access should be assured to the knuckle region and to the lower side wall. Concerns here are the existence of trapped water between secondary tank and the concrete and/or stress-corrosion cracking originating at the external surface due to additives in the concrete.

- Examine the vapor region of the inner tank above stored highlevel waste, using VT from the inside of the tank for evidence of attack. If observed, use appropriate surface or volumetric $\mathrm{NDE}$ procedures to determine depth of observed attack.

\subsubsection{Tank Evaluation Criteria}

Additional inspection or other management action will be needed under certain conditions, as described below:

IWC-2420 (Successive Examinations) shall be required at onehalf the values cited in this paragraph. IWC-2430 (Additional Examinations) shall be required by evidence of pits ( $50 \% t$ ), cracks ( $20 \% t$ for one foot or longer cracks, or $50 \% t$ for shorter cracks), or wall thinning $(20 \% t)$. This will require sizing within the limits of $\pm 20 \% t$.

Repair or other corrective action(s) such as lowering the liquid level below the crack/pit, if feasible, shall be considered if successive examinations confirm crack/pit penetration exceeding $75 \% t$. On a case-by-case basis it should be considered whether lowering the liquid level would expose a detected flaw to an even harsher environment; however, if the liquid level is not raised again subsequently, leaks should not occur at the defect involved. The repair technique or other option shall be at the discretion of the operating organization with approval of DOE (see Chapter 8).

The program shall revert to the original examination plan as cited in IWB-2420 when there is no evidence of growth after three successive examinations at 1 to 2 -year periods. 
A procedure for fracture mechanics evaluation of flaws having substantial length is described in Chapter 6. Levels A, B, C, and Design Loads, plus seismic Level D loads will be used unless any other load combinations are considered necessary or justified.

\subsubsection{Concrete Inspection Reguirements and Procedures}

The potentially significant mechanisms which can degrade concrete and reinforcing steel are discussed in chapters 3 and 4. In the following subsections, the inservice examinations and tests, which may be used to confirm structural integrity of the concrete for continued operation, as well as the qualification of personnel and equipment are described.

\subsubsection{General Reguirements for Inspection and Testing of Concrete}

Direct visual examination is the standard method for an initial evaluation of the concrete [5.2]. Since the concrete is inaccessible and is situated in a highly radioactive field, remote visual examination and ultrasonic testing should be the preferred methods of inspection. This can be achieved by using video cameras and fiber optics in boreholes dug adjacent to the outside concrete surface. If the initial inspection indicates signs of deterioration of the concrete, the zones of downhole probe inspection. should be enlarged by excavating and inspecting wider areas of the suspected concrete surfaces. Additional evaluation should include core drilling of the internal concrete, preferably in the tank's wall, for laboratory testing. The drilling should be outside the zones of the reinforcing steel. Also, examination and evaluation of vintage concrete in existing reinforced concrete structures in the sites can reveal useful information. In particular, examination of buried portions of existing structures may reveal important characteristics of the soil in that region and its influence on the degradation of concrete and reinforcing steel.

The general tests required to confirm structural integrity of the concrete should conform to applicable industry standards and codes. As a minimum they should include strength properties (compressive strength, modulus of elasticity), chemical analysis (presence or absence of chlorides and other corrosion products), and extent of internal or surface chemical reactions.

The initial inspection interval should be 5-10 years, and, depending on the information gained, subsequent inspection periods can be determined. Only those tanks in which the concrete is suspected to have been degraded should be inspected. The inspections are to be directed by a professional engineer experienced in evaluating concrete structures as specified in subsection IWL-2512 of Section XI of the ASME Boiler and Pressure Vessel Code. 


\section{3 .6 .2 Selection of Location for Concrete Inspection}

The examination locations should be selected on the basis of highly stressed regions, construction joints, concrete pour regions and, of particular importance, regions of extreme environmental conditions. In a DST, the high stress regions are (1) the outer portion of the dome including the haunch and the top wall, (2) the lower portion of the wall, and (3) the foundation.

A vertical and/or inclined bore-hole should be used for probe survey of the external surface of the concrete. The inclined probe path could be used to investigate conditions at the bottom surface of the basemat. The vertical probe hole could be either adjacent to the concrete surface or at a short distance from it with connecting paths to the desired locations on the concrete surface.

\subsubsection{Nondestructive Tests for Concrete}

Various nondestructive tests can provide useful information on the quality of the concrete in the waste storage tanks. The following are some examples:

- Ultrasonic pulse velocity measurements:

This test [5.4], can reveal information about the compressive strength and stiffness (modulus of elasticity) of the concrete. When used over time, the tests can monitor deterioration and cracking in the concrete, and delaminations along the reinforcement steel [5.3].

- Rebound Number Test:

This test [5.5], which is also known as schmidt hammer or impact hammer test, can be used to generate information about the location and extent of voids, honeycombs, and uniformity at the outside surface of the concrete.

- Acoustic Emission Tests:

The acoustic emission characteristics of concrete reveal useful information about the quality and structural integrity of the concrete. It may be useful to explore the use of such a technique to monitor and inspect the highly stressed locations of the concrete vaults [5.6].

- Electrochemical Testing:

This test [5.7], permits determination of the corrosion activity of steel reinforcement in concrete. 
Such tests use $\mathrm{X}$-ray and/or gamma-ray sources placed in the annulus of a DST and radiographic films placed in the bore hole opposite the source. The pictures can reveal useful data on location and extent of pitting and general thinning of the reinforcing steel [5.3].

Computerized equipment to carry out the above tests is commercially available. The equipment should be calibrated and its reliability benchmarked before used in the inspection.

In general, it is expected that none of these NDE tests in concrete will be required. However, if a degraded region is observed or suspected and more information is needed, these tests could produce useful materials data.

\subsection{PROGRAM INITIATION}

An NDE program conforming to the requirements of this document shall be developed for each site and put in operation according to the following:

- Each site shall develop a program plan within one year of the submittal of this document to DOE for approval.

- Examinations in compliance with this document and the program plan shall be initiated not more than two years after DOE approval of the program plan.

- Any tanks expected to be no longer in use within five years of the release of this document are exempt from examination.

- Exemption requests based on inaccessibility shall be reviewed on a case-by-case basis by DOE. If a portion of a tank is accessible, examinations should take place, rather than giving a blanket exemption.

- The initial examination shall serve as a baseline for the respective regions and be considered a pre-service examination in the absence of a prior examination. If something is found, the region(s) shall be reexamined to determine if and at what rate growth is occurring.

- If a new tank is constructed, a 100\% baseline examination of all welds that will be accessible after construction, and that will be examined in subsequent in-service inspections, shall be provided. Ultrasonics rather than radiography are an option for weld acceptance provided that ASME Section III has approved this option. If this is done, the weld acceptance may be used as a baseline. In addition at least 20 regions of 
$2-f t^{2}$ to $4-f t^{2}$ size in the anticipated liquid-vapor interface shall be examined to provide wall thickness baselines.

\subsection{DEFINITIONS, ABBREVIATIONS, AND ACRONYMS}

Accessible - For existing tanks accessible is based on existing conditions related to top head penetrations, weld-knuckle, regions not covered by cooling coils or ducts, and not requiring highly specialized UT techniques such as creeping wave. A region such as that below the bottom plate in old tanks may be accessible if specialized equipment such as a "mouse" capable of examination through the air cooling ducts under the base plate is available; it does not mean that such equipment must be developed.

Generic - Applicable or referring to a class or kind of system. In this instance it refers to a failure mode which, if found, would be expected to be found in other tanks having similar operational histories.

All acronyms and abbreviations used are common to ASNT and ASME. In ASME Codes $V$ (Nondestructive Examination) and XI (Rules for Inservice Inspection of Nuclear Power Plant Components) such terms as VT (visual examination, more specifically VT-1 detection of discontinuities and imperfections on the surfaces of the tanks), RT (radiographic examination) and UT (ultrasonic examination) are identified. The 1992 edition of the ASME Codes shall be used, with appropriate additions or later editions if the criteria have not changed drastically.

\section{REFERENCES}

5.1 ASME Boiler and Pressure Vessel Code, section V, Nondestructive Examination, and Section XI, "Rules for Inservice Inspection of Nuclear Power Plant Components, "ASME, New York, 1989, with Annual Addenda.

5.2 ACI Committee 201, Guide for Making Condition survey of Concrete In Service, ACI 201-1R, American Concrete Institute, Detroit, Michigan, 1992.

5.3 Malhotra, V.M., Testing Hardened Concrete: Nondestructive Methods, American Concrete Institute Monograph No. 9, The Iowa State University Press, Ames, Iowa, 1976.

5.4 ASTM C 597 (latest edition), Standard Test Method for Pulse Velocity Through Concrete, American Society for Testing and Materials, Philadelphia, Pennsylvania. 
5.5 ASTM C 805 (latest edition), Standard Test Method for Rebound Number of Hardened Concrete, American Society for Testing and Materials, Philadelphia, Pennsylvania.

5.6 Non-Destructive Testing, H.S. Lew, Editor, ACI SP 112, American Concrete Institute, Detroit, Michigan, 1988, p. 221.

5.7 ASTM C 876 (latest edition), Standard Test Method for HalfCell Potentials of Uncoated Reinforcing steel in Concrete, American Society for Testing and Materials, Philadelphia, Pennsylvania. 
CHAPTER 6

\section{EVALUATION OF THE EFFECTS OF DEGRADATION}

\subsection{INTRODUCTION}

In the previous chapters, the potential aging mechanisms, resulting material degradation, data collection on possible material degradation, and applicable failure modes are discussed. The use of these materials data in verifying the structural integrity of tanks is described in this chapter. The data from the leak-detection systems and relevant inspection programs should be evaluated for verification of the leak-tightness of the tanks. Similarly, the structural data should be used for verification of integrity of the tank structures against the design and postulated loads. Both these subjects are separately discussed in the following sections. The reliability of models in estimating the remaining service life or ensuring safe operation of a tank for a stipulated period is also explored in this chapter.

\subsection{VERIFICATION OF LEAK-TIGHTNESS}

The data from the surface monitoring and other leak detection systems (described in Section 4.4) should be reviewed periodically to determine whether any leakage has occurred. If no leakage within the tolerance of the instruments has been detected, the leak-tightness function is maintained. If a small amount of leakage is observed, the volume and the rate should be compared with the acceptable limits. If the leakage does not exceed the allowable value, the condition may be considered acceptable but immediate steps should be taken to determine the cause of leakage and institute preventive actions. If the leakage exceeds the acceptable limits, the tank will be considered to have lost the leak-tightness capability. However, for a double-shell tank, leakage from the primary tank may be safely retained in the secondary tank. In any event, management actions will be required to determine the cause of leakage and take appropriate measures.

The inspection data from the NDE plan described in Chapter 5 should also be evaluated to determine any trace or potential of leakage. Appropriate precautionary measures should be taken if any indication is observed.

\subsection{VERIFICATION OF STRUCTURAL INTEGRITY}

The structural and materials data such as reduction of shell thicknesses and material properties, or existence of flaws should be evaluated to verify the structural integrity of the tank structure. The most likely failure modes should be considered in the evaluation (Section 2.3.1). If the structural integrity needs to be verified for a stipulated service life, the materials 
degradation data projected through this stipulated period should be used for the structural evaluation. As stated earlier, it is expected that design basis loadings will be available in the respective structural specifications. If not, such loadings and load combinations should be developed as part of the structural integrity assessment program (a separate document on structural evaluation currently in preparation will address these issues). If loadings beyond the design basis events need to be considered for the purposes of the safety analysis or risk calculations, such loading should also be justified or developed as part of this program. The seismic analysis guidelines for the underground tanks are described in BNL-52361 [6.1].

If the structural responses obtained from the analyses based on the end-of-life or end-of-a-stipulated-period material and geometry data are within the code acceptable limits, the structural integrity is confirmed. Otherwise, a refined analysis with more realistic assumptions may be performed to demonstrate adequate safety margins. If even a refined analysis cannot assure structural integrity for the planned tank conditions, appropriate actions such as reduction of the waste level, limitation of vehicular and other live loads, or declassification of the tank safety status may be required. The structural integrity evaluation should identify such options. On the other hand, continued assurance of the structural integrity through analytical tools may require development of material degradation, monitoring changes in geometry and mathematical models.

\subsection{ANALYTICAL MODELS}

This section describes analytical models for evaluating the integrity of the tank structures. The steel tanks and the concrete shells are discussed separately.

\subsubsection{SteeI Tanks}

The primary function of the steel tank is to confine the waste and maintain it in a leak-tight condition. Verification of leaktightness is discussed in section 6.2. For normal operating loads and temperature levels, the leak-before-break condition is assured since the steel shell is constructed from ductile material with adequate fracture toughness values. Thus, a surface crack subject to the design loads would, in the worst situation, grows through the wall thickness without causing sudden rupture. Stress corrosion, pitting, and large plastic strains are the main sources of surface cracks in the steel tanks.

The steel tank shells could be subject to several forms of corrosion. It would be desirable to identify the ones that are relevant to a given tank, and to determine the rate at which each of these is progressing. If available, these data can then be used as the basis of a predictive model to estimate service life and/or

$$
6-2
$$


to determine the end-of-life material properties. Modeling for general corrosion of carbon steel and stainless steel now exposed to a variety of waste types seems to be unnecessary because the rates of attack are low (Section 4.2.1), unless extraordinary changes in the waste chemistry occurs in the future. Excessive general corrosion and thinning of the steel could lead to local ductile rupture and/or buckling of the wall of the tank. Actual data from the field or from simulated tests should be used in estimating remaining life and safety margins.

Pitting/crevice corrosion has a poorly defined induction period, which causes difficulties with predictive modeling. However, some knowledge has been gained through statistical analysis of data, which defines relationships between the concentration of nitrite needed for inhibition and variables such as temperature, and concentration of other ions in solution (section 3.2.2). This has a very important practical impact on tank management. The determination of pitting/crevice corrosion rates, on the other hand, appears to be so dependent on specific waste characteristics, as well as being tied to an uncertain initiation time, that the best tool for this purpose is in-service inspection or coupon testing. Both of these have limitations, such as accessibility (for in-situ measurements) and prior history of waste chemistry variations (new coupon testing). In any event, the inspection and experimental approaches seem preferable at least until such time as a good understanding of waste characteristics is obtained, which appears unlikely to be at an early date.

The potentially most damaging of the plausible forms of attack is stress-corrosion cracking, which has occurred in the field, and which is more likely than other forms of corrosion to cause larger leaks if not controlled. The initiation time for the development of cracks is still very dependent on residual tensile stress and waste chemistry, as indicated in section 3.2.3, and sufficient hydroxide and nitrite ion additions (as well as stress relief) can suppress the onset of cracking. However, experimental data have shown that, once a crack has started, there is little effect of bulk solution chemistry on crack tip environment and crack growth rates. This means that the crack propagation is largely dependent on the stress at the apex of the crack. Relationships between stress intensity and crack growth have been developed. Knowing the initial crack dimensions and loading, they can be used to estimate the amount and time required for crack growth (Section 6.5.I).

In case of load conditions beyond the design loads (faulted condition) the threshold load of the steel tank should be based on a strain criterion, namely, the calculated maximum strain in the steel tank should be a fraction of the ultimate strain of the material in a uniaxial test. Also, the maximum displacement in the tank should be limited to the value which would prevent possible contact with the secondary liner or with probes and other objects in the annular space between the primary shell and the secondary 
liner. If there is reason to believe that brittle fracture conditions or unstable ductile tear could occur then fracture mechanics methodologies should be used to determine the critical crack size and/or the critical load (Section 6.5).

\section{4 .2 Concrete Shells}

The primary function of the concrete shell is to provide a barrier against soil pressures and transfer the loads to the foundation. The potentially significant degradation mechanisms which could affect the concrete properties are discussed in Sections 3.3 .1 and 4.5 .

In Section 3.3.1.1, the influence of elevated temperature on the mechanical properties of concrete are given. In particular, the reductions in the compressive strength and modulus of elasticity with rise in temperature are quantified. Additional information are given in a BNL report [6.2]. The end-of-service values of the mechanical properties should be used to ensure that the concrete structure will meet the requirements of the design code. In this respect, it would be noted that the actual temperature distribution in the concrete tank has a gradient through the wall thickness resulting in progressively decreasing temperatures across the wall thickness. This should be considered in determining the overall impact of elevated temperatures on the concrete behavior. In addition, since the concrete's strength increases with age, any gain in strength should be included in the evaluation.

Another effect of the rise in temperature of the concrete is to increase its creep strain [6.2]. The elevated creep strain could affect the distribution of stress and deformation in the concrete structure and may cause undesirable effects. In particular, it could induce large deflections in the dome which in turn induce undesirable plastic strains in the steel tank. Also, creep of the concrete could cause the reinforcing steel to support a large portion of the load and sustain higher than the allowable stresses. The effect of elevated temperatures on the increase in creep strain of the concrete structure should be evaluated to ensure that the concrete is operating within the design allowables.

\subsection{FRACTURE MECHANICS}

The aim of the fracture mechanics evaluation is to provide a rational basis for establishing the flaw tolerance of the structural components of the tanks [6.3]. In particular, the leaktightness of the primary shells of the double-shell tanks, which provide the first barrier for confinement of the waste, needs to be ensured under normal loading conditions. Crack initiation and crack growth due to the operating and accident loadings need to be addressed. Since under normal operating conditions there is insignificant cyclic load, crack initiation is mainly influenced by 
the corrosion of the material, composition of the waste, and the operating stresses including the residual stresses in the weld regions. The impact of thermal fatigue on crack initiation is a tank-specific issue and should be included in the evaluation whenever it is applicable. All locations of pits and crevices detected on the surfaces of the primary tanks and the heat-affected zones near the weld regions are plausible sites for new crack initiation.

Another application of fracture mechanics which relates to the tank structure involves determining the critical crack size and/or the critical load. This issue will be of concern if brittle fracture or unstable ductile tear conditions are suspected especially when the tank is subjected to loading beyond design level. In the following sections these two applications of fracture mechanics methodologies are discussed.

\subsubsection{Evaluation of Crack Growth}

Should future cracking occur in the waste tanks, it is expected to occur by stress corrosion. Thus, the evaluation of propagation rate should be based on stress-corrosion crack-growth data. Specific data applicable to the environment of each tank farm are needed. Such data are usually obtained from testing of pre-cracked specimens and the formulation of a relationship between the stress-intensity factor $(K)$ and the crack growth per unit time, $\mathrm{da} / \mathrm{dt}, \mathrm{i} . e ., \mathrm{da} / \mathrm{dt}=\mathrm{f}(\mathrm{K})$. Specimens subjected to $\mathrm{K}$-values below a threshold level, known as the stress corrosion cracking threshold $\left(\mathrm{K}_{\mathrm{scc}}\right)$, do not fail. The values of $\mathrm{K}_{\mathrm{scc}}$ and the rate of crack growth, $f(K)$, depend upon the environment in the tanks. For conservative estimates, a lower-bound relationship which envelopes all available experimental data is needed. This will yield the fastest time for crack growth. Such data may be obtained from site information or from the open literature (see also section 3.2.1.3.1 where some specific numbers are cited). In addition to the applied stress from external loads, the weld residual stress contributes significantly to the crack growth behavior. Estimates of both the axial and circumferential weld residual stresses are needed for the evaluation. Once the crack growth analysis is carried out then estimates of final crack dimensions (depth and length) can be obtained. For leak-tightness of the tank the crack depth should be less than the wall thickness by a suitable factor of safety.

\section{5 .2 Critical Crack Size}

For faulted conditions, the onset of unstable crack growth in the primary tank can be predicted by using the concept of a crackgrowth resistance curve, usually referred to as the R-curve [6.3] . since the primary shell is made of ductile material (carbon steel or stainless steel), the resistance of the material to crack growth is expected to increase as the crack growth progresses. In other words, the material experiences stable crack extension and failure

$$
6-5
$$


occurs by tearing of the metal. Hence, the critical crack dimensions (radial depth and circumferential or axial length) under faulted loading conditions may be determined by using methodologies of Elastic-Plastic Fracture Mechanics (EPFM) or limit load approach. The flaw may be modeled as a semi-elliptical surface crack located on the internal surface of the tank either in the circumferential or axial orientation. The aspect ratio of the crack, i.e., ratio of the semi-minor to the semi-major axes of the ellipse should be specified as in Section XI of the ASME Boiler and Pressure Vessel Code. The driving force for circumferential crack growth is the axial stress in the primary tank, whereas for axial cracks the driving force is the circumferential or hoop stresses. For elastic-plastic loading in EPFM, the J-integral parameter is used to characterize the crack driving force while the crack growth resistance of the material is expressed through the $J-R$ curve [6.4]. The degradation in the fracture toughness due to irradiation of the metal, although believed to be insignificant for the HLW tanks, should also be investigated, and if any nilductility temperature exists, it should be included in the evaluation. Two methods of analysis are recommended for determining the critical crack size in EPFM. These are:

- J-R Curve Analysis

- Deformation Plasticity Failure Assessment Diagram

These methods are elastic-plastic techniques and are currently being investigated by ASME Section XI Code committees. They are known to provide acceptable predictions of experimental behavior of flawed components in similar structures $[6.4,6.5]$.

In addition to the above analysis, the methodology of Iimit load or net section plastic collapse may be used to determine the loads required to initiate crack extension and crack growth by ductile tear mechanism at the operating temperature level in the tanks [6.6].

\section{REFERENCES}

6.1 Bandyopadhyay, K., A. Cornell, C. Costantino, R. Kennedy, C. Miller, and A. Veletsos, "Seismic Design and Evaluation Guidelines for The Department of Energy High-Level Waste Storage Tanks and Appurtenances," BNL-52361, Brookhaven National Laboratory, Upton, N.Y., 11973, Revised October 1995.

6.2 Kassir, M.K., et al., "Thermal Degradation of Concrete in the Temperature Range From Ambient to $315^{\circ} \mathrm{C}\left(600^{\circ} \mathrm{F}\right)$, " BNL Report 52384 (Rev. 10/96), October 1996.

6.3 Anderson, T.L., Fracture Mechanics, 2nd Edition, CRC Press, 1995 . 
6.4 Paris P.C., and R.E. Johnson, "A Method of Application of Elastic-Plastic Fracture Mechanics to Nuclear Vessel Analysis," ASTM STP 803, 1983.

6.5 Bloom, J.M., "Prediction of Ductile Tearing Using a Proposed Strain Hardening Failure Assessment Diagram," International Journal of Fracture, Vol. 6, pp. 73-77., 1980.

6.6 Kanninen, M.F., et al., "Instability Predictions for Circumferentially Cracked Type-304 stainless steel Under Dynamic Loading," EPRI Report NP-2347, 1982. 
CHAPTER 7

TRANSFER PIPING

\subsection{INTRODUCTION}

Transfer piping integrity needs to be maintained in order to ensure that radionuclides and hazardous materials will not leak out and contaminate the environment. Although many of the degradation mechanisms for piping are generically the same as for the tanks, there are also significant differences such as in usage, design, accessibility, leak testing, replacement or repair procedures, among others. For this reason, the same major elements for guiding the development of a structural integrity program that were discussed over several chapters for the tanks, are presented, but more briefly, in this chapter, focused specifically on transfer piping.

Piping with a variety of geometries, enclosures, materials, and vintages is located, mostly underground, at the DOE high-level waste sites. The earliest piping dates back to the 1940's. Typically, piping only contains waste intermittently during the actual transfer process. Some lines have not been used for one or two decades. Transfer piping designs vary considerably from site to site and from facility to facility within a given site. Most of it is 2 to 3 -inch diameter carbon steel schedule 40 pipe, some of which is doubly-contained. All piping connections to the tanks come through the top or above the liquid level. Individual lengths of piping range from less than 100 feet to approximately two miles. At the Idaho site, stainless steel transfer piping is used for acid waste solutions. However, much of the pertinent detail on the design criteria and operating history appears to be lacking, and completeness of records varies markedly from site to site. Aging has resulted in deterioration of many of the pipelines, and leaks have been detected in several instances over the years. Plugging during or after waste transfer has led to abandonment of some pipelines.

\subsection{STRUCTURAL INTEGRITY VERIFICATION}

\subsubsection{Data Collection}

Data are required on the main factors involved in verifying transfer-line integrity. These factors are loading, geometry, and material properties. The obvious purpose is to ensure that radionuclides will not escape to the environment. In addition, transfer lines should be available for waste transfer if and when needed.

All three parameters can change during the life of a pipeline, for example, as a result of soil settlement or corrosion. In the 
case of transfer piping, geometry at the time of making a transfer of waste is of greatest importance.

\section{2 .1 .1 Loading}

Since pipelines are mostly underground, soil overburden and soil settlement will exert external pressure. Nominal internal pressure will result from pumping fluids. In addition to these, thermal cycling ranging from soil temperature to that of HLW solutions will result in thermal loads. Earthquake loadings on transfer lines are discussed in BNL 52361 [7.1]. The safety Analysis Report of a facility should provide requirements for loading. Therefore, the present guidelines will not elaborate on loading or load combinations, although they recognize that loading is an important variable in the verification of structural integrity of transfer piping.

\subsubsection{Geometry}

Physically, the pipes may be in direct contact with the soil, or coated, with the coating in contact with the soil, or coated and inside some form of caisson, or buried pipe-within-pipe with coatings, or pipe-within-pipe coated and in a caisson. Pipes are predominately horizontal. They may or may not terminate in a junction box. Portions of the pipes are vertical near tanks, and are connected to the tanks in various fashions. There are elbows where piping changes direction.

On a different scale, geometry relates to the pipe wall thickness and thus to its integrity. As piping ages, there can be degradation of both the internal and external surfaces. The loss of metal can be localized or general, with corrosion being the most likely cause.

\subsubsection{Pressure Testing}

Of prime importance is the need to establish, at the time of making a transfer, that a line is not degraded to the extent that leaks and contamination of the environment are possible. Pressure testing is the method most commonly used for this purpose. Furthermore, programs should also exist to ensure the future availability of transfer lines.

Pressure testing is normally performed at pressures slightly greater than (i.e., 1.1 times) the design pressure, accompanied by appropriate leak sensing techniques. Site-specific procedures for pressure testing of transfer piping prior to each use need to be developed by the sites, considering the unique design of the run of the piping intended to be used. 


\section{2 .1 .4 other Analysis of Transfer Line Condition}

Additional analyses for estimating the condition of transfer lines at the end of their service lives should be considered. Since information on changes in dimension, such as those due to thinning, pitting, or cracking may not exist, data will be required for this purpose. Data on whether pipes leak or are plugged should be collected, and procedures for doing so are available. However, it is more difficult, and not usually practical to inspect and determine the cause(s) of leaks or anomalous behavior occurring at remote locations. In some instances, pipes have been uncovered to determine why there were problems. Borescopes have also been used for inspection of defects, but this has been limited owing to inaccessibility. Where possible, such inspection techniques should be considered to determine the mechanisms that caused leaks and to form a basis for estimating future performance, for example by establishing the rate of degradation due to general or localized corrosion.

\subsubsection{Material Properties}

Initial material property data, although not always complete, should be available from design specifications and testing during construction. Aging can, however, degrade the properties of some materials, and such data should be developed whenever needed as part of the piping structural integrity program.

\subsubsection{Data Collection Summary}

In summary, loading data should be obtained from existing site-specific design and safety documents. Additional data that may be needed in relation to changes in geometry (e.g., corrosion degradation) and possibly material properties should be derived from the structural integrity program. At present, very little is known about the status of transfer piping other than leak test data and a limited number of reports on failures. Routine inspections are not generally made. Details that are available on construction, installation, and design criteria are usually incomplete.

\subsubsection{Data Evaluation}

Results of pressure testing for leaks or blockage are of highest priority in evaluating whether a transfer line is suitable for use at a given time. For additional procedures to analyze effects of loading, geometry, and material properties, relevant and practical parts of the discussion in section 2.2.2 (Chapter 2, "Data Evaluation") should apply. 


\subsection{STRUCTURAL INTEGRITY PROGRAM DEVELOPMENT}

A consistent data collection system is necessary. History to date at one site suggests that records are difficult to find. $A$ program to test lines periodically, at least those expected to have future use, should be considered. Magnetostriction procedures, developed by Southwest Research, are capable of detecting corrosion on either the inner or the outer surface through insulation on the pipe [7.2]. This approach may be worthy of consideration, provided that pipes can be reached to carry out the inspection.

Pipes are buried; however, they are accessible at various valve boxes or at jumper locations (when such exist). Therefore, borescopes can be used to examine segments of pipe. The outer surface of the inner pipe-in-pipe may be accessible for examination in some instances. Excavation of failed or leaking pipes can also be conducted.

\subsubsection{Identify Aging Mechanisms}

The obvious aging mechanisms are external corrosion, often microbiologically induced (MIC), internal corrosion, and plugging of lines used to pump high-solids slurries. All of the above have been observed in the field. Additional mechanisms include erosioncorrosion when pumping slurries through ferritic piping.

Both carbon and stainless steel pipes are being used for HLW transfer. They may be contained, heat-traced, insulated, pipe-inpipe, or combinations of these options. A limited sampling has been performed consisting of borescoping pipes known to leak to determine the cause, and, in a few instances, pipes have been excavated to determine the degree of damage and the aging mechanism responsible for the damage. Existence of such information is quite limited so that global conclusions are not possible.

\subsubsection{Potentially Significant Degradation Mechanisms in Transfer Piping}

External corrosion has been the predominant failure mechanism, often related to inadequate cathodic protection. Plugging is not an aging mechanism; however, it is very effective in putting a line out of service. Internal corrosion is a possibility; pitting attack and acid corrosion have been encountered in service. However, due to the limited number of lines excavated after leakage, the prevalence of internal corrosion cannot be established. MIC, discussed in paragraph 3.2.1.4, can also occur on both external and internal surfaces when cathodic protection is inadequate. Usually slurries are pumped in austenitic stainless steel pipes, minimizing the possibility of slurry erosion. Erosion and wear cannot be ruled out; however, the data available are insufficient to permit definitive conclusions. Systems fabricated of austenitic stainless steel may be subject to stress corrosion

$$
7-4
$$


cracking, particularly with intermittent pumping of solutions, or due to exposure to soils containing chlorides. Crevice corrosion under sediments inside the piping due to differential aeration cannot be ruled out as a degradation mechanism.

Cathodic protection systems for transfer piping are in use at several sites. Their design and effectiveness in maintaining integrity needs to be included in the site-specific integrity program. In particular, the standards used in designing the cathodic protection systems need to be referenced.

After transfer pipes are used and flushed, residual dilute solutions may remain in areas that did not drain properly; these conditions may lead to local corrosion processes.

\subsubsection{Non-Significant Aging Mechanisms}

Many aging mechanisms are regarded as irrelevant. Included in this category are:

- Thermal embrittlement

- Radiation embrittlement

- Creep/stress relaxation

- Fatigue - very low service life

- Erosion - although a possibility in carbon steel

- Wear

- Hydrogen embrittlement

- Stress corrosion, although it might occur in austenitic stainless steels or at welds in carbon steel.

Reasons are as follows:

Temperatures are much too low for thermal embrittlement of steel; even when combined with neutron irradiation, no embrittlement problem is expected since the intermittent use of pipelines together with relatively low neutron irradiation from the HLW will restrict fluence values to several orders of magnitude below those that cause loss of toughness and ductility.

Relatively low temperature creep is only potentially significant in steels when exposed under conditions approaching those very near to a nuclear reactor core, which are far more severe than for transfer piping. Stress relaxation, even if it did occur, would be immaterial since it would not affect the safety function of piping.

Fatigue would require many more stress cycles than expected in the service life of piping with limited use. A large loading source for moderately high stress amplitudes would be thermal transient stresses during the transfer and subsequent flushing processes; the waste being transferred may well be significantly warmer than the empty pipe and the flushing water.

$$
7-5
$$


Erosion of stainless steel is unlikely because the austenitic steels are highly resistant. Wear would normally result from relative movement of touching surfaces, which is not the case for piping. (Erosion could be a concern for carbon steel pipes, especially for those transferring slurries.)

Hydrogen embrittlement occurs more readily in high strength steels than in those used for piping, whether ferritic or austenitic. Even the absorption of hydrogen from acid waste transfer is very unlikely to pose problems.

Stress-corrosion cracking (SCC) in ferritic steels is of no significance under conditions of HLW transfer. However, stainlesssteel, if sensitized or if placed in a high chloride content soil may be subject to intergranular (IGSCC) or transgranular (TGSCC) stress-corrosion cracking in regions of high tensile stress, such as near welds. For this to occur, very prolonged times of pumping hot HLW would be required. While possible, SCC is of low probability.

\subsubsection{Quantify Degradation}

The quantification of degradation is limited to analyzing data obtained from borescope examinations, excavating and examining failed lines, and spot checking at valve boxes, etc. This is not a true quantification; rather it is a recording of observed damage. No technique is known to determine the level of degradation throughout a piping system. The pressure test is the best option for determining whether a pipe leaks; however, this will not predict severe uniform attack that has not penetrated the wall.

Corrosion is the major problem: primarily external, but also internal, corrosion needs to be detected. Possible methods of detecting degradation of transfer piping are:

- Periodic pressure/leak testing

- Borescoping sections of accessible pipe

- Limited UT of accessible sections at jumper attachments, valve pits, etc.

- Magnetostriction of sections of excavated pipe.

\subsubsection{Evaluate Effect of Degradation on Pipe Integrity}

Reports of leakage provide some data; these small diameter ( 1 3-in.) lines do not lend themselves to extensive volumetric or visual examination. In any event, a major in-service inspection program probably is not justified for lines that will experience limited service. The pressure test is the best method of establishing leak tightness and blockage. Structural stability should not be a problem; however, it will be difficult to detect loads and deformation due to soil settlement. Where possible, data should be used in an effort to predict the future course of 
degradation. It is recognized that many sections of pipelines cannot be inspected so as to provide the necessary input for data analyses.

The questionnaire shown in Figure 7.1 in the form of an event tree provides a plan for assessment of transfer lines on a case-bycase basis. Table 7.1 provides additional explanatory information regarding the use of this (event tree) figure. The upper portion of the event tree is concerned with the potential for leaks in tank-pipe interfaces, particularly due to a seismic event. Critical cases are the sidewall entry if the entry is below the liquid level, or if a pipe is full of liquid so that siphoning can occur even if the pipe is attached above the level of liquid in a tank. If tanks have pipes attached below the liquid level, even when disabled, the question that needs to be answered is: "can the disabled pipe fail and lead to leakage to the soil?" The case of drain lines is significant only when drainage is possible from the tank. If the answer to the critical items in the upper part of the Event Tree is "no", then the failure of lines, while empty, because of a seismic event is not a problem unless the failure is common mode and all redundant lines fail. This possibility should be considered.

The second third of the event tree considers the type and history of the transfer lines. If the operating frequency is low, i.e., $\leq 10^{-2}$ per year, the conditional probability of release of HLW in the event of a severe earthquake may be low. Higher usage rates may need to be reviewed. The next tier covers the status of the piping. Single-wall pipes are of greater concern than encased pipes, particularly when the encased pipes consist of a pipe-in-apipe. The failure history, when available, should indicate where the major concern is. This failure history, to a major degree, will be related to the results of the pressure tests so that their documentation is critical. Any information pertaining to specific degradation mechanisms and histories of failures due to these degradation mechanism is valuable.

The third part of the event tree deals with design parameters. If pipes are known to be badly degraded and leaking, based on pressure testing, common-mode failures are possible, either due to the degradation, or to a seismic event. The issue of redundancy is tied to both common mode failures and seismic events. Badly degraded piping, particularly unencased pipes, should be a concern. The issue of seismic qualification should apply to new piping systems. The value of a seismic analysis of a piping system that has been operating for several years may be marginal because the degree of degradation is not known. A severe loss of wall thickness makes any seismic analyses of marginal value. While it would be desirable to have lines inspectable over their length, this is virtually impossible for small diameter lines, particularly with tight bends. Robots have been used; however, the lines inspected have been greater than $10 \mathrm{in.}$ in diameter. 
Tank Interface

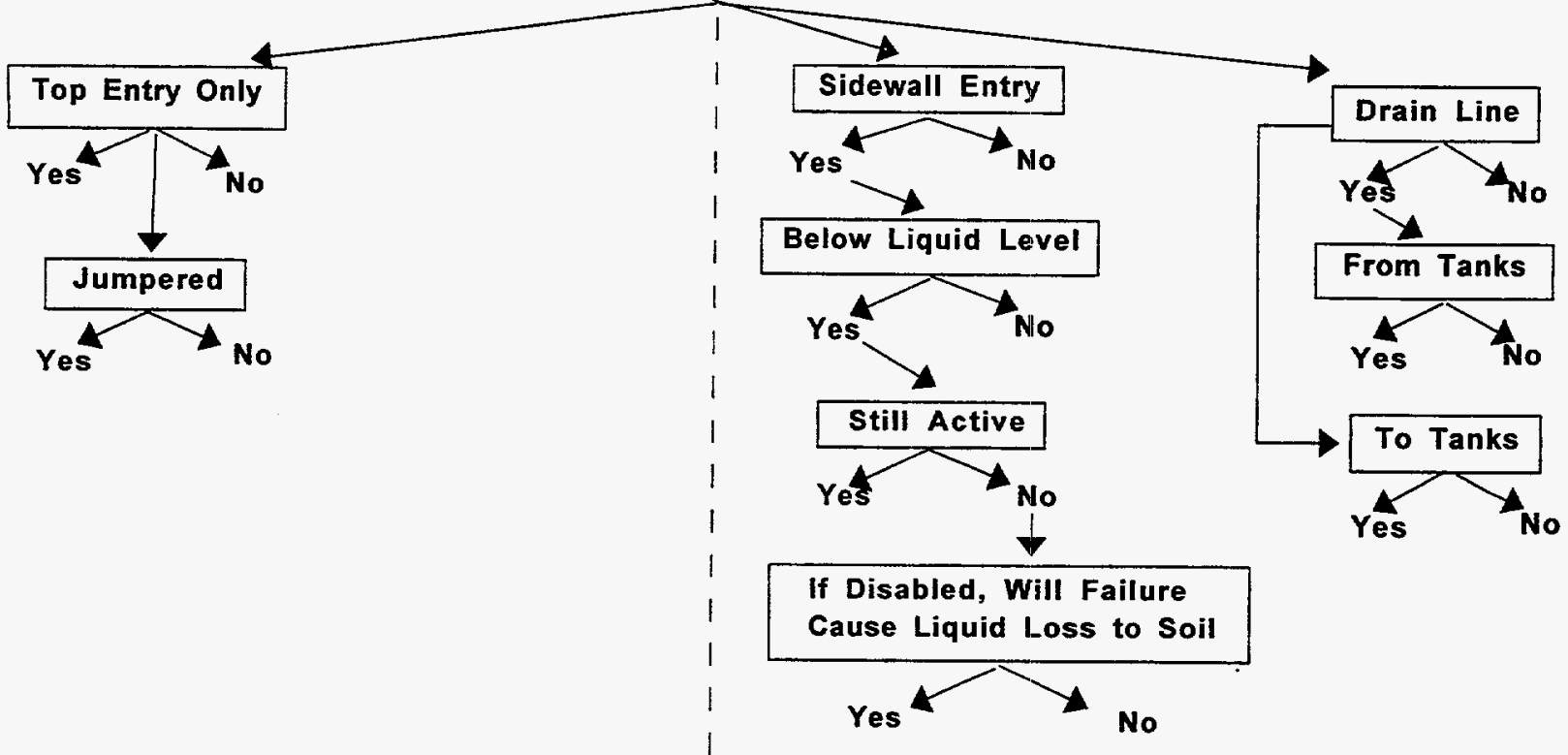

Transfer Lines
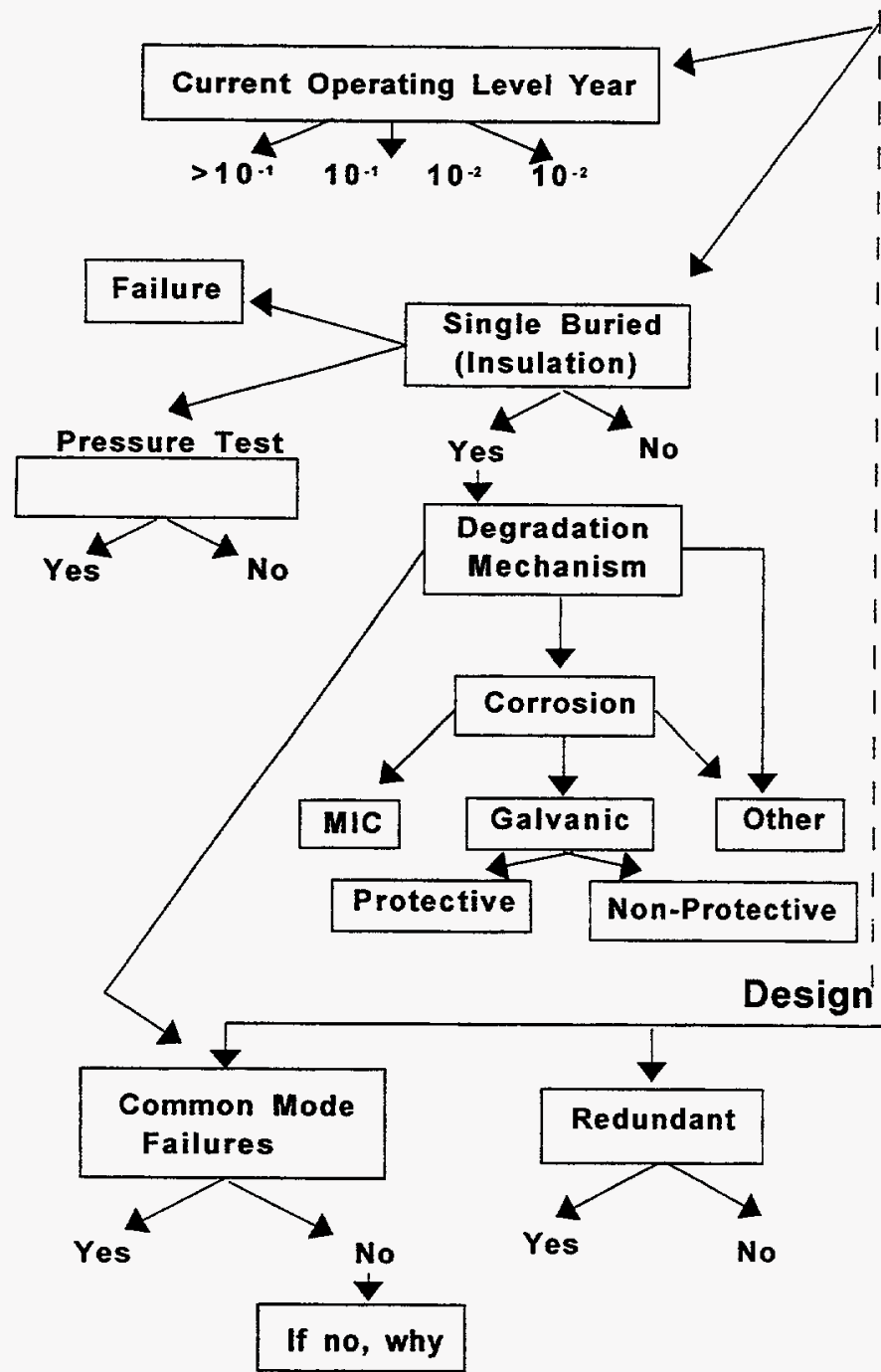

Design Parameters

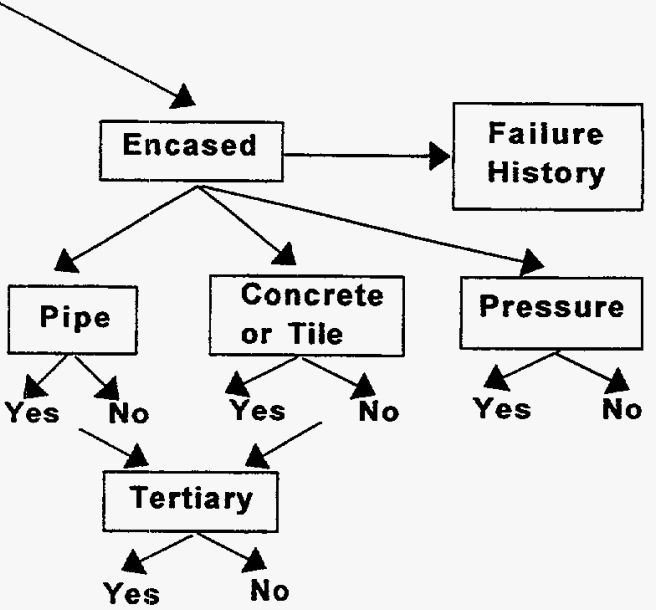

Figure 7.1 An Event Tree for Transfer Line Assessment 
- Many tanks have top entry for transfer piping and use jumpers from the junction box to make connections. Therefore, there are two yeses in the figure. Drain lines from the tank do not exist. There are some sidewall entry lines, most or all of which are above the liquid level.

- The top part of the event tree is designed to determine if the tank-transfer pipe interface can be a source of release to the environment of the HLW tank contents.

- The operating years cited are to determine the amount of time the Iines are used, e.g., > $10 \%,<10 \%,>1 \%,<1 \%$. Most are $<1 \%$. This usage factor is needed to establish integrity programs for the piping.

Single buried lines generally have been retired; however, any remaining are of concern. Encased pipes represent the majority of transfer piping; however, some forms of encasement provide better protection than others. The figure attempts to treat all types of piping.

Since, in many cases, operating records are inadequate, the intent of Figure 7.1 was to guide the user along possible lines of transfer line assessment. 
The Event Tree and operation and design data should permit a reasonable assessment of the level of degradation of the piping systems. If a site does not have critical in-situ data or answers to the items in the Event Tree cumulatively yield less than optimum results, the site should consider corrective actions.

A concern is a severely corroded pipe with gross wall thinning, but no detectable leak, and a seismic event. In particular, problems in a seismic event include the cases of pipes directly attached to HLW tanks. Guidelines for seismic analyses of transfer piping are provided in a separate report [7.1].

\subsubsection{Management and Options}

A systematic pressure testing program shall be implemented. The results of such pressure testing should be made part of a computerized data base. Lines shall be purged, if possible, after a transfer has been made.

Where not already in use, cathodic protection systems should be installed to protect external pipe surfaces against corrosion. These systems should be checked periodically.

When a line is leaking, repair or replacement shall be made. When the cause of a leak is known, an option is to substitute a material that is resistant to the particular mechanism of degradation.

\subsection{SUMMARY}

Piping integrity needs to be verified, especially just before a transfer is made. Piping integrity should also be maintained to ensure future availability if HLW needs to be pumped from one point to another. Data should be collected on loading, geometry, and material properties where possible, and evaluation of such data should be made as part of developing a structural integrity program. Verification depends in a large part on continued leak detection and pressure testing.

Aging mechanisms have been separated into significant and nonsignificant categories, so that the latter group can be excluded from further attention. Corrosion is the major problem. Quantification of degradation is limited to analyses of data from defined testing programs. An Event Tree for a plan of attack on a case-by-case basis has been provided, to be used together with operation and design data to assess the level of piping degradation. 
CHAPTER 8

MANAGEMENT OPTIONS

\subsection{INTRODUCTION}

Previous chapters of this document dealt with the identification, quantification, and evaluation of damage to HLW storage tanks and transfer piping resulting from possible, significant aging degradation mechanisms. The goal of the program already described is to determine the present and future capability of HLW storage tanks to provide confinement of the wastes. This Chapter adds to the goal by providing a discussion of some preventive measures and actions or procedures that could aid in safeguarding against the release of radioactive waste to the environment in the event that leak-tightness and structural stability of the double-shell waste storage tanks cannot be demonstrated. This is by no means an exhaustive list of options, since alternatives that are not included here may be or become available. Finally, depending on individual circumstances and/or availability of equipment or techniques, some of the options may not be practical.

\subsection{MANAGEMENT OPTIONS, INCLUDING PREVENTIVE MAINTENANCE}

A discussion of the following is included in this section:

- Corrosion Control

Chemistry Control Including Use of Inhibitors

Electrochemical Techniques

- Retrieval of Waste

Partial Removal of Liquid

Maximum Liquid Removal

Total Retrieval

\section{- Repair}

- Add new Barriers or Build New Tanks

\subsubsection{Corrosion Control}

Only some out of a number of methods that exist to resist, slow down, or stop general and localized corrosion of metals are practical, and possibly could be useful in cases where tanks are degraded but not leaking, or to prevent increases in waste release from tanks with small leaks. Others, such as substituting better alloys or providing resistant coatings apply only to new tanks or to empty ones with accessible surfaces, and will not be discussed. 


\subsubsection{Chemistry Control Including Use of Inhibitors in Alkaline Wastes}

Experience with operating tanks and experimental work has indicated that localized pitting/crevice attack on the tank metal is. related to temperature, $\mathrm{pH}$, ions in solution, and time. The same factors are involved in stress corrosion, except that tensile stress is also necessary for cracks to develop.

Section 4.2.2 identifies nitrate, sulfate, chloride, and fluoride as aggressive ions for pitting, with nitrate the worst. Nitrite additions were first identified to improve resistance to stress corrosion cracking, and have also been found to inhibit pitting corrosion. An initial equation for the relation between nitrate, nitrite, and temperature is included. Also known is the fact that low $\mathrm{pH}$ (possibly below 10.5) may result in pitting when other adverse factors are present. It may not be feasible to control the aggressive species that are already present, but controliing the $\mathrm{pH}$ in the range above about 10.5 but below 14 would reduce pitting (above 14 other corrosion problems can occur). Combining pH control with a minimum nitrite content would further reduce localized corrosion and stress corrosion cracking of carbon steels. The required nitrite level varies with the concentration of other adverse ions. When controlled before pitting/crevice corrosion sets in, the initiation time could be lengthened very considerably. However, the metal surface has to be accessible to the inhibitors to achieve results, and good distribution of the nitrite should be achieved.

Section 4.2.3 describes nitrate as the aggressive ion in the stress corrosion of carbon steel. Laboratory work showed that induction times depended on stress level and nitrate, but that crack growth was less sensitive to the bulk solution chemistry. other than stress relief, control of hydroxide (pH) level and nitrite are the known mitigating factors, similar in effect to preventing or slowing pitting corrosion.

Lack of information makes it difficult to determine whether chemistry changes similar to those discussed above can affect microbiologically-induced corrosion or waterline attack.

\subsubsection{Electrochemical Techniques}

Corrosion rates, forms of corrosion, and types of corrosion products formed are strongly influenced by electrochemical potential, as well as $\mathrm{pH}$ and the presence of other ions. Shifts in electrochemical potential are accomplished by impressed direct current. A sufficient negative shift provides cathodic protection, while anodic protection of metals that show active-to-passive behavior can be achieved by a positive shift. In the case of corrosion of waste tanks, or transfer lines, anodic protection should not be considered because it could aggravate the attack. 
Cathodic protection is theoretically possible, and could be of value if practical. Buried structural components that have metal surfaces in contact with the soil would benefit. In many instances, cathodic protection has been applied to transfer pipelines, as described in paragraph 7.3.1.1. Preventing corrosion of internal surfaces, or external surfaces surrounded by additional barriers by electrochemical methods may be more difficult or impossible because, first, there may not be access for the counterelectrode; second, current distribution may be uneven and some areas could be obscured by solids and receive little benefit, and third, at high currents, hydrogen evolution is a possibility at the cathode so that steps may be needed to avoid hydrogen build-up. However, in cases where the practical problems can be overcome, cathodic protection could be helpful. Cathodic protection of reinforcing bars in the concrete vessels has not been deemed practical or used in high-level waste tank farms.

\section{2 .2 Retrieval of Waste}

Depending on conditions in a given tank, partial or complete removal of the waste could eliminate or reduce the possibility of leaks, as discussed below.

\subsubsection{Lowering the Waste Level}

The purpose of lowering the liquid level in a tank is to prevent liquid from escaping through existing perforation at the waterline due to local corrosion, most likely at or near welds. In cases where local corrosion in the vicinity of the waterline is significant but not through-wall, lowering (or actually also raising) the waterline would shift the site of corrosion to an area where the wall thickness is greater, thus extending useful life of the tank.

\subsubsection{Complete Removal of the Iiquid Phase}

When a tank develops an unacceptable leak, and the leakage paths are towards the bottom of the vessel and cannot be eliminated, then complete removal of the liquid may be the only way to stop the release of HLW. Obvious additional requirements will accompany this option: an alternative container for the removed waste is to be available, and the remaining waste will require monitoring to ensure that there are no deleterious effects resulting from liquid removal.

\subsubsection{Total Removal of the Contents of the Tank}

This procedure may be needed if 1 ) removal of the liquid phase from a tank has adverse effects, 2) treatment for permanent disposal, such as vitrification, is available, and 3) structural stability of the tank cannot be demonstrated. 


\subsubsection{Making Repairs}

Making repairs to tanks may be feasible only under certain conditions, and could require the removal of at least some of the waste beforehand. The exterior surface of the primary shell or the interior surface of the secondary liner in a double-shell tank could possibly be repaired from the annular space. Similarly, repairs to the external surface of the concrete vault including the dome can be undertaken after excavating the surrounding soil. This option is available, but can only be implemented on a case-by-case basis with varying degrees of difficulty.

\subsubsection{Additional Barriers and New Tanks}

Seen simply from the point of view of assuring waste confinement, the substitution of new tanks for degraded ones is the best choice. However, this would require a very high investment of resources. It is also conceivable that additional barriers could be erected to surround degrading tanks completely, but a similar cost argument in addition to an effectiveness concern applies. Furthermore, even if the enormous effort and cost involved in either of these two options were available, it would not eliminate the eventual need (and cost of) permanent disposal. Moreover, a barrier tank itself may be a waste form if it serves its purpose. For these reasons, it is believed that a combination of using the best available methods of ensuring the interim confinement of the $\mathrm{HLW}$ through aging management and inspection programs, and accelerated efforts to complete the design and construction of equipment needed for permanent disposal would provide the best overall results. In any event, reliable transfer piping will be required whether it be for waste retrieval, for resolution of safety issues, or for further processing of wastes. Therefore, laying out new transfer lines seems to be prudent whenever the integrity of existing lines can not be reliably confirmed; the design of new lines should consider resistance to seismic events. 


\title{
APPENDIX A
}

\author{
PHILOSOPHY AND INTERPRETATION OF BASES USED IN \\ NONDESTRUCTIVE EXAMINATION (NDE) GUIDELINES
}

\section{A. 1 INTRODUCTION}

This Appendix expands on the NDE guidelines described in Chapter 5 to permit a better understanding of the approach used, the reasons for its use, and intended exceptions to the guidelines not explicitly stated. It also describes the exemption process used by the commercial nuclear power plant utilities to obtain relief from ASME Code requirements (e.g., Section XI). Usually these exemptions are based, for example, on an inability to comply because of access problems, or specialized NDE equipment not yet available.

\section{A. 2 SCOPE}

The following issues are discussed:

- Purpose of generic NDE guidelines

- Approach taken

- Bases for flaw sizes

- Basis for examination percentages

- Reasons for selection of UT angles

- Implications of Section XI Articles cited

- Exemption mechanism with examples

\section{A. 3 PURPOSE OF GENERIC NDE GUIDELINES}

The development of the NDE guidelines in Chapter 5 is in response to the need for continued operation of the high-level waste storage tanks. Although ASME Code section XI provides requirements for the nuclear reactors, no such guidelines are available for the underground atmospheric nuclear waste storage tanks.

A viable alternative to constructing new tanks is to justify the continued use of existing tanks for an extended period, for example 60 to 70 years total. This could be achieved through a structural integrity program that includes a plan such as the NDE guidelines (Chapter 5). An added benefit of this approach would be that early detection of generic degradation such as severe pitting, wall thinning, stress-corrosion cracking, will minimize panic solutions when leakage is detected. 


\section{A. 4 APPROACH TAKEN}

Two options were considered in developing the NDE guidelines:

- A complete, stand-alone plan, including justification for every position cited, or

- A "lean" guideline based on a consensus code such as Section $\mathrm{XI}$.

Stand-Alone Approach - Such an approach could have used existing inspection "standards" such as those of the American Petroleum Institute for thin-walled tanks. This approach was discarded for the following reasons:

- The API "standards" are not true consensus standards; therefore, all values would require justification.

- While the API standards have a good technical basis, they lack any tie to nuclear. This was considered a possible limitation.

- A complete stand-alone NDE guideline document would be about 100 pages in length and require $3-5$ years to develop.

Consensus Code Approach - It is recognized that section XI was developed for thicker walled vessels; however, piping examinations with ultrasonics often are on thicknesses less than those of the waste tanks. The principal differences are in the diameter-to-thickness ratios. This approach was selected because:

- Section XI is a consensus code approved for use in commercial nuclear power plants by the USNRC.

- About 25 years experience and thousands of man-days effort have been expended in the development of section XI.

- The sampling approach used in section XI represents the only viable NDE option for the high-level waste tanks because of time/manpower limitations.

- Many articles can be cited by reference without further justification.

- NDE techniques, including both equipment and NDE operator qualification are well defined.

- Section XI relies heavily on feedback from utilities, regulators and other interested parties to modify and upgrade the Code continuously so that real problems can be solved.

- The use of relevant parts of section XI permits a concise and defensible guideline document. 


\section{A. 5 BASES USED FOR EVALUATING DEGRADATION}

\section{A.5.1 Bases for Flaw Sizes}

The waste storage tanks have thicknesses of one inch or less, are fabricated of carbon steel in most cases, and must be examined with remote UT, VT, or PT. A significant factor is the relatively low loads to which the tanks are exposed. Basically, the major load is hydrostatic with some cyclic thermal and mechanical loads. The Cumulative Usage Factor (CUF) probably is less than 0.1. This limits significant degradation mechanisms to corrosion (e.g., pitting, crevice, bulk, and stress). Because of low loads and thin sections triaxial stresses are eliminated so that an unstable flaw should be quite long, even under Level D seismic loads. Therefore, the intent of NDE programs is to detect generic failure mechanisms and to provide early warning of such failure mechanisms within the limitations inherent in a sampling program.

In contrast to section XI where the cut-off for flaw sizes requiring no additional action is $2.5 \% t$, the low loads of the tanks and the biaxial stresses inherent in thin sections permit much larger permissible flaw sizes before there is a need to increase the examination sample size. These reasons are the justification for the values of $20 \% t$ and $50 \% t$.

\section{A.5.2 Bases for Examination Percentages}

The approach was to select regions for examination that were believed to be most susceptible to the anticipated mechanisms of pitting, crevice, bulk, or stress corrosion. The sample size was selected to provide a reasonable confidence of detecting generic degradation. The sample size was a compromise based on complexity of remote automated NDE. The sample represents a lower bound for reliable detection of generic degradation; it is roughly comparable to section XI IWC values.

\section{A. 5.3 Reasons for Selection of NDE Angles}

The lack of success in detection and sizing of flaws with single angle UT in the early years of section XI and the statistically validated results of the Program for the Inspection of Steel Components led to the decision in section XI to require four angles $\left(0^{\circ}, 45^{\circ}, 60^{\circ}\right.$, and $75^{\circ} \mathrm{L}$-wave). The $0^{\circ}$ choice is obvious for pits and for wall thinning. With stress corrosion, the lack of success in the absence of a definite qualification program and in detecting intergranular stress corrosion in wall thicknesses of 0.2 to 1.5 inches was confirmed in the IGSCC occurring in BWRs and in PISC programs using implanted fatigue and stress-corrosion cracks. 


\section{A.5.4 Implication of Section XI Articles Cited}

Several articles/appendices of section XI are cited; namely, IWA-2240, IWA-2430, IWB-2420, IWB-2430, IWC-2420, IWC-2430, specific articles in Appendix III and specific articles in Appendix VIII. The examination interval of ten years in IWA-2430 was selected as a reasonable interval. This was divided into two inspection periods of five years rather than the three of section XI. IWA-2240 permits alternative examinations; however, the burden of proof is on the user to determine the reliability of this alternative procedure. IWB-2420 covers successive examinations from interval to interval. IWB-2430 covers additional examinations when flaws are found that exceed in size those permitted by the acceptance standards.

Two appendices are cited; Appendix III is usually used for piping. The procedure in the appendix has been revised to include more examination angles. The three angles required represent a conservative position. If the results from Appendix VIII indicate that a sufficient level of reliability can be obtained with two angles for SCC, then the guidelines should be revised. Appendix VIII represents a performance demonstration using samples comparable in thickness to the tank and containing the most probable flaws (pits, thinning, SCC). Use of these specimens should qualify the UT equipment and establish the reliability of flaw detection and flaw sizing.

\section{A.5.5 Exemption Mechanism with Examples}

The section XI code is made up of a number of requirements. In some instances a utility cannot comply. For example, a terminal end weld may be inaccessible (walls, pipes, supports). Another and relevant instance is the examination of BWR reactor pressure vessels where access predominantly is from the external surface; gaps between vessel and biological shield often are limited so that specialized small remotely controlled crawlers represent the only viable option for UT. Utilities often request repeated exemptions, pending the development and availability of the necessary UT equipment.

An example of the high-level waste storage tanks is cited below. This example, it is believed, represents a valid exemption and should be accepted:

At one site, some waste storage tanks were not stress relieved and have experienced through-wall SCC. The number of through-wall cracks range from a few in some tanks to a large number in others. There is a high probability that these tanks contain SCC that has not penetrated the wall. Certainly, some of the non-stressrelieved tanks should be included in the examination sample. Also, it is quite probable that SCC will be detected. The following are further guidance for this specific example:

$$
\mathrm{A}-4
$$


- "New" SCC detected should comply with IWC-2420 regarding successive examinations. If three successive examinations confirm no crack growth, further UT is not required per IWC2420. The lack of flaw growth, if confirmed, will be a valuable validation that inhibitors halt the growth of SCC, even after it initiated.

- "New" SCC detected should not invoke IWC-2430 regarding additional examinations. It is known that SCC has occurred. Invoking IWC-2430 has a high probability of expanding the sample to $100 \%$ of accessible welds. This would require an expenditure of time and resources out of proportion to the value added information. The purpose of the NDE guidelines program should be to detect new generic degradation, not to trigger more examinations with a known and well documented problem. 